Efeito da ciclagem de pH na liberação/recarga de flúor e na microinfiltração de materiais restauradores resinosos

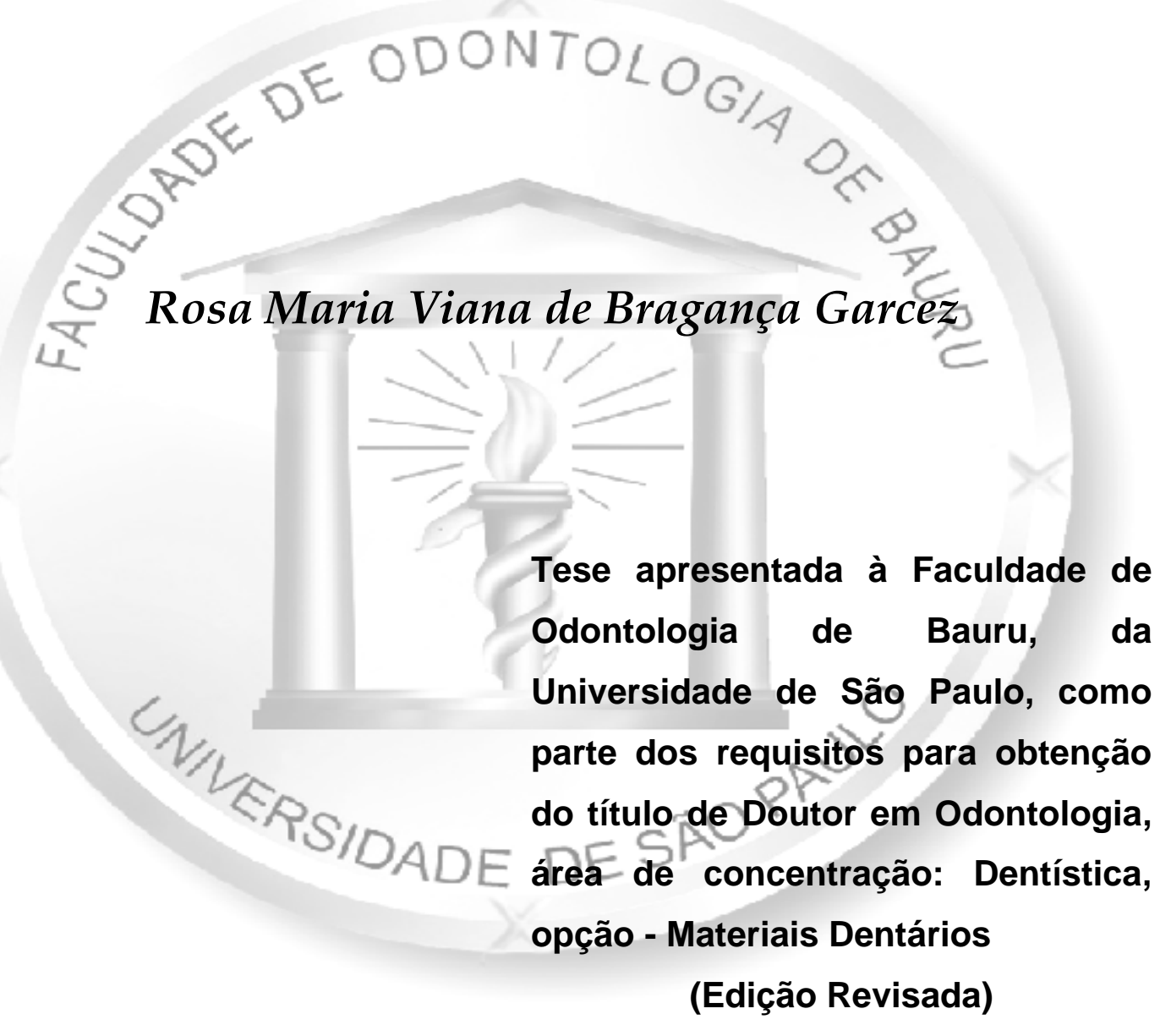

BAURU 



\title{
Efeito da ciclagem de pH na liberação/recarga de flúor e na microinfiltração de materiais
} restauradores resinosos

Rosa Maria Viana de Bragança Garcez

\begin{abstract}
Tese apresentada à Faculdade de Odontologia de Bauru, da Universidade de São Paulo, como parte dos requisitos para obtenção do título de Doutor em Odontologia, área de concentração: Dentística, opção - Materiais Dentários

Orientador: Prof. Dr. Paulo Amarante de Araújo
\end{abstract}

(Edição Revisada)

\section{BAURU}




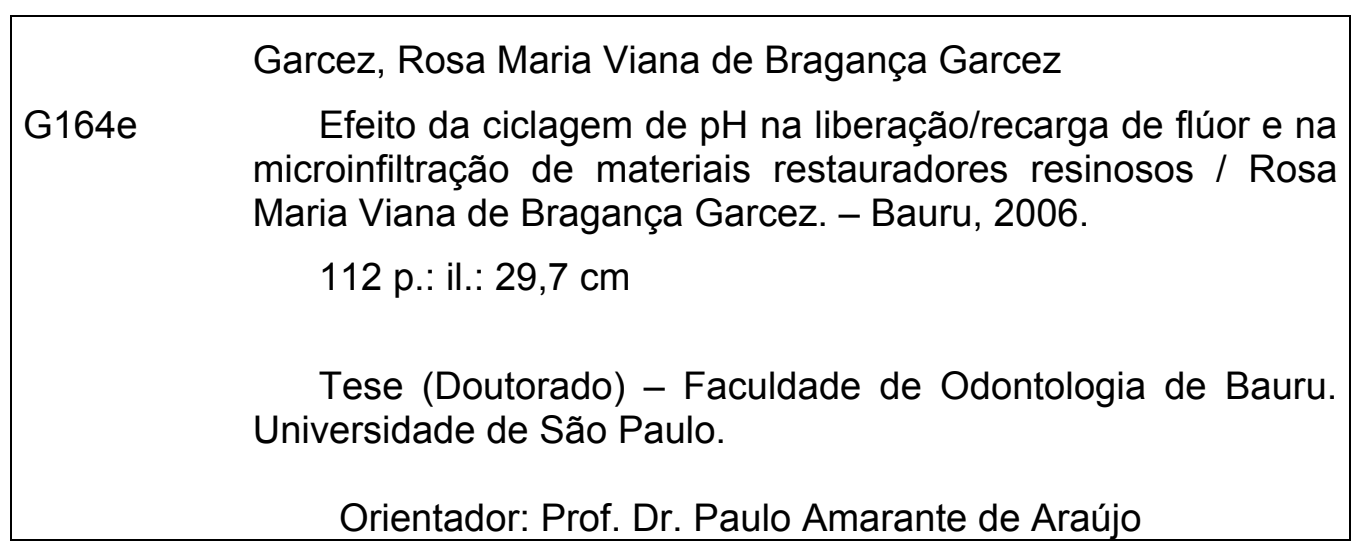

Autorizo, exclusivamente para fins acadêmicos e científicos, a reprodução total ou parcial desta dissertação/tese, por processos fotocopiadores e outros meios eletrônicos.

Assinatura:

Comitê de Ética da FOB

NN. do Protocolo: 096/2003

Data: $27 / 08 / 2003$ 




\section{ROSA MARIA VIANA DE BRAGANÇA GARCEZ}

20 de janeiro de 1955

Aracaju-SE

Filiação

1973-1976

1979

$1998-2000$

$1999-2001$

2001-2006

Associações
Nascimento

Francisco José Plácido Tavares de Bragança

Maria Viana Tavares de Bragança

Curso de Odontologia - Universidade Federal de Sergipe.

Professora Assistente do Departamento de Odontologia da Universidade Federal de Sergipe.

Curso de Especialização em Odontologia em Saúde Coletiva no Hospital de Reabilitação de Anomalias Crânio Faciais, Universidade de São Paulo.

Curso de Pós-graduação em Odontologia, na área de Dentística, opção Materiais Dentários, nível Mestrado, Faculdade de Odontologia de Bauru, da Universidade de São Paulo.

Curso de Pós-graduação em Odontologia, na área de Dentística, opção Materiais Dentários, nível Doutorado, Faculdade de Odontologia de Bauru, da Universidade de São Paulo.

Associação Brasileira de Odontologia, Seção-SE Associação Brasileira de Odontologia de Promoção de Saúde Grupo Brasileiro de Professores de Dentística Grupo Brasileiro de Professores de Materiais Dentários

International Association of Dental Research 



\section{Dedicatória}





\title{
A Deus,
}

foi conselheiro com o Pai nos momentos difíceis,

\author{
nos semeou com o Filho de esperança, $e$ \\ pelo Espírito Santo nos \\ iluminou
}

de amor, sabedoria e luz. 

A todos os meus verdadeiros

\section{AMIGOS}

Que não permitiram desistir

Que dividiram angústias, tristezas e alegrias

Que souberam recuar para que pudesse ver o caminho

Que souberam acolher para serem acolhidos

Que nos amaram e nos permitiram ser

ora mãe, ora filha, ora irmã, ora companheira

para sermos sempre uma inesquecível

\section{FAMÍLA}

Rosa ("Lady") 

Marcelo,

Filho na obediência e no respeito, Companheiro de todas as horas, Outrora meu "menino" Ontem um jovem Hoje um homem

O mais nobre de todos os amigos.,

Obrigado. 

Agradecimentos 

À minha mãe Maria, hoje acolhida ao Pai,

Tem a minha gratidão e eterno amor de filha.

\author{
À meu pai Bragança, \\ Guarde o meu carinho de filha, \\ De sua querida Rosinha.
}

Aos meus irmãos Martha e Ricardo, Rose,

aos sobrinhos Pedrinho, Mônica, Petra,

Ricardo, Rafaella e Roberto,

pelo apoio solidário nessa caminhada.

Tia Gigi, Tia Vânia, Tio Augusto

pelo acolhimento como filha, Aos primos Maria e Cláudio pelo exemplo de fé e esperança, Meus familiares, tios, primos que estiveram ao meu lado, compartilhando dificuldades e vitórias. 



\title{
À Linda,
}

amiga de todas as horas, sabedoria oriental,

que sabe acolher, partilhar, silenciar...

hoje irmã, pelos laços do coração.

Fernanda e Ana Paula

a amizade sincera, o cuidado e o carinho compartilhado, as tornaram sempre

Minhas filhas...

\begin{abstract}
Alaíde,
respeitar as diferenças,

estar junto nas dificuldades,

compartilhar todos os momentos,

fazem os segredos de uma amizade
\end{abstract}

\section{À D. Leila, Leilinha, Gabriel \\ Luciana, Cláudia e João \\ pelo carinho e atenção.}

\author{
À Jorge Luiz, \\ sempre presente \\ compartilhando dificuldades, \\ angústias, alegrias e vitórias \\ do nosso maior tesouro, nosso filho \\ Marcelo
}



Ao Prof. Dr. Paulo Amarante de Araújo,

sempre presente frente às nossas dificuldades, incertezas, angústias, soube aconselhar, acolher, ouvir, falar, ora como sábio, ora como amigo, ora mestre, ora orientador exemplo de sabedoria, paciência e dedicação Pelo seu carinho, minha eterna gratidão. 

A todos os que fazem o Departamento de Materiais Dentários

Prof. Dr. César Antunes de Freitas,

Prof. Dr. Paulo Afonso Silveira Francisconi

Sandrinha, Lô, Alcides

que têm a nobreza de acolher e transformar o ambiente sombrio

em ambiente fraterno e, nos sentirmos em família...

Aos professores

Dr. Afrânio Bastos, Dra. Zilnah Maciel,

Dr. Fernando Vasconcelos,

o reconhecimento dos seus exemplos de mestre e

amizade, nos fortaleceram nessa caminhada.

Ao Departamento de Bioquímica,

Profa. Dra. Marília Buzalaf, Telma, Ovídio e Gilmar

pela acolhida na parte experimental

Ao Prof. Dr. José Roberto Pereira Lauris, pela disponibilidade no momento de dúvidas e realização da análise estatística. 



\section{A Renato Cilli,}

Seu espírito solidário, companheiro e amigo o fazem especial

Tudo isso o tornam "guardião"

Aos colegas e amigos do Curso de Doutorado e Mestrado,

Luisa, Dani, Henrique, Paulo, Nádia, Júlio, Fábio, Flávia, Luiz, Juan, Rosana, Celiane, Lawrence, Dani Cefaly, Cláudia, Carla Porto, Sérgio, Heitor, Dani, Cris, Anderson, Léo, Anuradha, pelo convívio fraterno em todos os momentos...

\section{Cristiane, Maria Carmem,}

Pedro (eterno guardião), Lilli, João

mesmo distante, a força da amizade nos unem.

Amigos para sempre.....

Aos amigos de Bauru,

Pe. Jesus, Zé Guilherme e Tereza,Carminha e Beto, Norma, grupo do "Sabadão"... Tereza Valente,"Mar"celo,

D. Lúcia Araújo, Tereza Atta,

e em especial a Ciça, compartilhar reuniões, orações, lazer, família contribuíram para o crescimento espiritual e pessoal nessa caminhada. 

À Faculdade de Odontologia de Bauru, da Universidade de São Paulo, representada pelo seu Diretor Prof. Dr. Luiz Pegoraro

e Vice-diretor Prof. Dr. José Carlos Pereira

A todos os professores do Curso de Pós-Graduação, pelos ensinamentos, experiências e conhecimentos transmitidos durante o curso

Aos funcionários da Pós-Graduação,

Giane, Letícia, Meg,

Cleusa e Aninha, pela atenção.

Salvador, Lígia, Paula, pela presteza e dedicação.

A todos os funcionários da biblioteca,

Cybelle, Rita, César, Mônica, Jane, Ademir, Maria Helena,

Célia, Ana Paula, Marcelo, Vera, Valéria, Sonia,

Maria Caetano, Tereza, Maristela

sempre prontos a solucionar nossas dificuldades. 



\section{AGRADECIMENTOS ESPECIAIS}

Aos amigos Tânia, Fátima, Carlinhos, Ivana, Anderson, Anuska, Patrícia, Hermenegildo, Pacheco, Luís Carlos, André Lucas, Alexandre, Heloísa, Mirabeau, Derileda, Maria Helena, Marta, Maria José, Arivaldo, Edith, Edvaldo, Denise, Karina, Pedro Jorge pela partilha de todos os momentos

À Celinha e Nilza pela amizade sincera, por me incentivarem em todas as decisões.

A José Luiz e Antonio, determinação como a de vocês nos faz acreditar que vale a pena ensinar. Obrigada pelo apoio na digitação.

A Luiz Herminio,

pelo apoio em todos os momentos, como amigo, como médico. 

À Universidade Federal de Sergipe, na pessoa do

Magnífico Reitor Prof. Dr. Josué Passos Modesto

Aos colegas e amigos do CCBS, funcionários da UFS

pelo apoio na finalização desse projeto, de modo especial ao Prof. Dr. Byron Ramos

As colegas e funcionários do

Departamento de Odontologia da UFS

pelo apoio para a conclusão do Curso de pós-graduação,

em especial ao Prof. Dr.José Rogério Vieira de Almeida,

Cristiane e Eliane.

À todos os

funcionários da Faculdade de Odontologia de Bauru, da Universidade de São Paulo, que atendem gentilmente às nossas solicitações.

Meu muito obrigado!!! 



\section{SUMÁRIO}

LISTA DE ABREVIATURAS E SÍMBOLOS XxxV

LISTA DE TABELAS Xxxix

LISTA DE FIGURAS xli

RESUMO Xlv

1 INTRODUÇÃO 3

2 REVISÃO DA LITERATURA

2.1 liberação e recarga de flúor 9

$\begin{array}{ll}2.2 \text { Microinfiltração } & 25\end{array}$

3. PROPOSIÇÃO 39

4. MATERIAL E MÉTODOS 43

4.1 Análise da liberação de fluor sem e com recarga 43

4.2 Analise da microinfiltração 48

4.3 Ananalise estatística 56

5. RESULTADOS

5.1 Análise da liberação de flúor 59

5.2 Análise da microinfiltração $\quad 71$

6. DISCUSSÃO

6.1 Liberação e recarga de flúor $\quad 77$

6.2 Microinfiltração 86

7. CONCLUSÃO 95

REFERÊNCIAS BIBLIOGRÁFICAS 99

$\begin{array}{ll}\text { ABSTRACT } & 111\end{array}$

APÊNDICE 



\section{LISTA DE ABREVIATURAS E SÍMBOLOS}

$\%$

${ }^{\circ} \mathrm{C}$

$\mu \mathbf{g}$

$\mu \mathbf{g F}^{-}$

$\mu \mathrm{gF}^{-} / \mathrm{cm}^{2}$

$\mu \mathrm{gF}^{-} / \mathrm{mL}$

APF

Bis-GMA

$\mathrm{Ca}^{+}$

CDTA

CIV

cm

$\mathrm{cm}^{2}$

$\mathrm{CpH}$

DES $^{-}$

dp

$\mathbf{F}^{-}$

Fator-C

g

gl

h

$\mathbf{H}^{-}$ porcentagem

grau Celsius

micrograma

micrograma Flúor

micrograma Flúor/centímetro quadrado

micrograma Flúor/mililitro

fosfato flúor acidulado

bisfenolA-glicidil-metacrilato

cálcio

ácido 1,2-cicloexanodiaminotetracético

cimento(s) de ionômero de vidro

centímetro

centímetro quadrado

ciclagem de $\mathrm{pH}$

desmineralização

desvio-padrão

flúor

fator de configuração cavitária

grama

grau de liberdade

horas

hidrogênio 



\begin{tabular}{|c|c|}
\hline HA & hidroxiapatita \\
\hline HEMA & 2-hidroxi-etil-metacrilato \\
\hline $\mathbf{L}$ & litro \\
\hline M & Molar \\
\hline MFP & mono flúor fosfato \\
\hline mL & mililitro \\
\hline $\mathbf{m m}$ & milímetro \\
\hline $\mathbf{m M}$ & milimolar \\
\hline $\mathrm{mm}^{2}$ & milimetro quadrado \\
\hline $\mathrm{mV}$ & milivolts \\
\hline $\mathrm{mW} / \mathrm{cm}$ & miliwatts/centrímetro \\
\hline $\mathbf{N}$ & Normal \\
\hline $\mathrm{NaCl}$ & cloreto de sódio \\
\hline $\mathrm{NaF}$ & fluoreto de sódio \\
\hline $\mathrm{OH}^{-}$ & Hidroxila \\
\hline pH & concentração hidrogeniônica \\
\hline ppm & partícula por milhão \\
\hline QM & Quadrado médio \\
\hline RE & remineralização \\
\hline $\mathbf{s}$ & segundos \\
\hline TEGDMA & dimetacrilato de trietilenoglicol \\
\hline TISAB & Total lonic Strength Adjustment Buffer \\
\hline UDMA & uretano dimetacrilato \\
\hline UEDMA & uretano ethoxi-dimetacrilato \\
\hline $\mathrm{YbF}_{3}$ & trifluoreto de itérbio \\
\hline
\end{tabular}





\section{LISTA DE TABELAS}

Tabela 4.1 - Apresentação dos grupos, materiais restauradores, de acordo com sua classificação, lote e fabricantes..

Tabela 4.2 - Apresentação das soluções para ciclagem de pH.

Tabela 4.3 - Sequência restauradora para os diferentes materiais, submetidos ao teste de infiltração marginal em água deionizada (A) e em ciclagem de $\mathrm{pH}(\mathrm{C})$.

Tabela 5.1 - Médias das quantidades de liberação de flúor em $\mu \mathrm{g} / \mathrm{cm}^{2} \mathrm{e}$ desvios padrão dos materiais restauradores em $\mathrm{CpH}$ sem recarga, durante 15 dias, e os totais acumulados nas $1^{\text {a }}$ e $2^{\text {a }}$ semanas.

Tabela 5.2 - Médias das quantidades de liberação de flúor em $\mu \mathrm{g} / \mathrm{cm}^{2}$ e desvios padrão dos materiais restauradores em $\mathrm{CpH}$ com recarga, durante 15 dias, e os totais acumulados nas $1^{\text {a }}$ e $2^{\text {a }}$ semanas.

Tabela 5.3 - Análise de variância a dois critérios, meio e material, durante 24horas, no período de 15 dias.

Tabela 5.4 - Análise de variância a dois critérios, meio e material, no total de 6 horas, em solução DES ${ }^{-}$, durante 15 dias.

Tabela 5.5 - Análise de variância a dois critérios, meio e material, no total de 17 horas, em solução RE, durante 15 dias.

Tabela 5.6 - Médias das quantidades de liberação de $\mathrm{F}^{-}\left(\mu \mathrm{g} / \mathrm{cm}^{2}\right)$ dos materiais restauradores em $\mathrm{CpH}$ sem e com recarga, durante 15 dias, em $24 \mathrm{~h}$.

Tabela 5.7 - Médias e desvios padrão de microinfiltração dos materiais restauradores, nos meios de imersão $\mathrm{A}$ e $\mathrm{CpH}$, durante 15 dias.

Tabela 5.8 - Análise de variância a dois critérios, meio e material.

Tabela 5.9 - Distribuição das médias de microinfiltração de acordo com o meio de imersão (teste de Tukey, $p<0,05$ ).

Tabela 5.10- Média do grau de microinfiltração dos materiais em relação ao meio de imersão, água e $\mathrm{CpH}$ (teste de Tukey, $\mathrm{p}<0,05) \ldots$. 



\section{LISTA DE FIGURAS}

Figura 4.1 - Apresentação comercial dos materiais restauradores

Figura 4.2 - llustração da preparação dos espécimes nas matraizes de teflon (A); polimerização do material restaurador (B); fixação do corpo-de-prova (C); corpos-de-prova imersos de solução fuida fluoretada com creme dental "Crest" (D).

Figura 4.3 - Desenho esquemático da cavidade preparada.

Figura 4.4 - Apresentação comercial dos materiais e os sistemas adesivos utilizados na técnica restauradora.

Figura 4.5 - Materiais e instrumentais utilizados na etapa de acabamento das restaurações.

Figura 4.6 - Amostra dos dentes dos grupos restaurados (1) Definite ${ }^{\circledR} ;(2)$ Dyract AP; (3) Vitremer ${ }^{\mathrm{TM}}$; (4) Ariston ${ }^{\circledR}$ AT; (5) Tetric ${ }^{\circledR}$ Ceram..

Figura 4.7 - Visualização da área infiltrada (A) escaneada pelo Software Image Tools.

Figura 5.1 - Gráfico da liberação diária de $\mathrm{F}^{-}$, em $\mathrm{CpH}$-solução $\mathrm{DES}^{-}$ (6h), sem recarga, durante 15 dias.

Figura 5.2 - Gráfico da liberação diária de $\mathrm{F}^{-}$, em CpH-solução RE (17h), sem recarga, durante 15 dias.

Figura 5.3 - Gráfico da liberação diária de $\mathrm{F}^{-}$, em $\mathrm{CpH}$-solução $\mathrm{DES}^{-} / \mathrm{RE}$ (24h), sem recarga, durante 15 dias.

Figura 5.4 - Gráfico da liberação diária de $\mathrm{F}^{-}$, em $\mathrm{CpH}$-solução $\mathrm{DES}^{-}$ (6h), com recarga, durante 15 dias.

Figura 5.5 - Gráfico da liberação diária de $\mathrm{F}^{-}$, em CpH-solução RE (17h), com recarga, durante 15 dias.

Figura 5.6 - Gráfico da liberação diária de $\mathrm{F}^{-}$, em $\mathrm{CpH}$-solução $\mathrm{DES}^{-} / \mathrm{RE}$ (24h), com recarga, durante 15 dias.

Figura 5.7 - Gráfico da liberação total de $\mathrm{F}^{-}$, solução $\mathrm{DES}^{-}$(6h), sem e com recarga.

Figura 5.8 - Gráfico da liberação total de $\mathrm{F}^{-}$, solução RE (17h), sem e com recarga.

Figura 5.9 - Gráfico da liberação total de $\mathrm{F}^{-}$, solução $\mathrm{DES}^{-} / \mathrm{RE}(24 \mathrm{~h})$, sem e com recarga.

Figura 5.10 - Gráfico da distribuição das médias de microinfiltração em cm, dos materiais avaliados, em A e $\mathrm{CpH}$

Figura 5.11 - Gráfico das médias de microinfiltração dos materiais restauradores avaliados. 



\section{Resumo}





\section{RESUMO}

Quedas cíclicas de $\mathrm{pH}$ no meio bucal parecem ser um dos maiores desafios aos quais estão expostos os materiais restauradores. Desta forma, a capacidade de liberação/recarga de flúor $\left(\mathrm{F}^{-}\right)$e a avaliação da interface dente/restauração pelo teste de microinfiltração em ciclagem de $\mathrm{pH}(\mathrm{CpH})$, durante 15 dias, pode complementar in vitro, a simulação de situações clínicas de alto desafio cariogênico. Foram confeccionados 12 corpos-deprova na forma de discos (1,1 cm de diâmetro, $0,15 \mathrm{~cm}$ de espessura) dos materiais, distribuídos em dois grupos sem e com recarga $(R)$, Vitremer ${ }^{\mathrm{TM}}$ (V/VR), Dyract AP (DY/DYR), Ariston ${ }^{\circledR} A T$ (A/AR), Definite ${ }^{\circledR}$ (D/DR), Tetric ${ }^{\circledR}$ Ceram (TC/TCR). Os corpos-de-prova foram imersos individualmente em $4 \mathrm{~mL}$ de solução $\mathrm{CpH}, 6$ horas em solução desmineralizante (DES ${ }^{-}$) e 17 horas em solução remineralizante (RE). A recarga foi iniciada no $2^{\circ}$ dia com pasta fluoretada fluida 3:1(Crest), realizada diariamente, entre as trocas das soluções DES $/$ RE. As soluções DES $/$ RE dos dois grupos, com e sem recarga eram trocadas diariamente, e armazenadas durante 15 dias. A análise da concentração de $\mathrm{F}^{-}$da liberação e da recarga foi medida com 0,5 $\mathrm{mL}$ de solução teste adicionada a igual volume de TISAB II, por um eletrodo ín $\mathrm{F}^{-}$específico acoplado ao aparelho analisador $\mathrm{pH} / \mathrm{F}^{-}$. Os resultados foram submetidos a ANOVA e teste de Tukey $(p<0,05)$. Os maiores valores $\mathrm{F}^{-}$foram registrados em solução $\mathrm{DES}^{-}(\mathrm{pH} 4.3)$. Todos os materiais, em ambos experimentos, apresentaram o mesmo padrão de liberação de $\mathrm{F}^{-} \mathrm{e}$, os maiores valores foram do $\mathrm{V}\left(418,04 \mu \mathrm{gF}^{-} / \mathrm{cm}^{2}\right)$ e $\mathrm{VR}\left(818,39 \mu \mathrm{gF}^{-} / \mathrm{cm}^{2}\right)$. Ao $3^{\circ}$ dia, materiais sob recarga apresentaram maiores valores de $\mathrm{F}^{-}$ liberado, com declínio lento e alcançando valores estáveis ao $15^{\circ}$ dia, quando os valores de $\mathrm{F}^{-}$aproximaram-se aos sem recarga, obtidos ao $2^{\circ}$ dia. As resinas compostas D e TC apresentaram os mais baixos valores de $\mathrm{F}^{-}$liberados, D (5,16 $\left.\mathrm{gFF}^{-} / \mathrm{cm}^{2}\right)$; DR $\left(10,25 \mu \mathrm{gF}^{-} / \mathrm{cm}^{2}\right)$; TC $\left(10,09 \mu \mathrm{gF}^{-} / \mathrm{cm}^{2}\right)$; TCR $\left(16,85 \mu \mathrm{gF}^{-} / \mathrm{cm}^{2}\right)$, em ambos experimentos, mas sem diferenças estatísticas significantes entre DR e TC. Entre as resinas compostas, a maior liberação foi da AR $\left(327,20 \mu \mathrm{gF}^{-} / \mathrm{cm}^{2}\right)$. Para avaliar a microinfiltração, 
foram utilizados $3^{\circ s}$ molares extraídos preparados com cavidades Classe V $(4,00 \mathrm{~mm}, 2,00 \mathrm{~mm}, 1,5 \mathrm{~mm})$, em esmalte, restaurados com os mesmos materiais e distribuídos em dois meios de imersão, água deinozada (A) e $\mathrm{CpH}\left(\mathrm{DES}^{-} / \mathrm{RE}\right)$ durante 15 dias. Em seguida, foram imersos em fucsina básica $0,5 \%$ por 24 horas, lavados, seccionados, visualizados em estereomicroscópio óptico com 60X de aumento. Os cortes mais infiltrados foram escaneados e uma medida linear $(0,5 \mathrm{~cm}=115$ pixels $)$ foi obtida pelo softweare Image Tool. Ao teste de Tukey, houve diferença estatística significante entre os meios de imersão, o maior grau de microinfiltração foi em $\mathrm{CpH}$. Todos os materiais apresentaram microinfiltração na interface dente/restauração, sendo observada a maior infiltração na resina composta $D$, seguida da TC, V, DY e A. Entretanto, não houve diferença estatisticamente significante entre os materiais TC, V, DY e A. Diante das limitações desse estudo e frente aos resultados encontrados, observa-se que apesar das quantidades de $\mathrm{F}^{-}$liberadas no experimento sem e com recarga, não deixou de ocorrer o processo de microinfiltração na interface dente/restauração dos materiais avaliados. 



\section{Introdução}






\section{INTRODUÇÃO}

A odontologia restauradora no século XXI vem sendo realizada com base em novas tecnologias, desenvolvimento de biomateriais que possibilitem o mais exato diagnóstico e tratamento adequado às diferentes patologias, sempre procurando associar estética e função no perfeito equilíbrio do aparelho estomatognático e a integridade da estrutura dentária aos desafios do meio bucal.

A adequação de hábitos alimentares, hábitos de higiene bucal e o controle do biofilme agem nos fatores etiológicos podendo contribuir para esse equilíbrio, principalmente, quando associados ao uso do flúor. Os efeitos da ação do flúor no meio bucal já estão consolidados na prevenção da doença cárie por esse elemento atuar favorecendo o processo de remineralização e revertendo a desmineralização em esmalte/dentina ${ }^{25}$, o que caracteriza a sua propriedade anticariogênica.

O mecanismo de ação do flúor requer a sua presença em forma iônica, sendo capaz de restabelecer o equilíbrio do meio bucal. Diferentes níveis de flúor contribuem para promover a remineralização do esmalte e da dentina expostos ao desafio ácido ${ }^{34}$. Entretanto, os conceitos atuais da sua ação anticariogênica demonstram uma maior eficiência quando este elemento está presente em baixa concentração e com maior freqüência no meio bucal ${ }^{44}$. Desta forma, a presença constante do íon na água de abastecimento e nos produtos para aplicação tópica, tais quais as soluções, géis, vernizes e dentifrícios, são métodos eficazes na prevenção e controle da cárie dentária ${ }^{1}$.

Outra fonte de liberação de flúor encontra-se nos materiais restauradores, sendo os cimentos de ionômero de vidro (CIV) os mais difundidos pela sua capacidade de prevenir a desmineralização inicial e secundária da estrutura dentária nas margens da restauração ${ }^{23}$, mais particularmente na interface dente/restauração, como também, pela suas 
propriedades adesivas. A fim de solucionar as dificuldades técnicas de manipulação e tempo de trabalho, bem como à baixa resistência mecânica e as características ópticas dos CIVs, surgiram os CIVs modificados por resina e os compômeros.

Esses materiais apresentam melhores características de estética e de durabilidade, constituindo-se numa fonte de liberação de flúor na interface dente/restauração em baixa concentração, por períodos prolongados de tempo ${ }^{16}$, além de atuar na redução de cáries secundárias por meio do flúor liberado sendo capaz de minimizar as quedas cíclicas intrabucais de $\mathrm{pH}$, especialmente em pacientes com alto desafio cariogênico 20,50,51. Por outro lado, as resinas compostas têm sido bastante indicadas pelos dentistas e solicitadas pelos pacientes devido aos constantes apelos à estética. O tratamento prévio da dentina e principalmente do esmalte, utilizado atualmente, possibilita retenção micro-mecânica o que minimiza a necessidade do desgaste da estrutura dentária sadia, para a obtenção dos parâmetros biomecânicos de retenção e resistência em relação aos preparos para a utilização do amálgama.

Não existe material restaurador, mesmo os capazes de aderir quimicamente aos tecidos dentários que possa resistir às mudanças de temperatura sem alterações volumétricas, e assim mesmo proporcionar um perfeito selamento marginal. As técnicas restauradoras consideradas adesivas ainda não proporcionam um perfeito selamento e vedamento marginal das restaurações ${ }^{39,72}$. A contração de polimerização durante a presa assim como as diferenças dos coeficientes de expansão térmica e do módulo de elasticidade entre o tecido dentário e os materiais possibilitam a formação de fendas marginais que permitem a passagem de bactérias, fluidos, moléculas ou íons entre as paredes cavitárias e o material restaurador, característica do processo de infiltração marginal ${ }^{2,14,39,48}$.

O teste de microinfiltração marginal é realizado sob ciclagem térmica e/ou de carga, na tentativa de simular respectivamente as condições às quais estão expostos os órgãos dentais, quando da ingestão de alimentos 
em diferentes temperaturas e dos esforços mastigatórios. Portanto, a interface dente/restauração torna-se uma área crítica, susceptível a microinfiltração, como também a reinstalação de lesões cariosas.

Por outro lado, a quantidade de íons flúor capaz de atribuir propriedades anticariogênicas ao material restaurador não está ainda, bem definida na literatura. Segundo ROTHWELL, ANSTICE, PEARSON ${ }^{57}$ a quantidade de flúor liberada do CIV talvez não seja tão importante, quanto a capacidade de recarga desse material quando exposto às outras fontes externas desse íon, como dentifrícios fluoretados, soluções de bochecho e aplicações tópicas de flúor ${ }^{9}$.

Desta forma, a avaliação da capacidade de liberação/recarga de flúor de materiais restauradores resinosos bem como a avaliação da interface dente/restauração pelo teste de microinfiltração, realizados em ciclagem de $\mathrm{pH}$, vem complementar in vitro a simulação de situações clínicas às quais os materiais restauradores estão expostos no meio bucal. 


\section{Revisão da Literatura}




\section{REVISÃO DE LITERATURA}

A revisão de literatura foi dividida em dois tópicos, liberação e recarga de flúor e microinfiltração, para melhor entendimento do comportamento dos materiais avaliados frente a essas situações.

\subsection{Liberação e recarga de flúor}

CREANOR et al. ${ }^{17}$, em 1994, estudaram as características de liberação e absorçã de flúor dos CIV. Foram preparadas 10 amostras em forma de disco (6 mm de diâmetro e 1,5 mm de altura) dos materiais KetacFil, Chemfil Superior, Fuji II LC, Aquacem e Vitrebond e submersas individualmente em $2 \mathrm{ml}$ de água deionizada por um período de 60 dias, sendo trocada a cada 6 horas no $1^{\circ}$ dia e diariamente até $\mathrm{o} 15^{\circ}$ dia e, em seguida, a cada 3 e 4 dias até o final do experimento. A quantidade de flúor liberada foi medida em cada solução com eletrodo específico. A absorção de flúor pelo CIV foi verificada após 60 dias, em água deionizada. As amostras foram divididas em 2 grupos. Para o grupo teste as amostras foram expostas a solução de 1000 ppm F por 2 minutos, diariamente, e as do grupo controle eram mantidas em água deionizada, por um período de 20 dias. Todos os materiais testados liberaram quantidades mensuráveis de flúor durante o período avaliado, com a mais alta taxa no $1^{\circ}$ dia, diminuindo rapidamente no $2^{\circ}$ dia e atingindo um nível quase constante a partir do $10^{\circ}$ dia; continuando a liberar níveis menores até o $60^{\circ}$ dia. No teste de captação/liberação de flúor, as amostras expostas a solução fluoretada 
liberaram mais flúor iônico que o grupo controle, indicando que CIV tem a capacidade de absorver e posteriormente liberar flúor.

FORSTEN ${ }^{24}$, em 1995, estudou o padrão de liberação de flúor e a capacidade de recarga dos ionômeros modificados por resina (Fuji II LC, LC, Photac Fil, Variglass), do compômero (Dyract), e do ionômero convencional (Fuji II), como também, a influência da proporção pó-líquido e do meio ácido na quantidade de flúor liberada. Após 1 mês, todos os materiais, exceto o Fuji II LC, apresentaram uma liberação de flúor significantemente menor comparada àquela observada após 24 horas. Todos os materiais avaliados, exceto o Dyract e o Variglass, após 9 meses de armazenamento em água, liberaram significantemente quantidades menores de flúor comparadas com as observadas após tratamento de recarga com 50 ppm de flúor, durante 1 semana. A liberação de flúor em pH 5.0 foi maior do que em pH 6.0, para todos os materiais, após 11 meses de estocagem em água corrente.

FARAH; POWERS ${ }^{20}$, em 1998, em uma revisão sobre os materiais restauradores com capacidade de liberar flúor abordaram a propriedade de liberação e recarga desses materiais por fontes externas, as aplicações tópicas de flúor e os dentifrícios fluoretados. A presença de íons flúor no meio bucal possibilita a remineralização do esmalte pelo aumento do crescimento do cristal e produção de fluorapatita com menor solubilidade do que apatita carbonada original. Os autores consideram os CIVs modificados por resina um dos materiais restauradores com maior capacidade de recarga, seguido dos CIVs, dos compômeros e das resinas compostas. Os CIVs atuam como reservatório de fluoretos, sendo que os ionômeros de vidro modificados por resina (Fuji II LC, Photac Fill Quick, Vitremer) oferecem o melhor equilíbrio de liberação de fluoretos, capacidade de recarga e durabilidade clínica para os pacientes de alto desafio cariogênico, embora os compômeros (Dyract AP, Compoglass, Elan, F2000, Hytac) estejam sendo aperfeiçoados para proporcionar maior liberação de flúor e melhores propriedades mecânicas. Os autores relataram sobre a forma de liberação de flúor de materiais restauradores: CIVs têm sua reação de presa por uma reação ácido-base e contém água. A mistura do pó e líquido resulta 
na liberação de fluoretos como subproduto da reação. A água é o meio de transporte através da qual íons se movem causando o endurecimento do material. Para evitar a perda de água, uma resina fluida ou verniz é aplicado na superfície da restauração. Os ionômeros de vidro híbridos endurecem pela reação ácido-base e pela reação de polimerização da resina. O pó é semelhante ao do ionômero de vidro e o líquido contém monômeros, poliácidos e água. O material Vitremer tem uma base fotopolimerizável porosa que permite a difusão do fluoreto. Os compômeros contêm carga capaz de liberar flúor e, alguns desses materiais possuem monômeros modificados que promovem liberação de flúor adicional, devido à carga de vidro de fluorsilicato de vidro de estrôncio e alumínio, ou fluorsilicato de vidro de bário e itérbio trifluoretado, ou itrium trifluoretado e vidro de fluorsilicato de alumínio e cálcio, ou vidro de flúor-alumínio silicato e um diluente hidrofílico que facilita o transporte de água e a liberação de fluoretos. A absorção de água pelos compômeros ocorre após a sua colocação e em contato com a saliva, sendo esta absorção importante para a transferência de íons flúor. As resinas compostas liberam flúor por um mecanismo de troca iônica. As partículas de carga das resinas contêm fluoretos dispersos na matriz de resina cujos íons flúor migram da resina composta para o meio bucal e retornam com íons de $\mathrm{OH}^{-}$da saliva. A resina Heliomolar apresenta como fonte de íon flúor o trifluoreto de itérbio e, na resina Tetric Ceram além desta fonte, contém carga de vidro de fluorsilicato de bário e alumínio. Os autores relataram que os ionômeros de vidro híbridos e compômeros são materiais restauradores utilizados para pacientes com alto desafio cariogênico, uma vez que aderem à estrutura dentária, são estéticos, liberam íons flúor a longo prazo e que podem ser recarregados com aplicações tópicas de flúor.

Considerações sobre os CIVs e materiais híbridos com capacidade de liberação de flúor foram relatadas em 1998, por FORSTEN ${ }^{23}$. Entre estas, a ação do flúor destes materiais restauradores, sua composição, além da quantidade necessária para promover efeito clínico real e a indicação como materiais conservadores. De forma geral, os 
materiais com capacidade de liberar flúor apresentam alta liberação inicial, que diminui drasticamente com o tempo, e se mantém depois em níveis estáveis. Esta liberação tem efeito na remineralização da dentina subjacente, assim como do esmalte. A maior atividade corresponde aos períodos iniciais do endurecimento do CIV. Isto porque esta liberação está intimamente ligada ao processo de endurecimento, mas não interfere nas propriedades físicas do material. Entretanto, quando o flúor é apenas adicionado à sua composição, a liberação é bem menor, caso contrário, enfraqueceria o material, como em resinas compostas modificadas por poliácidos e resinas compostas que liberam flúor. O autor concluiu que a propriedade anticariogênica e remineralizante dos cimentos ionoméricos está relacionada à liberação de flúor, com evidências clínicas e laboratoriais. A atividade de cárie do paciente e o tipo de cavidade são fatores importantes na determinação da escolha do material restaurador a ser aplicado.

KAWAl et al. ${ }^{36}$ estudaram, em 1998, a quantidade de liberação de flúor de 3 resinas compostas (FluorEver, FluoroCore, Pertac-Hybrid) e a capacidade de captação de flúor pelo esmalte e cemento. Os autores concluíram que a quantidade de flúor absorvido por esses tecidos está relacionada com a quantidade de flúor liberada por essas resinas compostas Parte da quantidade desse flúor movimenta-se na camada híbrida através da água e a outra parte se direciona à superfície das restaurações que já absorveram água do ambiente bucal e é, posteriormente, transferida para as áreas de esmalte adjacentes a elas.

Em 1998, BILGIN; OZALP ${ }^{9}$ avaliaram, inicialmente, a liberação de flúor de três CIVs durante 28 dias imersos em saliva artificial e, posteriormente, após exposição em solução de fluoreto de sódio ( $\mathrm{NaF}$ ) ou gel de flúor fosfato acidulado, durante 20 dias. A capacidade de liberação de flúor dos CIV já é amplamente comprovada, ocorrendo a maior liberação nas primeiras 24 horas, com posterior declínio brusco para níveis baixos, que se tornam constantes após algumas semanas. Porém, o conteúdo de flúor e a sua capacidade de liberação diferem entre os materiais. Foram confeccionadas 10 amostras de um CIV convencional (Kromoglass), um CIV 
fotoativado (Vitrabond) e uma resina modificada por poliácidos (Dyract), na forma de discos, medindo $6 \mathrm{~mm}$ de diâmetro e $1,5 \mathrm{~mm}$ de altura, e mantidas em estufa a $37^{\circ} \mathrm{C}$ por 1 hora. Cada amostra foi suspensa em $2 \mathrm{~mL}$ de saliva artificial e estocada a $37^{\circ} \mathrm{C}$. As soluções eram trocadas diariamente no período de 28 dias. Nos períodos de 24 horas, 3, 7, 14 e 28 dias de estocagem igual volume da solução tampão TISAB (Total lonic Strenght Adjusting Buffer) foi adicionado à solução teste, para medir a quantidade de flúor liberada, utilizando o eletrodo flúor seletivo acoplado a um analisador de íon digital. Após análise estatística, os autores concluíram que a maior liberação de flúor ocorreu após 24 horas e o material Kromoglass apresentou a maior liberação, seguido pelo Vitrabond e pelo Dyract. A diferença entre os grupos, a partir do $3^{\circ}$ dia, não foi estatisticamente significante.

Na revisão sobre a atividade cariostática do flúor no meio bucal, em 1999, EKSTRAND; OLIVEBY ${ }^{19}$ citam que essa atividade ocorre em função da concentração de íons flúor no fluido circundante ao dente. De acordo com o grande número de pesquisas clínicas, o mais efetivo regime de flúor na prevenção de cárie dentária é a freqüência da exposição diária do flúor, em baixas concentrações, como água fluoretada ou pasta fluoretada. Nas pastas dentais, o monofluorfosfato de sódio e NaF são as fontes de flúor mais comuns de liberação de flúor para o meio bucal por meio de diferentes mecanismos. A presença de maior concentração de fluoreto de sódio disponível nos fluidos orais decorre da dependência de uma reação de decomposição do monofluorfosfato de sódio por hidrólise a partir de uma reação enzimática com componentes orgânicos para que ocorra a liberação de íons flúor no meio bucal.

Em 1999, ATTIN et al. ${ }^{7}$ testaram a capacidade de liberação e captação de flúor, de resinas compostas modificadas por poliácidos, os chamados compômeros, (Dyract, Compoglass) e de um CIV convencional (GIC Vivaglass Base), como grupo controle, imersos em soluções tampão neutra e ácida. Foram confeccionados 40 espécimes de cada material, 20 deles foram imersos em $5 \mathrm{~mL}$ saliva artificial $(\mathrm{pH} 6.4)$ por 5 minutos e os 
outros 20 em dentifrício fluoretado fluido contendo $5 \mathrm{~mL}$ de saliva artificial $(\mathrm{pH}$ 5.4) por 5 minutos. Após lavagem em água destilada e secagem com papel absorvente, 10 espécimes fluoretados e 10 não fluoretados foram imersos, separadamente, em $3 \mathrm{~mL}$ de solução tampão neutra ( $\mathrm{pH} \mathrm{6.8)} \mathrm{a} 37^{\circ} \mathrm{C}$ e os restantes foram estocados em solução ácida $(\mathrm{pH} \mathrm{4.0)}$. Esse tratamento foi realizado em intervalos de $1,2,3,4$ e 5 dias, e transferidos, a cada um destes, para novas soluções, neutra ou ácida. As soluções testadas foram então tamponadas com igual volume de TISAB II (ORION) e a quantidade de flúor foi medida por um eletrodo flúor sensível sendo os valores convertidos em $\mu \mathrm{gF}^{-} / \mathrm{cm}^{2}$. A liberação de flúor foi observada em todos os materiais testados declinando durante todo o experimento mas, significantemente maior no meio ácido quando comparada com a da solução tampão neutra. Os espécimes de CIV convencional, expostos ao dentifrício fluoretado fluido, apresentaram maiores concentrações de flúor liberado, o que não ocorreu com os compômeros. Os autores concluíram que o Dyract e o Compoglass não têm capacidade de reincorporar flúor, independentemente do valor do $\mathrm{pH}$ do meio.

VIEIRA; SOUZA; MODESTO ${ }^{67}$, em 1999 avaliaram a capacidade de liberação e recarga de flúor de materiais resinosos e materiais ionômericos: CIV convencional (Chelon Fil); CIV modificado por resina (Vitremer); resina composta modificada por poliácidos (Dyract, Variglass); resina composta (Heliomolar), em situação de desafio cariogênico. Os corpos-de-prova, de forma cilíndrica foram confeccionados com os materiais de acordo com as orientações dos fabricantes. Em seguida, todos os materiais protegidos com a tira de poliéster foram armazenados em estufa a $37^{\circ} \mathrm{C}$ e $100 \%$ de umidade relativa por 24 horas. Após esse período foram inseridos em solução desmineralizante ( $\mathrm{pH} 4.0$ ), sob agitação, por 6 horas, sendo lavados com água deionizada e transferidos para uma solução remineralizante ( $\mathrm{pH} 7.0)$, sob agitação, por 17 horas, repetindo esse ciclo por 14 dias. A partir do $8^{\circ}$ dia, antes da troca de cada solução, os espécimes foram expostos ao processo de recarga pela utilização de uma pasta fluida contendo $3 \mathrm{~mL}$ de água deionizada e $1 \mathrm{~g}$ de dentifrício com 1100ppm de $\mathrm{NaF}$, 
por 5 minutos. Todas as soluções foram lacradas, identificadas e estocadas sob refrigeração. A quantidade de flúor liberada foi mensurada com $0,5 \mathrm{~mL}$ de solução adicionada a $0,5 \mathrm{~mL}$ de TISAB pelo método do potenciômetro acoplado a um íon seletivo para flúor. Os resultados mostraram que as maiores quantidades de flúor liberadas foram observadas nos primeiros três dias, declinando nos dias subseqüentes. As quantidades de flúor liberadas na solução desmineralizante foram estatisticamente diferentes da solução remineralizante, com exceção do CIV, Chelon Fil, no $1^{\circ}$ dia e, no $8^{\circ}$ e $9^{\circ}$ dias para o Vitremer. As quantidades de flúor liberadas a partir do $8^{\circ}$ dia apresentaram um acréscimo em ambas as situações, mostrando que os materiais foram capazes de recarregar flúor a partir do meio e, novamente, liberá-lo.

Como citado por ITTHAGARUN; WEl; WEFWEL ${ }^{35}$ em 2000, o uso do flúor tem contribuído largamente para o declínio da prevalência de cárie dentária nas últimas décadas o que pode ser atribuído, principalmente, ao uso difundido das pastas dentais fluoretadas. A forma primária de ação das pastas se dá pelo efeito de ação tópica do flúor intensificando o processo de remineralização e inibindo a fase de desmineralização. Os autores observaram a ação de dentifrícios fluoretados fabricados em países desenvolvidos e em desenvolvimento considerando que a maioria dos estudos tem avaliado a eficácia de produtos de marcas reconhecidas mundialmente. Os dentes selecionados para o estudo foram molares íntegros que receberam uma camada de um verniz ácido resistente, deixando uma janela de esmalte de $1 \mathrm{~mm}$ de largura, e imersos, individualmente, em $10 \mathrm{~mL}$ de solução desmineralizante $(\mathrm{pH} 4.4)$ por 96 horas para produzir lesões. Em seguida, os dentes foram seccionados e cada secção foi coberta com um verniz ácido resistente, deixando exposta a superfície da lesão e, colocada em sistema de ciclagem de $\mathrm{pH}$, em mesa orbital, por 10 dias. Cada ciclo envolvia 3 horas, duas vezes ao dia, em solução desmineralizante, intercalado com 2 horas de solução remineralizante $(\mathrm{pH} 7.0)$. O tratamento com a pasta fluida na concentração de 3:1 (água deionizada/pasta dental), das oito diferentes marcas 
comerciais, em diferentes concentrações comerciais, foi realizado antes e depois dos ciclos de $\mathrm{DES}^{-}$, por 1 minuto, permanecendo durante o período noturno em solução remineralizante. A cada ciclo, os espécimes eram imersos nas respectivas soluções frescas e, seus conteúdos separados para cada grupo experimental. Os autores concluíram que somente os dentifrícios que continham o íon flúor a partir do fluoreto de sódio foram mais efetivos na inibição das lesões do que os que continham monofluorfosfato de sódio (MPA), considerando que a solução remineralizante tratava-se de uma solução inorgânica, com ausência de sistema enzimático necessário para a hidrólise do MPA.

A importância da ação do flúor no meio bucal também foi relatada por $\mathrm{NARVAI}^{44}$, em 2000, em uma revisão sobre a relação entre a cárie dentária e a ação do flúor. Essa relação tornou-se evidente nos estudos de comunidades que ingeriam água de fontes naturais com presença de flúor e nas quais a ocorrência de cáries era muito pequena. A fluoretação da água de abastecimento tornou-se um dos maiores benefícios na prevenção e controle da cárie dentária, no século XX. Da mesma forma, os estudos da ação tópica do flúor na redução da solubilidade do esmalte dentário disponibilizaram outros produtos como os dentrifícios fluoretados.

PENG et al. ${ }^{51}$, em 2000 avaliaram a liberação de flúor de materiais restauradores estéticos e a recarga, utilizando flúor gel fosfato acidulado. Inicialmente, os autores acompanharam a liberação de flúor de três CIV convencionais (ChemFlex, Fuji IX GP, lonofilmolar), quatro compômeros (Dyract AP, Compoglass F, Freedom, F2000) e uma resina híbrida (Ariston pHc), todos imersos em saliva artificial e com trocas realizadas em períodos de 6, 24 e 48 horas e a partir de então uma vez por semana, durante seis semanas Após esse período, os corpos-de-prova foram cobertos com $2 \mathrm{~mL}$ de gel APF, por quatro minutos, lavados com spray de água deionizada e imersos em $2 \mathrm{~mL}$ de saliva artificial. Este procedimento foi realizado nos mesmos intervalos de tempo antes da recarga. As mais altas quantidades de flúor liberadas foram registradas pelo Compoglass F, seguidas dos CIV convencionais, mas sem diferenças 
significantes, e na seqüência, Dyract AP e Ariston pHc. Todos os materiais apresentaram os maiores padrões de liberação nos primeiros dias, declinando rapidamente e estabilizando-se entre a segunda e a quarta semanas, embora em padrões variáveis. Os autores observaram que o tamanho e tipo de partícula podem ou não interferir na quantidade liberada de íon flúor. Dyract AP e Freedom que apresentam partículas de $1 \mu \mathrm{m}$ e contêm estrôncio-flúor-silicato liberaram menor quantidade que os que contem alumínio-flúor-silicato. Entretanto, o F2000 com partículas em tamanho médio, em torno de $3 \mu \mathrm{m}$ liberou quantidades semelhantes de flúor após o tratamento com APF gel. Os diferentes níveis de íons liberados após a recarga podem ter sido decorrentes da erosão superficial causada pelo tratamento. Os autores observaram que os compômeros e o Ariston pHc mantiveram níveis constantes de liberação durante o período de seis semanas apesar de não apresentarem uma alta liberação inicial concluindose que, a resina composta híbrida e os quatro compômeros estudados podem funcionar como reservatórios de flúor tal qual os três CIV convencionais.

WEIDLICH et.al. ${ }^{70}$, em 2000, avaliaram a capacidade de liberação e recarga de flúor dos CIVs modificados por resina (Vitremer e Fuji II LC), dois CIV convencionas (Fuji IX e Chelon Fill) e duas resinas compostas (Heliomolar e Z100). Foram preparados oito espécimes de cada material e conservados em umidificador por 24 horas, a $37^{\circ} \mathrm{C}$ e $100 \%$ de umidade relativa, imersos em $4 \mathrm{~mL}$ de saliva artificial em tubos de poliestireno. Após esse período, 5 corpos-de-prova foram transferidos para uma solução de flúor 1000ppm, por $1 \mathrm{~min}$ e este procedimento foi repetido, diariamente, durante 25 dias. Os corpos-de-prova restantes, em número de 3, não receberam tratamento de recarga. As soluções foram conservadas sob refrigeração a $4^{\circ} \mathrm{C}$ para posterior análise. A concentração do íon flúor foi determinada pela adição de $1 \mathrm{~mL}$ de TISAB II para $1 \mathrm{~mL}$ dessa saliva artificial utilizando um eletrodo especifico para flúor acoplado a um analisador de íons. Os resultados demonstraram que os CIVs liberaram significantemente maiores quantidades de flúor após a exposição à solução de fluoreto de 
sódio, comparado com o grupo que não recebeu o tratamento de recarga, enquanto as resinas compostas apresentaram os menores valores. Desta forma, os autores concluíram que os CIVs e os ionômeros de vidro modificados por resina foram capazes de absorver e liberar íons flúor a partir da solução de 1000ppm de $\mathrm{NaF}$ (VIT=FIILC=CHE>FIX) e, que as resinas compostas absorveram as menores quantidades. Os CIV liberaram mais flúor durante o primeiro dia e após este período a liberação de flúor decresceu enquanto a resina composta Heliomolar liberou flúor somente no primeiro dia e Z100 não liberou flúor. Em termo de tratamento com NaF, as resinas compostas, ao contrário dos CIV, não mostraram capacidade de absorção de F.

POSADA, EMILSON, BIRKHED ${ }^{54}$, em 2000 investigaram a liberação de flúor de um CIV modificado por resina (Vitremer) envelhecido e após recarga com soluções de pastas dentifrícias de $\mathrm{NaF}$ em diferentes concentrações aplicadas uma ou duas vezes por dia, por um longo período de tempo. Os autores ainda observaram a eluição do flúor pelo material coberto com uma camada de selante e, também, quando a camada superficial mais extensa tinha sido desgastada. Foram confeccionados 160 espécimes, estocados em 1 litro de água deionizada e mantidos a $37^{\circ} \mathrm{C}$ durante 12 semanas, sendo renovado diariamente o meio de imersão. Após esse período, o nível de flúor flutuante (baseline) foi alcançado e cada espécime foi transferido para $2 \mathrm{~mL}$ de água deionizada por 7 dias a $37^{\circ} \mathrm{C}$, sendo avaliado novamente o nível de basal de flúor liberado. Os 10 grupos de 16 discos foram recarregados com $5 \mathrm{ml}$ de $\mathrm{NaF}$ em duas formas: soluções (concentrações de $0.05,0.2,2 \%$ ) e pastas dentifrícias diluídas (2:1), de duas formas: 5 receberam recarga 1 vez e, os outros 5 duas vezes, durante 5 min, sendo então lavados com água deionizada, secos com papel absorvente e colocados em nova água deionizada. A recarga foi repetida no $2^{\circ}$ dia e nos as subseqüentes, durante 7 dias, sendo a água deionizada trocada na $1^{\text {a }}, 2^{\text {a }}$ e $3^{a}$ semanas. Os resultados mostraram que houve significativamente maior liberação após a recarga com solução de $\mathrm{NaF}$ 2\% $\left(9,048 \mathrm{ppm} \mathrm{F}^{-}\right.$) comparada com as outras soluções e as pastas fluidas, em todos os 
intervalos de tempo. A maior liberação ocorreu no $8^{\circ}$ dia, após o tratamento com a solução e a pasta dentifrícia de maiores concentrações de NaF. Neste estudo os autores demonstraram que em CIV modificado por resina pode ser reativado por exposição de fontes externas de flúor, soluções ou pastas e atua como um sistema recarregável de liberação lenta de flúor. Os resultados demonstraram que a quantidade liberada de íons flúor após recarga foi dependente da concentração da solução; quanto maior a concentração, maior quantidade de íons liberada.

ASMUSSEN; PEUTZFELDT ${ }^{5}$, em 2002 estudaram a liberação de flúor de CIVs, um compômero e resinas compostas experimentais por 3 anos. As resinas compostas experimentais foram preparadas em duas séries: a primeira com UEDMA (uretano-ethoxi-dimetacrilato) e TEGMA (trietileno-glicol-dimetracrilato) e, a segunda série UEDMA e HEMA (2hidroxi-etil-metacrilato). O HEMA e o TEGMA diferem com relação à capacidade hidrofílica. Partículas de vidro silanizadas e outras partículas contendo flúor, similares ao sal de alumínio da matriz dos CIVs foram adicionadas à mistura de monômero. Os CIVs e ionômeros de vidro modificados por resinas são conhecidos pela liberação de quantidades significativas de flúor, seguidos dos compômeros, que por serem materiais resinosos apresentam baixos valores de liberação quando comparados a outros materiais. A liberação de flúor a partir do material está associada ao transporte do íon, o qual é facilitado pelo ambiente hidrofílico ou iônico. Mas, outros fatores como permeabilidade, dissolução superficial e vários fatores intrínsecos podem controlar a liberação de flúor. A matriz de polímero de compômeros é modificada pela presença de grupos carboxílicos, o que confere a estes materiais alguma capacidade hidrofílica. Entretanto, as resinas compostas têm uma matriz de polímero modestamente hidrofílica, o que significa em transporte restrito de água e íons. Essas diferenças nas composições dos materiais podem justificar uma maior liberação de íons flúor pelos compômeros do que das resinas compostas. Neste estudo, as resinas experimentais apresentaram um leve acréscimo de flúor liberado devido à presença do sal de alumínio na matriz. 
Em 2002, ATTAR; ÖNEM ${ }^{6}$ investigaram inicialmente, as características da liberação de flúor de duas resinas compostas (Tetric, Valux Plus), duas resinas compostas modificadas por poliácidos (Compoglass, Dyract), cimento de ionômero de vidro convencional (Ceramfil $\beta)$ e, no segundo momento, avaliaram a capacidade de recarga e subseqüente liberação. As amostras foram preparadas, de acordo com as orientações dos fabricantes. Para a análise da liberação de flúor, as amostras individualmente foram imersas em tubos com $4 \mathrm{~mL}$ de água deionizada. A quantidade de flúor liberada foi observada nos 1, 2, 3, 4, 5, 15,30 e 60 dias, após o tamponamento da solução com igual volume de TISAB por um eletrodo íon flúor específico. Após 60 dias, as amostras foram expostas a uma solução padrão de $1000 \mathrm{ppmF}^{-}(\mathrm{pH}$ 6.6) por 10 minutos, lavadas e imersas em $4 \mathrm{~mL}$ de água deionizada, e o flúor liberado foi medido diariamente durante 5 dias. As leituras mostraram diferenças estatisticamente significantes entre os grupos, sendo o resultado do CIV maior durante o período de teste. Os autores observaram que os valores de flúor liberados, inicialmente, declinaram com tempo e, a maior quantidade foi detectada após as primeiras 24 horas. No processo de recarga, todos os materiais apresentaram maiores valores de liberação de flúor, seguidos de um rápido retorno a níveis anteriores nos três primeiros dias. Nesse estudo, os compômeros liberaram significantemente menos flúor que o CIV convencional e mais que as resinas compostas. Isto se deve, ao fato dos componentes adicionados à composição das resinas compostas levarem a baixa liberação de flúor. Provavelmente, o aumento da liberação se deve a retenção de íons flúor na superfície dos materiais após recarga, tal qual apresentado neste estudo pelo Tetric, Compoglass, Dyract..

O nível de liberação de flúor abaixo do que poderia ser considerado efeito não cariostático é desconhecido, como também, as dificuldades em realizar medidas de concentração de flúor quando os níveis forem extremamente baixos. A segunda situação levou em 2002, McCABE; CARRICK; SIDHU ${ }^{41}$ a medirem baixas concentrações de flúor comparando dois métodos, o método elétrodo íon-seletivo e o método cromatográfico de 
íon. A avaliação dos dois métodos foi realizada sob soluções diluídas de uma de solução aquosa padrão de fluoreto de sódio de 100ppm nas concentrações de 100,10,1, 0.1, 0.01 e 0.001ppm e, das quantidades de flúor liberadas da matriz de resina de dois sistemas adesivos dentinários. Para concentração de flúor acima de $1 \mathrm{ppm}$, tanto o método eletrodo íonseletivo como o método cromatográfico forneceram medidas confiáveis e reprodutíveis de concentração de flúor e os resultados a partir dos dois instrumentos foram bem correlacionados. O método elétrodo íon-seletivo, invariavelmente mostrou uma alta concentração de íons flúor e, este resultado foi explicado pelo uso do tampão TISAB. O tampão TISAB garante um $\mathrm{pH}$ ácido, necessário para o uso correto do eletrodo e ocorra a decomposição do íon flúor complexo, de modo que pudesse ser mensurada a quantidade de flúor total. O método cromatográfico mediu somente a concentração do íon flúor livre sendo mais efetivo para baixas concentrações. Baixas concentrações de flúor apresentadas em sistemas biológicos só eram possíveis de mensurar por meio das técnicas de difusão de concentração empregando o hexametilsiloxano ou, pelos sistemas multielétrodos, em soluções ácidas. Sob o ponto de vista terapêutico, provavelmente, somente o íon flúor livre pode ter um efeito tópico direto não existindo evidências que o flúor complexo possa interagir com o esmalte dentário e modificar a sua composição.

MARTIN; JEDYNAKIEWICZ; FISHER ${ }^{40}$, em 2003, quantificaram as alterações de dimensão, peso e solubilidade de materiais restauradores após 64 dias utilizando como meio de imersão água ou saliva artificial. Os materiais restauradores investigados foram uma resina organicamente modificada por cerâmica (Definite), um composto liberador de íons (Ariston $\mathrm{pHc}$ ), duas resinas condensáveis de alta densidade (Solitaire, Surefil) e duas resinas híbridas (Pertac III e Spectrum TPH) que ao final do período do teste, ganharam peso com exceção do material Ariston pHc. Os espécimes imersos em água destilada mostraram significativamente alguma dissolução do material. Muitos materiais poliméricos absorvem água dentro da matriz através de um processo de difusão controlada e alguns absorverão água 
como um resultado da reação de presa. Nos compômeros, isto se torna claro, onde a reação iônica secundária para polimerização é dependente da presença de moléculas de água causando a dissociação das moléculas carboxilícas. Alguns fatores determinam o coeficiente de difusão para materiais a base de polímeros como: tipo de resina, percentual de carga, tamanho de partícula, reatividade do vidro, e a presença ou não de agentes de união de silano. Os autores observaram que o material Ariston pHc apresentou uma maior dissolução em função da troca iônica pela diferença de $\mathrm{pH}$ entre o material e o meio de imersão, sobretudo em água destilada, não sendo observado em saliva artificial pelo fato de ter $\mathrm{pH}$ neutro. Ariston pHc é identificado por liberar íons alcalinos, flúor, cálcio e hidroxilas quando os valores de $\mathrm{pH}$ diminuem, proporcionando a liberação de maiores quantidades de substâncias ativas no meio bucal do que em pH neutro. Portanto, quando os materiais são imersos em água deionizada, a saída de íons aumenta até que seja alcançado o equilíbrio osmótico entre a superfície do material e a solução de imersão, o que ocorre em aproximadamente 21 dias, quando começa então a ser observado o aumento de peso do material. Os materiais imersos em saliva apresentaram apenas aumento em peso, que pode ser interpretado como uma absorção de tipos de íons pesados dentro do material e não dos que estão sendo liberados.

Em 2003, PEDRINI et al. ${ }^{50}$ avaliaram a liberação de flúor antes e após a aplicação tópica de fluorfosfato acidulado de materiais restauradores classificados como: CIV convencional (Ketac-Fill); CIV modificado por resina (Vitremer, Fujill LC); e resina modificada por poliácido (Freedom). Os espécimes preparados foram colocados, individualmente, em $2 \mathrm{~mL}$ de água deionizada e deixados sob agitação por 24 horas, sendo então lavados em água deionizada, secos com papel absorvente e transferidos para novos tubos com $2 \mathrm{~mL}$ de água deionizada, por 15 dias. Após esse período, receberam tratamento com gel de fluorfosfato acidulado contendo $1,23 \%$ de íons flúor ( $\mathrm{pH} 3.6-3.9)$, por 4 minutos, sendo então lavados vigorosamente, sob água deionizada por 30 segundos, secos e imersos em tubos contendo $2 \mathrm{~mL}$ de água deionizada, e agitados por períodos de 24 horas. Os 
procedimentos descritos no período anterior da recarga foram repetidos por 15 dias. As soluções diárias foram estocadas a $4^{\circ} \mathrm{C}$ e as quantidades liberadas foram determinadas até o $30^{\circ} \mathrm{dia}$, utilizando um eletrodo específico para flúor conectado ao analisador digital de íons e, expressadas em $\mu \mathrm{gF}^{-} / \mathrm{cm}^{2}$. Os resultados mostraram que a maior liberação de flúor foi encontrada no $1^{\circ}$ dia para o CIV convencional seguido do Vitremer, Fuji II LC e Freedom, declinando ao longo dos 15 dias. No $16^{\circ}$ dia, houve uma significante diferença na quantidade de flúor liberada após a aplicação tópica do flúor em comparação com aquela do $1^{\circ} \mathrm{dia}$, para cada material, com exceção do Ketac-Fil. Entre os materiais, o Vitremer apresentou a maior liberação. Como a presença constante de flúor é uma condição importante na prevenção, segundo os autores, o sucesso do tratamento tópico depende da formação de reservas capazes de liberar íons flúor, por períodos prolongados de tempo. Portanto, a recarga de íons pelos materiais restauradores promove uma reserva desse elemento, em potencial, para liberação no meio bucal. Os CIVs convencionais e os CIVs modificados por resina apresentam vários comportamentos, principalmente, como resultado da diferença na composição, difusão do íon através do material e a diferença na energia de superfície, além de outros fatores como porosidade, proporção pó/líquido, além da solubilidade dos materiais que podem alterar a liberação desses íons. Uma maior liberação de flúor apresentada pelo CIV modificado por resina, após a recarga e a constante liberação por todo o período, pode ser explicada pela difusão do íon dentro da matriz desses materiais. Mas, isso não ocorreu com a resina composta modificada por poliácidos (Freedom), o que pode indicar que houve somente uma absorção de flúor na superfície do material.

PRESTON, et. al. ${ }^{55}$, em 2003 compararam in vitro durante dois anos, o potencial de liberação de flúor após recarga de oito materiais restauradores estéticos: dois CIVs (Chemfil, Ketac-Fil), dois CIVs modificado por resina (Photac-Fil Aplicap, Vitremer); dois compômeros (Dyract, Compoglass); e duas resinas compostas (Heliomolar, Concise). Os espécimes em forma de disco foram imersos em $500 \mathrm{~mL}$ de saliva artificial, e 
removidos após 23 horas, lavados e imersos em $5 \mathrm{~mL}$ de saliva artificial por 1 minuto. Após 8 dias, os discos foram lavados e imersos em solução $\mathrm{NaF}$ (500ppm) por dois minutos, sendo removidos, lavados, secos e imersos novamente em $5 \mathrm{~mL}$ de saliva artificial por 1 hora. A quantidade de flúor liberada antes e após a recarga foi analisada em $1 \mathrm{~mL}$ da amostra. Este procedimento foi repetido 13 vezes, em períodos pré-estabelecidos, finalizando em 720 dias. Todos os grupos de materiais apresentam capacidade de recarga, destacando os CIVs incluindo os ionômeros modificados por resina. As resinas compostas apresentaram baixos valores de liberação e recarga, provavelmente, representados pelo flúor remanescente na superfície após recarga e lavagem dos ciclos. Esses valores no período de pós-recarga permaneceram maiores ou constantes. Segundo os autores, essas diferenças podem estar relacionadas com o mecanismo de recarga do flúor, sendo a permeabilidade de cada material um dos maiores fatores, ou seja, a sua capacidade de absorver e liberar flúor. Os resultados confirmam a capacidade relativamente baixa de sorção das resinas compostas, ou seja, baixa permeabilidade a água. O flúor presente nas resinas pode difundir-se por meio da matriz polimérica, o que é inerentemente mais difícil do que a difusão através do hidrogel como acontece com compômeros. Nesses materiais a água penetra na matriz polimérica por processo de difusão para que através da matirz de hidrogel ocorra a liberação de flúor. Nesse estudo em todos os intervalos de tempo a liberação de flúor pós-recarga dos materiais ao final de dois anos foram significantemente diferentes. As resinas compostas Heliomolar e Concise apresentaram os menores valores de liberação pós-recarga, respectivamente 0,2 e $0,3 \mu \mathrm{gF} / \mathrm{cm}^{2} / \mathrm{h}$, seguidos dos compomeros (Compoglass $=5,0 \mu \mathrm{gF} / \mathrm{cm}^{2} / \mathrm{h}$ e Dyract $=3,6 \mathrm{gF} / \mathrm{cm}^{2} / \mathrm{h}$ ) enquanto que os CIV modificados por resina (Photac-Fil Aplicap $=12,1 \mu \mathrm{gF} / \mathrm{cm}^{2} / \mathrm{h} \quad$ e Vitremer $=9,0 \mu \mathrm{gF} / \mathrm{cm}^{2} / \mathrm{h}$ ) e os CIV convencionais (Chemfil=10,3 $\mu \mathrm{gF} / \mathrm{cm}^{2} / \mathrm{h} \mathrm{e}$ Ketac-Fil=3,0 $\mathrm{gF} / \mathrm{cm}^{2} / \mathrm{h}$ ) apresentaram a maior capacidade de recarga.

HSU et al. ${ }^{32}$, em 2004 desenvolveram um sistema de fluxo contínuo para simular a cinética do fluxo salivar e estudar as características 
de liberação e recarga de um CIV convencional (Fuji IX) e um CIV modificado por resina (Vitremer). Discos dos materiais foram suspensos em $2 \mathrm{~mL}$ de água deionizada e o fluxo foi controlado por uma bomba de infusão, em $20 \mathrm{~mL} / \mathrm{h}$. A liberação de flúor foi acompanhada por 6 dias consecutivos e no $7^{\circ}$ dia, os discos receberam um tratamento de solução $\mathrm{NaF} 0,2 \%$, por um minuto. Os níveis liberados foram medidos em períodos de tempo até completar 12 horas. Os resultados obtidos mostraram que após o tratamento de flúor houve um aumento na liberação de $52 \%$ para o CIV convencional e $97 \%$ para o Vitremer, comparados aos valores de prérecarga. Os resultados da liberação e recarga, quanto ao teor de flúor acumulado, registraram os mais altos valores para o CIV modificado por resina quando comparados ao CIV convencional. Entretanto, os valores de flúor alcançados foram os mesmos aos iniciais após 90 minutos do tratamento com recarga, significando que íons flúor podem ser facilmente recarregados e rapidamente liberados. As características de liberação dos dois materiais estudados sugerem que o mecanismo restaurador de flúor demonstra pequena ou nenhuma interação com a matriz, após recarga de flúor em formas solúveis.

\subsection{Microinfiltração}

Para PASHLEY ${ }^{48}$, em 1990, a maioria dos materiais restauradores sofre infiltrações marginais, ou seja, substâncias corantes, radioisótopos ou bactérias penetram pela interface das paredes da cavidade e o material restaurador, podendo em certos casos, atingir o assoalho da cavidade em dentina e até mesmo alcançar a câmara pulpar. Para a avaliação in vitro de microinfiltração utiliza-se a área mais infiltrada como a 
quantidade máxima de infiltração e, essa condição pode corresponder ou não à situação clínica in vivo. Assim, em estudos in vitro, se o material não apresentar microinfiltração pode-se deduzir que existe uma grande probabilidade de sucesso clínico desse material.

SCHERER et.al. ${ }^{58}$, em 1992, compararam a microinfiltração em cavidades tratadas com vários monômeros promotores de adesão e primers estudando seus efeitos sobre a superfície da dentina. Todos os sistemas adesivos estudados apresentaram também primers como agentes de molhamento. O HEMA atua como uma resina bi-funcional, na qual a porção hidroxietil é hidrofílica e ávida para estabelecer ligação com a dentina enquanto o componente metacrilato é hidrofóbico e copolimeriza-se com a resina adesiva o BisGMA (bisfenol-glicidil-metacrilato). Todos sistemas apresentaram selamento capaz de limitar a microinfiltração e, a forma mais efetiva foi obtida às custas do tratamento ácido da dentina pela utilização de substâncias condicionantes ou primers com pH ácido para aumentar a possibilidade do mecanismo de adesão.

BRACKETT; GUNNIN; GILPATRICK ${ }^{11}$, em 1998 compararam in vitro a microinfiltração de restaurações com dois CIVs modificados por resina (Vitremer, Fuji II LC) e de um compômero (Dyract). Foram utilizados 12 incisivos bovinos que receberam preparos classe $V$, localizados na junção cemento-esmalte, medindo $1,5 \mathrm{~mm}$ de profundidade por $2 \mathrm{~mm}$ em altura e $3 \mathrm{~mm}$ de largura, mantendo o ângulo cavo superficial em $90^{\circ}$ e um bisel de $45^{\circ}$, nas margens de esmalte, nas faces lingual e vestibular. Os materiais restauradores foram inseridos nas cavidades de acordo com as instruções dos fabricantes. Os dentes restaurados, após o acabamento e polimento, foram mantidos em temperatura ambiente, em água, por uma semana, sendo então submetidos a termociclagem em água na temperatura de $5^{\circ} \mathrm{C}$ e $55^{\circ} \mathrm{C}$, por 1 minuto. Em seguida, os dentes foram imersos em solução azul de metileno $10 \%$, por 4 horas, sendo então lavados, secos, incluídos em resina e seccionados longitudinalmente. Os cortes obtidos foram avaliados em microscópio óptico com aumento de 20 vezes para observar a penetração do corante ao longo das paredes cavitárias em três níveis. O 
maior grau de infiltração foi observado nas restaurações com Dyract, embora sem diferenças estatísticas significantes entre os 3 materiais.

CORTES et. al. ${ }^{15}$, em 1998, avaliaram a microinfiltração marginal de dois compômeros, Dyract e Compoglass em cavidades Classe V, preparadas com margem em esmalte e cemento, nas superfícies vestibular e lingual de 20 pré-molares humanos. Os grupos foram divididos dois para cada material, sendo que apenas um recebeu condicionamento com ácido fosfórico 37\%, o material restaurador foi inserido de acordo com as instruções dos fabricantes e fotopolimerizados por 40 segundos. As superfícies restauradas foram polidas e os espécimes estocados em água destilada em temperatura ambiente, por 24 horas. Os dentes foram seccionados, após terem sido imersos em fucsina básica $2 \%$, por 24 horas, e cada superfície foi avaliada em microscópio óptico, quanto à penetração do corante, sendo observado o maior grau de infiltração na região de cemento do que na superfície de esmalte. Entre os dois materiais não foram observadas diferenças significantes na microinfiltração como também entre superfícies tratadas ou não com condicionamento ácido.

GROBLER; ROSSOUW; VaN WYK KOTZE ${ }^{66}$, em 1999 avaliaram in vitro 65 caninos com preparos classe $V$, de forma circular, medindo $1,5 \mathrm{~mm}$ de profundidade por $3 \mathrm{~mm}$ de diâmetro localizados na face vestibular. Os dentes foram restaurados com 5 sistemas restauradores para cemento/dentina. Os sistemas adesivos foram aplicados nas paredes das cavidades de acordo com 0 material restaurador Dyract PSA (Primer/adesivo) para Dyract; ScothBond multiPurpuse para Z100; All-Bond 2 para resina Bis-Fil; OptiBond Multiuse filled adhesive para o XRV Herculite; Aelite Bonding para o Bis-Fil. As cavidades foram então restauradas e o acabamento final foi realizado com a série de discos SofLex. Os dentes foram termociclados em solução azul de metileno $2 \%$, e foram realizados cortes horizontais de $6 \mathrm{~mm}$ de espessura, com disco de diamante. Cada secção de dente foi colocada em tubos testes contendo $1 \mathrm{~mL}$ de ácido nítrico $50 \%$, por 24 horas, para dissolução completa e a concentração do corante foi determinada por espectrofotometria. Os autores 
concluíram que o Dyract apresentou a mais baixa microinfiltração na interface dentina/cemento, o que pode aumentar a longevidade da restauração em situação clínica, com nenhuma ou pouca lesão de cárie secundária.

TUNG; ESTAFAN; SCHERER ${ }^{63}$, em 2000 avaliaram a microinfiltração em 32 pré-molares com preparos classe $V$ medindo 3,0mm de largura, $1,5 \mathrm{~mm}$ de altura e $0,5 \mathrm{~mm}$ de profundidade e restaurados com o compômero (Dyract flow) e dois sistemas adesivos. Em seguida, foram realizados o condicionamento com gel ácido, por 15 segundos, lavados por 20 segundos com spray e secos com ar. O adesivo foi então aplicado por 15 segundos e, polimerizado por 40. Em seguida, foi inserido o material e, polimerizado por 40 segundos. Os cortes obtidos foram visualizados com aumento de 30 vezes por 2 avaliadores calibrados. Dentro dos limites do estudo os autores concluíram que a capacidade de selamento de sistemas adesivos de frasco único, em esmalte e dentina, não apresentou diferenças significantes. Ambos sistemas adesivos Primer Bond NT e PQI (Ultradent) demonstraram igual efetividade com relação a microinfiltração em restaurações classe $V$ de resina composta e Dyract flow e, que o compômero Dyract flow pode ser usado em cavidades Classe $\mathrm{V}$, como material restaurador.

MUSANJE; SHU; DARVELL ${ }^{43}$, em 2001 estudaram o efeito da sorção de água sobre o comportamento mecânico dos materiais estéticos: compômero (Dyract $A P$ ), resina híbrida (Surefil) e o ionômero de vidro (Chemflex), em saliva artificial. A química do meio bucal é mais bem simulada com a utilização de saliva artificial nos experimentos in vitro, com diferentes efeitos sobre o tipo do material e o tempo de imersão. Os materiais que apresentam reação ácido/base são mais sensíveis ao meio de imersão comparados às resinas compostas, que por outro lado apresentam maiores alterações nas suas propriedades mecânicas.

ÖRTENGREN et al. ${ }^{45}$, em seu estudo de 2001 relatam que a umidade do meio bucal pode causar degradação química e enzimática dos materiais à base de resina provocando a dissolução dos diferentes 
constituintes dos monômeros da matriz, em função do grau de ligações cruzadas existentes. O tipo e volume da carga podem afetar a sorção de água e a solubilidade dos materiais. A infiltração e a degradação hidrolítica são processos dependentes do tempo. As variações do pH no meio bucal e na superfície do dente afetam negativamente a resistência ao desgaste dos materiais à base de resinas compostas. Os materiais testados, resinas híbridas (Spectrum, Z100, Artglass) imersos em soluções com pH 4.6 e 8.0 apresentaram maior solubilidade no $\mathrm{pH}$ menor que foi aumentando no intervalo de 1 a 7 dias. $\mathrm{Em} \mathrm{pH}$ alto, para todos os materiais, foi observado menor sorção de água no prazo de 60 dias.

BESNAULT; ATTAL $^{8}$, em 2002 estudaram a influência do meio bucal sobre a microinfiltração de sistemas adesivos, Scotchbond Multi Purpose Plus (SBMP) e Clearfil SE Bond (SE Bond), em cavidades Classe II. As condições externas de alterações na temperatura e umidade relativa $\left(23^{\circ} \mathrm{C}\right.$ e $40 \%$ umidade), simulando o meio bucal diminuíram a capacidade de selamento dos sistemas adesivos utilizados.

CHIMELLO et. al. ${ }^{14}$, em 2002 avaliaram a microinfiltração em restaurações Classe $V$, comparando dois materiais restauradores, uma resina composta flow e uma resina composta híbrida associadas à dois sistemas adesivos. Foram preparadas em 20 dentes humanos, caninos e pré-molares, 40 cavidades com margem oclusal em esmalte e margem cervical em cemento/dentina, nas superfícies vestibular e lingual. Os dentes restaurados foram armazenados em água destilada por 24 horas e então submetidos a termociclagem em 600 ciclos, em temperaturas de $4^{\circ} \mathrm{C}$ e $55^{\circ} \mathrm{C}$. Os espécimes foram selecionados e examinados com 40 vezes de aumento por meio do microscópio óptico, para atribuição de escores de 0 a 3 a depender do grau de infiltração. Os autores concluíram que nenhum dos materiais restauradores selou completamente a interface dente/restauração nas margens cavitárias, mas que o sistema adesivo Optibond Solo apresentou melhores resultados que o Paama 2. Os autores relataram ainda que um dos fatores que contribuíram para o grau de infiltração marginal foi a contração que o material sofre durante a polimerização, além 
do efeito da termociclagem sobre o deslocamento da restauração nas paredes cavitárias, apesar de que estudos in vivo demonstraram que a mastigação tem uma maior influência na integridade marginal do que o estresse térmico. Durante o processo de termociclagem, podem ocorrer micro fendas em função das diferenças entre os coeficientes de expansão térmica da estrutura dentária e do material restaurador expostos a ciclos de contração e expansão. Neste estudo, as margens cervicais mostraram escores mais altos de microinfiltração quando comparados aos graus de infiltração com os dois materiais restauradores e o mesmo sistema adesivo. Não foram observadas diferenças estatisticamente significantes entre as margens cervicais e oclusais. Entretanto, entre os dois sistemas, as restaurações realizadas com o sistema adesivo Optibond Solo apresentaram menor microinfiltração do que com Paama 2, provavelmente porque os dois sistemas adesivos apresentam diferentes forças de adesão ao substrato.

FARIAS; AVELAR; BEZERRA ${ }^{21}$, em 2002 avaliaram in vitro o comportamento de sistemas adesivos dentinários, CIVs modificados por resina e resinas compostas modificadas por poliácidos no selamento marginal de cavidades classe $\mathrm{V}$. As cavidades medindo $4 \mathrm{~mm}$ de largura, $3 \mathrm{~mm}$ de altura e $2 \mathrm{~mm}$ de profundidade foram preparadas em molares humanos extraídos. As restaurações foram realizadas de acordo com a orientação dos fabricantes e armazenadas, em água, por 48 horas, para posterior acabamento com discos Sof-Lex (3M). Para avaliar a infiltração marginal os dentes foram termociclados, imersos em solução azul de metileno em regime de 3 ciclos de $5^{\circ} \mathrm{C}$ a $55^{\circ} \mathrm{C}$, a $37^{\circ} \mathrm{C}$, por 3 minutos em cada um deles. Após a termociclagem, os dentes foram seccionados no sentido V-L e os cortes avaliados com auxílio de lupa esterioscópica (40x), quanto à penetração do corante, em escores de 0 a 4 . Os autores observaram que a aplicação de um sistema adesivo hidrofílico constitui uma alternativa para o selamento marginal, mas não é capaz de promover um selamento hermético e de eliminar a microinfiltração, apenas pode minimizála, dependendo do material restaurador. 
PIVA, et. al. ${ }^{53}$, em 2002 avaliaram a influência dos corantes para detecção de cárie em estudos sobre microinfiltração em cavidades Classe $V$ na face vestibular e lingual restauradas com compômero (F2000) ou resina composta (Z100). O maior grau de infiltração foi detectada na margem dentina/cemento em restaurações com resina comparadas com os compômeros. A baixa infiltração na parede cervical observada nas restaurações de compômeros está relacionada ao fato destes materiais sofrerem pouca influência do fator-C. Assim, baixo estresse e menor penetração do corante e a melhor capacidade de selamento do compômero está relacionado à presença de grupos hidrofílicos que permitem a sorção de água, melhorando o selamento marginal. Os autores destacaram a influência dos sistemas adesivos convencionais que são menos suscetíveis às interferências das inúmeras variáveis do procedimento adesivo. Os agentes corantes para detecção de cárie não interferiram no grau de microinfiltração.

TURSSI et al. ${ }^{64}$, em 2002 avaliaram, o efeito de diferentes meios de armazenamento sobre a superfície de materiais restauradores resinosos. Um dos fatores é a sua resistência a biodegradação, por meio dos processos de deslizamento, abrasão, degradação química e fadiga e, ocorrem isoladamente ou em combinação com grande influência no desempenho clinico satisfatório dos materiais restauradores. Um efeito prejudicial nas propriedades físicas dos materiais restauradores resinosos tem relação com o grau de sorção da água que age na superfície, provocando hidrólise e dissolução de seus componentes. Nas condições do meio bucal, com ausência de forças mecânicas, os processos químicos ou de dissolução podem provocar um aumento da rugosidade devido à degradação química da superfície e da subsuperfície as quais podem envolver a matriz resinosa, a carga, ou a interface carga/matriz.

OSÓRIO, et. al. ${ }^{46}$, em 2003, estudaram a microinfiltração e a morfologia da interface dentina/esmalte/resina em cavidades Classe V com a utilização dos sistemas adesivos convencionais e self-etching com restaurações em resinas compostas. A qualidade de união à dentina é 
determinada pela profundidade de desmineralização e extensão da difusão e impregnação do monômero dentro da zona dos tecidos ricos em cálcio. A capacidade de selamento das restaurações está relacionada à localização e qualidade da dentina em restaurações Classe $V$. O uso dos sistemas adesivos para criar interfaces híbridas no cemento é ainda questionável. $O$ esmalte nesta região é geralmente pouco espesso, aprismático e menos receptivo à adesão. A microinfiltração em cemento foi menor com a utilização do sistema autocondicionante com um comportamento semelhante nas paredes cervical e oclusal.

TOLEDANO et.al. ${ }^{62}$, em 2003 consideram que a sorção de água pelos materiais à base de resina composta é um processo controlado de difusão e absorção de água na matriz da resina. A absorção de água pode levar à degradação hidrolítica alterando as propriedades mecânicas devido à quebra das ligações químicas na matriz e deslocamento da carga. A absorção de água foi diferente entre os materiais estudados, Compoglass, Prodigy, Z100, Dyract, Dyract AP, Vitremer, Fujill LC, caracterizando comportamentos diferentes a depender de suas composições. Os materiais à base de HEMA ou radicais hidrofílicos apresentam maior sorção de água como observados nos ionômeros modificados por resina (Vitremer e Fuji LC). O UDMA é mais hidrofílico que o Bisfenol $A$, sendo observado maior absorção no Dyract e Dyract AP (UDMA) comparados às resinas modificadas por poliácidos (Compoglass e CompoglassF). A resina Z100 apresentou maior absorção de água que a resina Prodigy e essa variação é devida às diferentes diluições que a Bis-GMA pode ter em função das diferentes proporções dos diluentes tais como TEDMA, empregados para melhorar a sua manipulação. Dentro do mesmo grupo de sistema de resinas, a absorção de água pode também depender do conteúdo de carga, natureza e agentes de união.

ARIAS; CAMPOS; PIMENTA², em 2004 avaliaram in vitro a eficácia de 3 sistemas adesivos hidrofílicos classificados em 3 passos (Amalgamabond Plus); passo único (Optbond Solo) e um autocondicionamento (Etch\&Primer 3.0) aplicados pela técnica de ataque 
ácido total. Foram preparadas cavidades classe II, em dentes molares humanos extraídos e, restauradas com resina composta Z100. Após a termociclagem, os resultados obtidos demonstraram que o adesivo Optibond Solo foi mais eficiente no controle da microinfiltração. Os sistemas adesivos apresentam diferentes condicionadores ácidos, com baixos valores de $\mathrm{pH}$. A desidratação da dentina pode causar um colapso na rede das fibrilas de colágeno não suportada, inibição do adequado molhamento e penetração da resina para produzir a camada híbrida. O excesso de água pode diluir o primer e reduzir sua efetividade, fenômeno este conhecido como "overwet". Nos sistemas autocondicionantes a presença de água pode influenciar a polimerização. Os sistemas adesivos atuais contém primer hidrofílicos que utilizam como solvente acetona, álcool e/ou água, que transportam primer resinoso para o interior da dentina desmineralizada pelo deslocamento de água na rede de fibrilas de colágeno. A penetração de resina no interior da rede de fibrilas de colágenos e sua ocupação na dentina desmineralizada são responsáveis pela formação da zona de interdifusão ou camada híbrida. A infiltração marginal da restauração de resina composta pode ser influenciada por estresses externos produzidos durante a termociclagem, e estresses internos produzidos pela contração de polimerização e diferenças nas características da expansão térmica dos materiais e do dente. $O$ declínio do módulo de elasticidade é mais pronunciado em sistemas que formam uma camada mais espessa ou inclui uma resina de carga com baixa viscosidade. Assim, sistemas adesivos que contém uma resina com carga podem ter elasticidade suficiente para aliviar o estresse que é gerado pela contração da resina composta usada como material restaurador final. Os adesivos com carga são indicados para aliviar o estresse proporcionado entre o dente e o material restaurador.

BRACKETT et al. ${ }^{10}$, em 2004, compararam in vitro a microilfiltração em cavidades Classe $V$ restauradas com resina composta e 3 sistemas adesivos assim classificados: auto condicionante com $\mathrm{pH}$ forte (Prompt L-Pop); auto condicionamento com pH intermediário (One-Up Bond F) e um adesivo primer e ataque ácido (ScotchBond Multi-purpose). Foram 
preparadas em terceiros molares, 12 cavidades classe $\mathrm{V}$ nas faces vestibular e lingual, medindo $2 \mathrm{~mm}$ de profundidade, $5 \mathrm{~mm}$ de largura e $3 \mathrm{~mm}$ de altura, com bordo cavo-superficial em $90^{\circ}$. Os sistemas adesivos foram aplicados de acordo com os fabricantes e restaurados com resina híbrida $Z$ 250 (3M) em 3 incrementos oblíquos, polimerizadas por 20 segundos por incremento. Em seguida, após o polimento os dentes foram termociclados. Os dentes selados foram imersos em solução azul de metileno 10\%, por 4 horas, lavados, secos e incluídos em resinas epóxica e seccionados em cortes longitudinais que foram visualizados com aumento de 20 vezes em microscópio óptico. Os resultados demonstraram que não foi observada infiltração na interface resina composta/esmalte, ou seja, os sistemas com $\mathrm{pH}$ baixo ou intermediário podem selar adequadamente as margens de esmalte e são menos efetivos nas margens de dentina. Na parede gengival foi observada infiltração em $50 \%$ das secções com adesivos e condicionamento ácido total e em $31 \%$ das secções para os dois sistemas de autocondicionamentos, embora não houvesse diferença significante entre os três sistemas adesivos.

GÖHRING et. al. ${ }^{29}$, em 2004, estudaram a microinfiltração na dentina selada com adesivo pela exposição ao ácido lático e saliva em cavidades MOD. Segundo os autores, a aplicação dos adesivos pode reduzir o risco de desenvolvimento de cáries secundárias e prevenir a infiltração microbiológica e dor pós-operatória. Os agentes penetram na dentina condicionada e os componentes cristalinos encapsulados agem como um envelope protetor na estrutura dentinária. In vitro, as condições experimentais diferem das condições in vivo devido à presença da proteção da película salivar e do efeito tampão. A dupla camada do sistema adesivo utilizado garantiu o selamento mesmo nas condições de $\mathrm{pH}$ ácido.

Segundo OZTURK et al. ${ }^{47}$, em 2004, existem muitas técnicas diferentes para avaliar microinfiltração nas margens das restaurações. O método mais simples e comumente utilizado é a exposição da amostra a uma solução corante e por meio de seccionamento, o grau de infiltração é determinado à luz de um microscópio óptico. Para avaliar a relevância do 
teste de microinfiltração, em relação ao tamanho efetivo da bactéria oral são utilizadas substâncias corantes como o azul de metileno e fucsina que permitem identificar a presença de falhas, que muitas vezes são consideradas, clinicamente, como irrelevantes. É um método simples, de relativamente baixo custo, com confiabilidade comparável aos métodos quantitativos utilizados para avaliar o comportamento de várias técnicas restauradoras.

PIEMJAIM, et.al. ${ }^{52}$, em 2004 consideram que a difusão incompleta dos elementos ácido-base na dentina leva ao aparecimento de falhas, de poros microscópicos entre as fibrilas de colágeno possibilitando a microinfiltração. O aumento no padrão de infiltração é decorrente do colapso na dentina inter e intratubular dificultando a penetração dos monômeros sem a formação da camada híbrida e tags de resina. A microinfiltração se processa na dentina desmineralizada entre a resina e a parede cavitária.

YAZICI; ÇELIK; OZGÜNCELTAY ${ }^{72}$, em 2004 avaliaram in vitro a microinfiltração em cavidades Classe $\mathrm{V}$, restauradas com três diferentes tipos de resinas compostas, a Tetric Flow.(resina composta flow), a Z100 (resina composta híbrida) e a Solitaire 2 (resina composta condensável) e, um ormocer Admira (cerâmica organicamente modificada). Após o condicionamento ácido total, com ácido fosfórico $37 \%$, os sistemas adesivos próprios de cada material restaurador foram aplicados de acordo com as orientações dos fabricantes, seguido pela inserção dos materiais restauradores em um único incremento, polimerização e realização dos acabamentos. Os espécimes foram armazenados em água a $37^{\circ} \mathrm{C}$, por 24 horas, e após o polimento final foram submetidos a termociclagem. O teste de microinfiltração foi realizado com a imersão de todos os dentes em solução fucsina básica $0,5 \%$, por 24 horas. As secções com maior infiltração foram examinadas com o auxílio de um estereomicroscópio com 20 vezes de aumento para determinar a penetração do corante a qual foi registrada em escores de 0-3. Os resultados demonstraram que não houve diferença estatística entre as margens de esmalte e de dentina nos grupos, embora tenha ocorrido um leve acréscimo da microinfiltração em margens de 
dentina, quando avaliado cada material. Nesse estudo, as margens oclusais das restaurações não apresentaram microinfiltração, embora, as margens gengivais em dentina apresentaram e foram discordantes de trabalhos anteriores em que a infiltração em margens de dentina foi significativamente maior que em margens de esmalte. Este fato pode ser atribuído pela à alta e confiável resistência adesiva dos sistemas adesivos utilizados em dentina. As falhas entre as paredes cavitárias e o material restaurador ocorreram quando a capacidade adesiva dos sistemas adesivos foi insuficiente para resistir às forças de contração de polimerização das resinas compostas.

LARSON $^{39}$, em 2005 se refere a microinfiltração citada desde a década de 1912, e descrita como o movimento de fluidos orais na interface dente/ restauração coma presença de bactérias ou substâncias nocivas capazes de afetar ou não a unidade biológica dente/polpa. A microinfiltração e a perda da integridade marginal das restaurações podem levar a sensibilidade dentinária e reinstalação de cáries secundárias. A permeabilidade da dentina é um fator importante para o fenômeno da microinfiltração além do meio bucal, com efeito, sobre a proservação dos materiais e restaurações. O autor considera que é possível minimizar a microinfiltração, mas é impossível eliminá-la.

Com base na revisão de literatura realizada para esse estudo fica evidente a capacidade de liberação e recarga dos materiais restauradores resinosos tendo como meio de imersão água deionizada em sua maioria e, a exposição à substâncias contendo flúor para avaliar a capacidade de recarga inicia-se após a estabilização dos níveis de liberação de flúor. Da mesma forma, os ensaios para avaliar a microinfiltração na interface dente/restauração são realizados em condições laboratoriais que não reproduzem as condições de desafio do meio bucal em constante ciclos de Des e RE. Sendo assim, avaliar o efeito da ciclagem de $\mathrm{pH}$ na liberação/recarga de flúor e na microinfiltração de materiais restauradores resinosos pode vir a complementar os estudos até então realizados in vitro. 


\section{Proposição}




\section{PROPOSIÇÃO}

Avaliar in vitro, a liberação de flúor sem e com recarga e a infiltração marginal de materiais restauradores resinosos expostos a um sistema de ciclagem de $\mathrm{pH}$, partindo das seguintes hipóteses nulas:

a) que a recarga de flúor não altera a taxa de liberação desse íon de materiais restauradores resinosos em ciclagem de $\mathrm{pH}$;

b) que a ciclagem de $\mathrm{pH}$ não interfere no padrão de infiltração marginal de materiais restauradores resinosos 
Material e Métodos 


\section{MATERIAL E MÉTODOS}

\subsection{Análise da liberação de flúor sem e com recarga}

\subsubsection{Amostra:}

Foram confeccionados 60 corpos-de-prova, sendo 12 para cada um dos 5 materiais restauradores. Eles foram distribuídos por grupos: 6 para o grupo sem recarga (V, DY, A, D, TC) e 6 para o grupo com recarga (VR, DYR, AR, DR, TCR) (Tabela 4.1).

TABELA 4.1 - Apresentação dos grupos, materiais restauradores, de acordo com sua classificação, lote e fabricantes.

\begin{tabular}{|c|c|c|c|c|}
\hline Grupos & Material & Classificação & Lote & Fabricante \\
\hline$V ; V R$ & Vitremer $^{\mathrm{TM}}(\mathrm{V})$ & $\begin{array}{l}\text { CIV modificado por resina } \\
\text { fotopolimerizável. }\end{array}$ & 2003014 & 3M Dental \\
\hline$D Y ; D Y R$ & $\begin{array}{c}\text { Dyract AP } \\
\text { (DY) }\end{array}$ & $\begin{array}{c}\text { Compômero restaurador } \\
\text { fotopolimerizável em } \\
\text { cápsulas. }\end{array}$ & 0103000903 & Dentsply \\
\hline$A ; A R$ & Ariston ${ }^{\circledR} \mathrm{AT}(\mathrm{A})$ & $\begin{array}{l}\text { Material restaurador estético } \\
\text { para dentes posteriores }\end{array}$ & D08082 & Vivadent \\
\hline$D ; D R$ & Definite ${ }^{\circledR}(D)$ & $\begin{array}{c}\text { Material restaurador estético } \\
\text { para dentes anteriores }\end{array}$ & 1325 & Degussa \\
\hline$T C ; T C R$ & $\begin{array}{c}\text { Tetric }{ }^{\circledR} \text { Ceram } \\
\text { (TC) }\end{array}$ & $\begin{array}{c}\text { Material restaurador estético } \\
\text { para dentes anteriores e } \\
\text { posteriores }\end{array}$ & D22993 & Vivadent \\
\hline
\end{tabular}


O grupo controle positivo foi constituído por um material com comprovada capacidade de liberar flúor, o cimento de ionômero de vidro modificado por resina, Vitremer (V; VR).

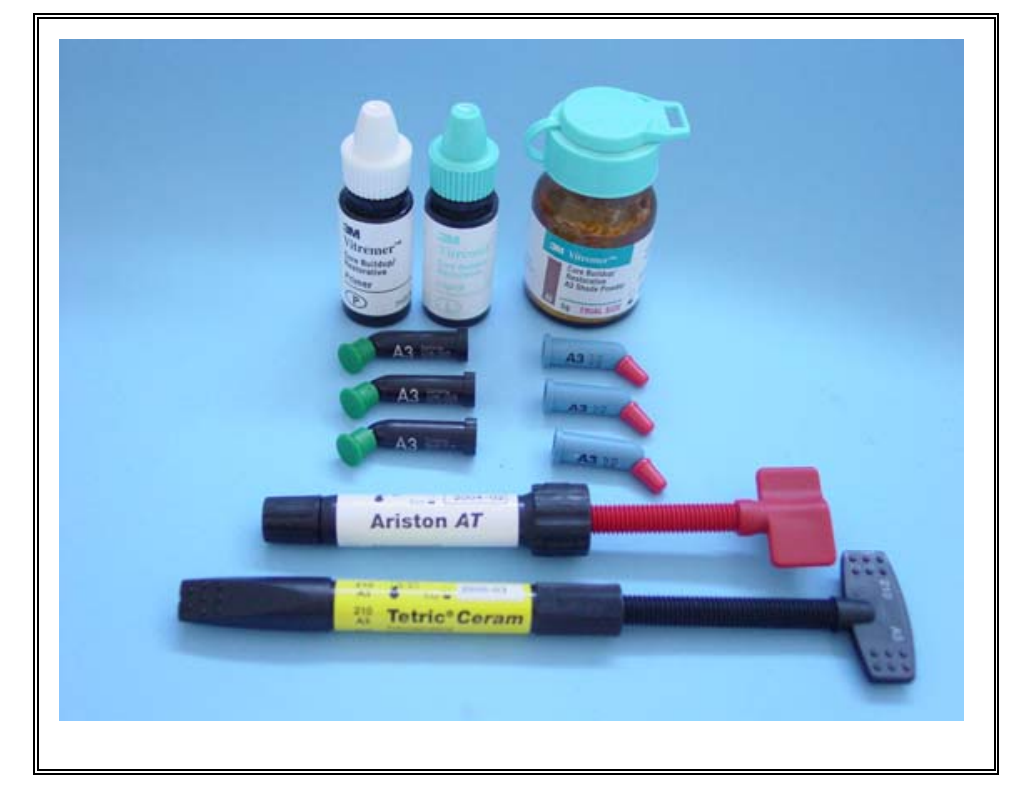

FIGURA 4.1 - Apresentação comercial dos materiais restauradores.

\subsection{2 - Confecção dos corpos-de-prova:}

Os corpos-de-prova foram confeccionados com uma superfície de $2,4178 \mathrm{~cm}^{2}(1,1 \mathrm{~cm}$ de diâmetro por $0,15 \mathrm{~cm}$ de altura), utilizando-se uma matriz de teflon com um orifício central e fenda para a passagem de fio dental, para manutenção dos mesmos em suspensão no meio de imersão, quando eram fixados à tampa do frasco de armazenamento (Fig. 4.2 A). Sobre uma placa de vidro foi colocada uma tira de poliéster e sobre esta a matriz devidamente preparada. Os materiais restauradores foram inseridos no interior da matriz com a utilização de uma seringa Centrix até o preenchimento total da matriz. O material foi fotoativado por 40 segundos 
com aparelho fotoativador Optilux (Model VCL 403 - Demetron Research Corporation-USA), aferido na potência de aproximadamente $500 \mathrm{~mW} / \mathrm{cm}^{2}$ e periodicamente monitorado por um radiômetro (Curing Radiometer, model 100P/N-150503 - Demetron Research Corp. Daubury, CT, USA).

material era sempre inserido com pequeno excesso e, pressionado digitalmente, por um minuto com uma lâmina de vidro colocada sobre outra matriz de poliéster. Os materiais foram selecionados na cor A3 da escala VITA, para que não houvesse interferência da cor nos graus de polimerização, exceto o Ariston ${ }^{\circledR} \mathrm{AT}$, que possui cor única. Concluída a ativação, os corpos-de-prova foram mantidos em repouso por 10 minutos. Os corpos-de-prova foram então removidos das matrizes e fixados individualmente pelos fios já referidos, nas tampas plásticas de polietileno flexível dos respectivos frascos de armazenamento (Fig. 4.2 C).

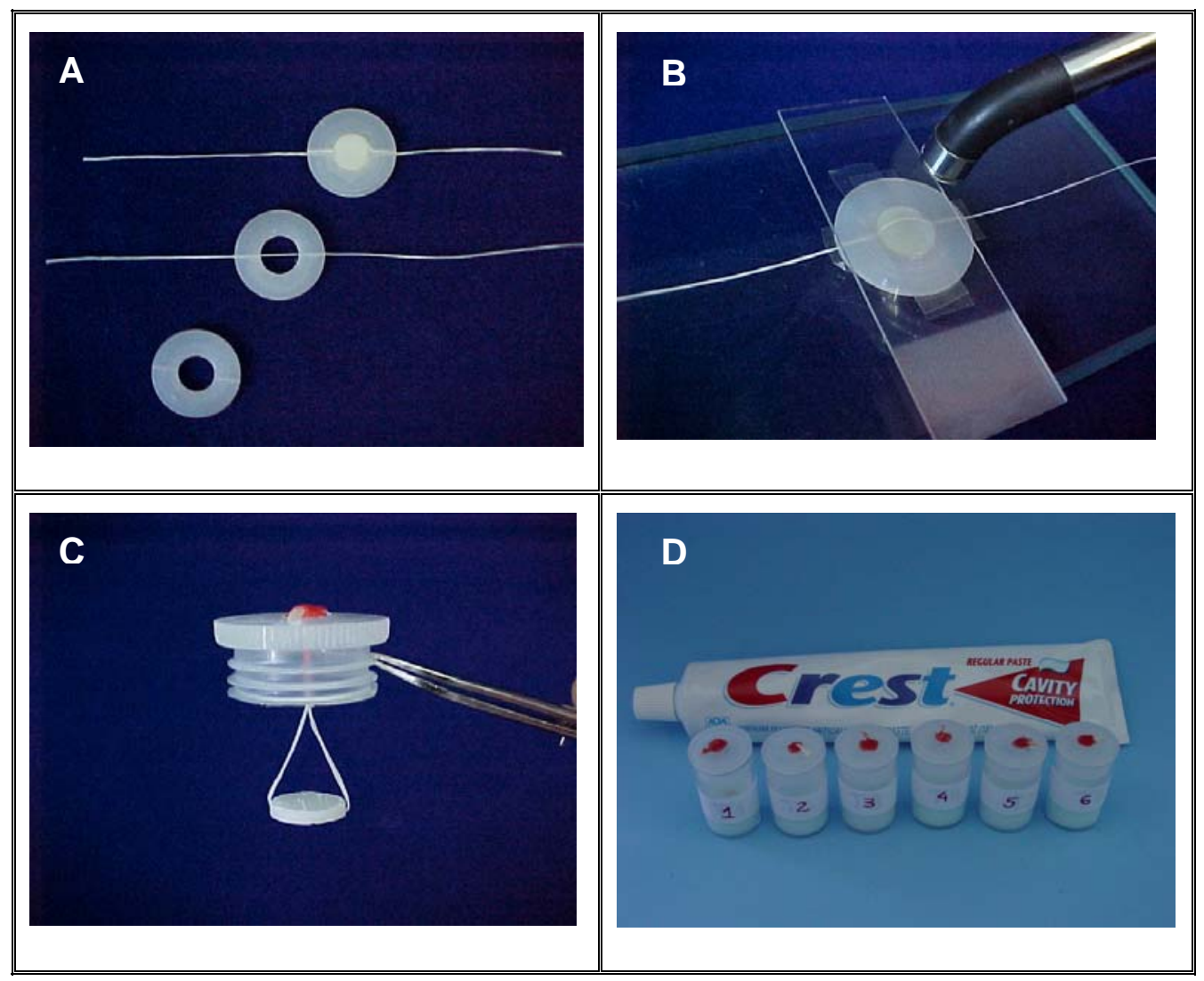

FIGURA 4.2 - Ilustração da preparação dos espécimes nas matrizes de teflon (A); polimerização do material restaurador (B); fixação do corpo-de-prova (C); corpos-de-prova imersos em solução fluida fluoretada preparada com creme dental "Crest" (D). 
Para a análise da liberação de flúor os corpos-de-prova eram submetidos à ciclagem de $\mathrm{pH}$, onde apenas a metade da amostra, ou seja, 6 corpos-de-prova de cada material, receberam recarga com dentrífricio fluoretado (CREST, Procter\&Gable, OH-USA) e foram denominados VR, DYR, AR, DR, TCR (Fig. 4.2 D) e, a outra metade sem recarga foram identificados por V, DY, A, D e TC.

\subsection{3 - Experimento sem recarga:}

Os corpos-de-prova dos grupos V, DY, A, D e TC foram imersos individualmente em recipientes plásticos cilíndricos de poliestireno, que tinham $3,4 \mathrm{~cm}$ de altura $X 2,0 \mathrm{~cm}$ de diâmetro, contendo $4,0 \mathrm{~mL}$ da solução desmineralizante com pH 4.3 (Tabela 4.2), durante 6 horas, mantidos sob agitação constante (mesa agitadora orbital Nova Técnica, modelo NT 145), à temperatura de $24^{\circ} \mathrm{C} \pm 1^{\circ} \mathrm{C}$. Após esse período, os corpos-de-prova foram removidos um a um, secos com papel absorvente, imersos em $4 \mathrm{~mL}$ da solução remineralizante com pH 7.0 (Tabela 4.2), e mantidos por 18 horas sob agitação constante, na mesma temperatura do período anterior, totalizando um ciclo de 24 horas. Esse ciclo era repetido por 14 dias, simulando in vitro, uma situação de alto desafio cariogênico, in vivo. (FEATHERSTONEetal. ${ }^{22}$,1986;CARVALHO; CURY ${ }^{13}, 1999 ;$ GARCEZ $^{26}$,2001).

TABELA 4.2 - Apresentação das soluções para ciclagem de pH.

\begin{tabular}{cll}
\hline \hline \multicolumn{1}{c}{ Solução } & \multicolumn{1}{c}{ Composição } & pH \\
\hline \hline \multirow{2}{*}{ Desmineralizante } & Cálcio $(\mathrm{Ca}) 2,0 \mathrm{mM}$ & 4.3 \\
& $\begin{array}{l}\text { Fosfato }\left(\mathrm{PO}_{4}\right) 2,0 \mathrm{mM} \\
\text { Tampão acetato } 75 \mathrm{mM}\end{array}$ & \\
\hline \multirow{3}{*}{ Remineralizante } & Cálcio $(\mathrm{Ca}) 1,5 \mathrm{mM}$ & 7.0 \\
& Fosfato $\left(\mathrm{PO}_{4}\right) 0,9 \mathrm{mM}$ & \\
& $\begin{array}{l}\text { Cloreto de potássio }(\mathrm{KCl}) 150 \mathrm{mM} \\
\end{array}$ & \\
\hline
\end{tabular}




\subsection{4 - Experimento com recarga:}

Os corpos-de-prova dos grupos VR, DYR, AR, DR e TCR foram também submetidos à ciclagem de $\mathrm{pH}$, com recarga por adição de solução de pasta fluoretada (pasta fluida contendo dentifrício fluoretado "CREST" com uma concentração de flúor $1000 p p m)$. A solução era obtida na proporção de $1 \mathrm{~g}$ de pasta para $3 \mathrm{~mL}$ de água deionizada (VIEIRA, SOUZA, MODESTO, 1999) $)^{67}$.

Os corpos-de-prova foram imersos individualmente em 4,0mL de solução desmineralizante durante 6 horas. O tratamento de recarga foi iniciado após as primeiras 24 horas, período de pico de liberação de flúor, com a imersão de cada corpo-de-prova em 4,0mL da solução fluida do dentifrício, por 5 minutos, sob agitação constante. Em seguida, eram lavados com água deionizada por 30 segundos, secos com papel absorvente e, imersos na solução remineralizante por 17 horas, considerando que o tempo do processo de recarga entre as trocas das soluções de DES e RE. Nessa seqüência os corpos-de-prova foram submetidos a mais uma recarga, totalizando um ciclo de 24 horas.

Nos dois experimentos, sem e com recarga, para cada material, ao final de cada período de imersão na solução de DES ou na solução de $\mathrm{RE}$, os corpos-de-prova foram removidos, secos suavemente com papel absorvente e colocados em novos frascos contendo novas soluções. Diariamente, os frascos com as soluções testes eram identificados, lacrados e conservados em geladeira a $4^{\circ} \mathrm{C}$, para posterior realização da leitura da concentração de flúor.

\subsection{5 - Determinação da concentração de flúor}

A quantidade de flúor liberada foi medida por um eletrodo $\mathrm{F}^{-}$ sensível (Orion, mod. 96-09) acoplado a um aparelho analisador digital de 
íons (Procyon AS-720) previamente calibrados com uma seqüência de soluções padrão nas concentrações de $0,1,0,2,0,4,0,8,1,6,3,2$ e $6,4 \mu \mathrm{gF}^{-} / \mathrm{mL}$, preparadas por diluição seriada de um estoque padrão,

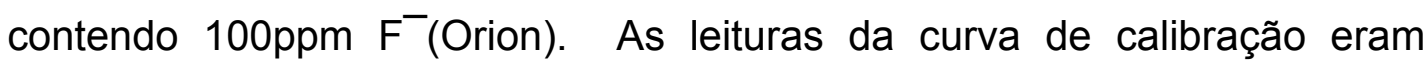
realizadas em triplicata, admitindo-se um percentual de variação de até $10 \%$ para todos os padrões. Em intervalos de $2 \mathrm{em} 2$ horas, leituras da solução padrão de $0,4 \mathrm{ppmF}^{-}$eram feitas para confirmar a curva de calibração.

Para a análise da quantidade do íon flúor $\left(\mathrm{F}^{-}\right)$liberado, utilizou-se $0,5 \mathrm{~mL}$ da amostra ( $0,5 \mathrm{~mL}$ das soluções de $\mathrm{DES}^{-} / \mathrm{RE}$ ) adicionados de $0,5 \mathrm{~mL}$ de TISAB II (tampão acetato $1.0 \mathrm{M}$, pH 5.0 contendo $\mathrm{NaCl} 1.0 \mathrm{M}$ e CDTA $0,4 \%$ ). As leituras das soluções obtidas em $\mathrm{mV}$ eram convertidas em $\mu \mathrm{gF}^{-}$lárea $\left(\mu \mathrm{g} / \mathrm{cm}^{2}\right)$, por meio do programa Excel (Microsoft). As leituras foram realizadas em duplicata. A quantidade de flúor liberada nos ciclos de 24 horas resultou da soma dos valores encontrados em cada uma das soluções desmineralizante e remineralizante.

A repetibilidade média das leituras, baseada nas amostras em duplicata foi de $98,63 \%$.

\section{2 - Análise da microinfiltração}

\subsection{1 - Amostra:}

Foram utilizados 80 terceiros molares extraídos e isentos de cárie, cedidos do estoque de dentes do Departamento de Odontologia da Universidade Federal de Sergipe, tendo seu emprego aprovado pelo Comitê de Ética da Faculdade de Odontologia de Bauru da Universidade de São 
Paulo. Os dentes foram armazenados em solução salina a $0,9 \%$ a qual se adicionava $0,1 \%$ de timol, à temperatura ambiente, limpos com espátula Lecron seguida da aplicação de taça de borracha com pedra-pomes e água, e que estavam armazenados por um tempo máximo de 6 meses.

\subsection{2 - Preparo cavitário}

Cavidades tipo Classe V (Figura 4.3), padronizadas, foram realizadas nas seguintes dimensões: $3,0 \mathrm{~mm}$ de largura, $2,0 \mathrm{~mm}$ de altura e $1,5 \mathrm{~mm}$ de profundidade.

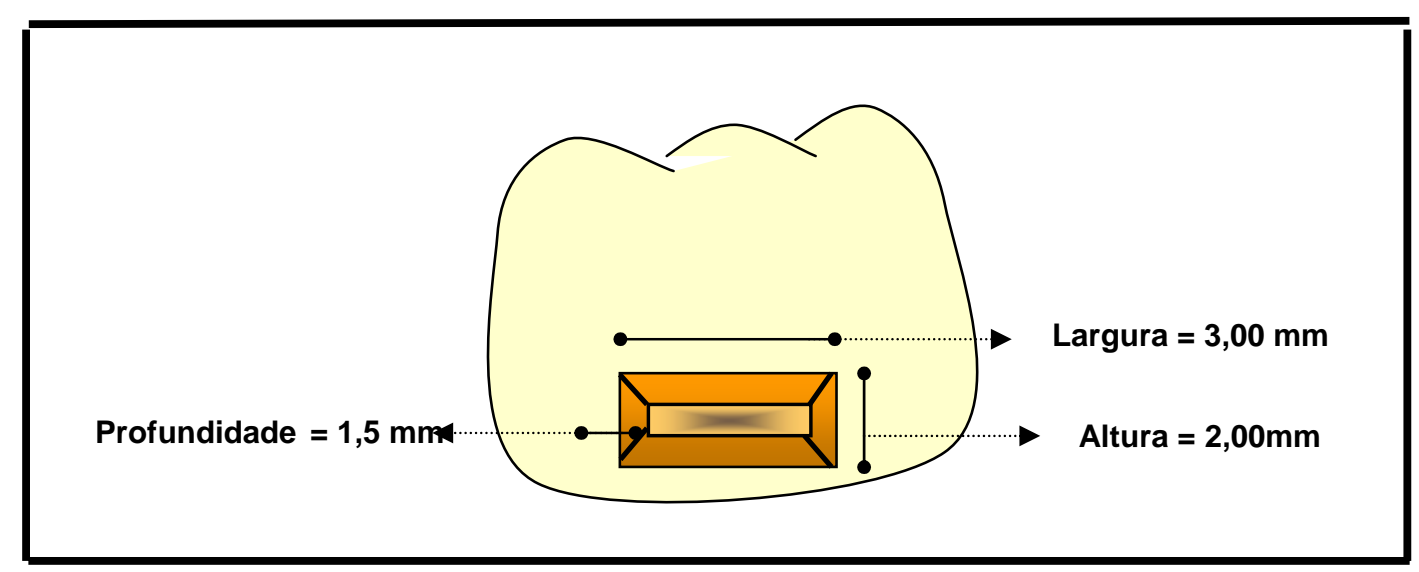

FIGURA 4.3 - Desenho esquemático da cavidade preparada

Os preparos foram executados por um único operador, utilizando uma lupa estereoscópica com $4 \mathrm{X}$ de aumento (BioArt-Indústria \& Comércio), conseguindo-se adequado controle das dimensões por meio de uma sonda periodontal milimetrada e paquímetro.

Previamente à realização dos preparos, as dimensões dos mesmos foram delimitadas com ponta de grafite $0,5 \mathrm{~mm}$ e, então os preparos realizados com aparelhos de alta e baixa rotação, modelo 23D (Kavo do Brasil, Ltda) sob refrigeração com spray ar/água constante e movimentos 
intermitentes com ponta diamantada $n^{\circ} 1013$ (KG Sorensen), e broca carbite $n^{\circ} 1156$ (SSWhite). Para acabamento das paredes foram utilizados ainda instrumentos manuais do tipo recortador de margem gengival $n^{\circ} 27$ (DUFLEX, Artigos dentários). A cada 6 preparos*, as brocas e pontas diamantadas eram substituídas e os dentes, imediatamente restaurados após o preparo cavitário, seguindo as instruções dos fabricantes de cada um dos materiais restauradores (Tabela 4.3).

\subsection{3 - Procedimentos Restauradores}

A figura e a tabela a seguir esquematizam os materiais e a seqüência da técnica restauradora.

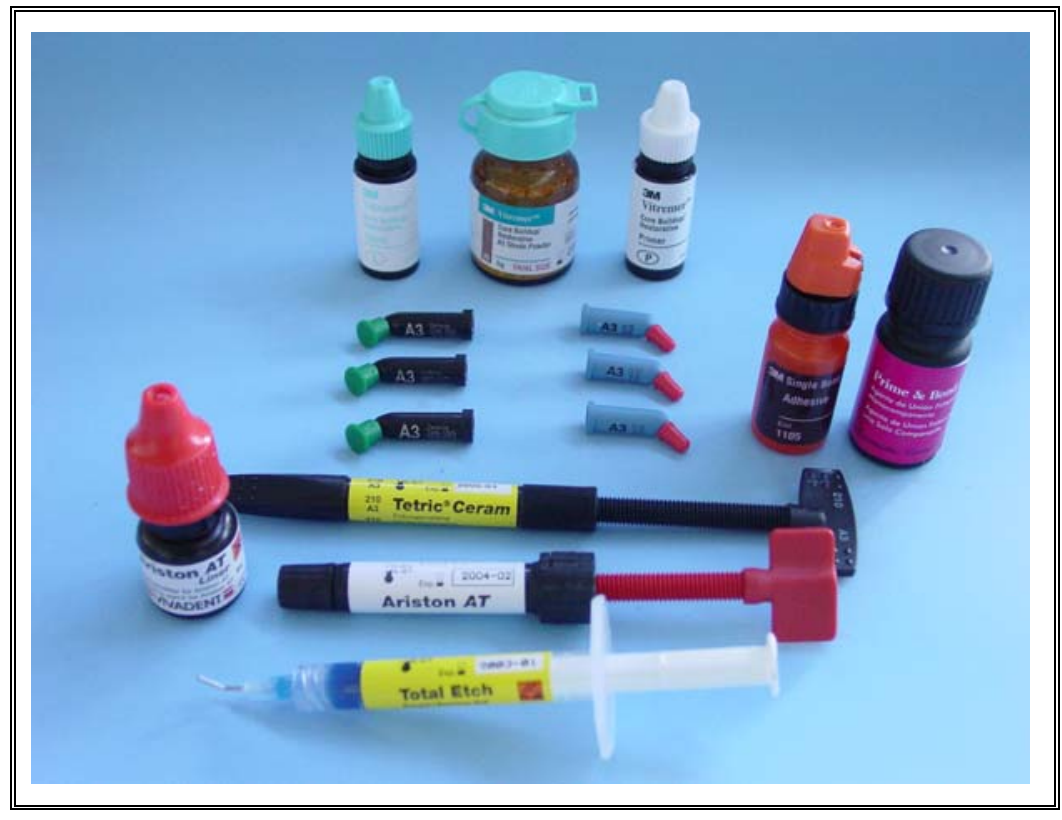

FIGURA 4.4 - Apresentação comercial dos materiais e os sistemas adesivos utilizados na técnica restauradora. 
TABELA 4.3 - Seqüência restauradora para os diferentes materiais restauradores, submetidos ao teste de infiltração marginal em água deionizada $(A)$ e em ciclagem de $\mathrm{pH}(\mathrm{C})$.

\begin{tabular}{|c|c|c|c|c|c|}
\hline GRUPO & $\begin{array}{l}\text { Tratamento } \\
\text { de esmalte }\end{array}$ & $\begin{array}{l}\text { Tratamento } \\
\text { de dentina }\end{array}$ & $\begin{array}{l}\text { Sistema } \\
\text { adesivo }\end{array}$ & Material & $\begin{array}{l}\text { Forma de } \\
\text { inserção }\end{array}$ \\
\hline$V A, V C$ & & Primer (kit) & & Vitremer $^{\mathrm{TM}}$ & $\begin{array}{c}02 \text { incrementos } \\
\text { horizontais }\end{array}$ \\
\hline$D Y A, D Y C$ & $\begin{array}{c}\text { Ácido fosfórico } \\
37 \% \text { (gel)/15s }\end{array}$ & & $\begin{array}{c}\text { Primer \& Bond } \\
2.1\end{array}$ & Dyract Ap & $\begin{array}{l}03 \text { incrementos } \\
\text { oblíquos }\end{array}$ \\
\hline$A A, A C$ & $\begin{array}{l}\text { Ácido fosfórico } \\
37 \% \text { (gel)/15s }\end{array}$ & $\begin{array}{l}\text { Ácido fosfórico } \\
37 \% \text { (gel) / 15s }\end{array}$ & AT liner & Ariston ${ }^{\circledR} \mathrm{AT}$ & $\begin{array}{l}02 \text { Incrementos } \\
\text { horizontais }\end{array}$ \\
\hline$D A, D C$ & $\begin{array}{c}\text { Ácido fosfórico } \\
37 \% \text { (gel)/15s }\end{array}$ & $\begin{array}{l}\text { Ácido fosfórico } \\
37 \% \text { (gel) / 15s }\end{array}$ & $\begin{array}{c}\text { Primer \& Bond } \\
2.1\end{array}$ & Definite $^{\circledR}$ & $\begin{array}{l}03 \text { incrementos } \\
\text { oblíquos }\end{array}$ \\
\hline TCA, TCC & $\begin{array}{c}\text { Ácido fosfórico } \\
37 \% \text { (gel)/15s }\end{array}$ & $\begin{array}{l}\text { Ácido fosfórico } \\
37 \% \text { (gel) / 15s }\end{array}$ & Single Bond & Tetric $^{\circledR}$ Ceram & $\begin{array}{c}03 \text { incrementos } \\
\text { oblíquos }\end{array}$ \\
\hline
\end{tabular}

As cavidades do grupo do material Vitremer $^{\mathrm{TM}}$ receberam inicialmente o primer específico, de acordo com as orientações do fabricante e, as demais cavidades dentárias dos outros grupos de materiais receberam tratamento ácido esmalte-dentina, sendo em seguida lavadas com jato de ar/água por 15 segundos e, secas com papel absorvente. Os sistemas adesivos eram aplicados na região condicionada com pincéis finos, descartáveis, sempre de acordo com as instruções de seus fabricantes. Os materiais Vitremer ${ }^{\mathrm{TM}}$, Dyract AP e Definite ${ }^{\circledR}$ foram inseridos com a utilização de uma seringa tipo Centrix, além de espátulas antiaderentes para inserção de resinas compostas (Hu-Fredy). Entretanto, para os materiais Ariston ${ }^{\circledR} A T$ e Tetric ${ }^{\circledR}$ Ceram apenas espátulas foram utilizadas. A forma de inserção de incremento único, ou vários incrementos oblíquos de aproximadamente $1 \mathrm{~mm}$ foi realizada de acordo com as instruções de cada fabricante. A fotoativação foi realizada com o aparelho fotoativador Degussa Soft-Start (Degussa-Hulls, AG-Alemanha).

Após a fotoativação das restaurações, os dentes foram armazenados em água deionizada à $37^{\circ} \mathrm{C}$ por 5 dias, quando eram realizados o acabamento e polimento com lâmina de bisturi $n^{\circ} 12$ e discos 
de lixa Soflex (3M) de granulação média e fina, assim como borrachas abrasivas (KG Sorensen ref. 8069CA) e discos de feltro com pasta diamantada (Poligloss TDV Bucal Ltda. BR) em baixa velocidade. Os dentes foram armazenados em água deionizada em estufa à $37^{\circ} \mathrm{C}$ por 48 horas, até a execução do teste de microinfiltração.

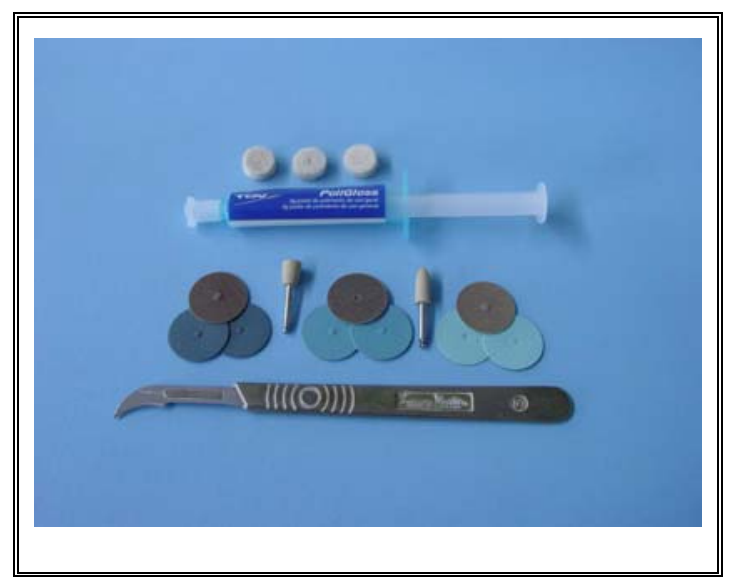

FIGURA 4.5 - Materiais e instrumentais utilizados na etapa de acabamento e polimento das restaurações.

\subsection{4 - Teste de Microinfiltação.}

A amostra foi dividida em dois grupos para cada material, submetidos a dois regimes de armazenamento: água deionizada (VA, DYA, AA, DA, TCA) e ciclagem de pH (VC, DYC, AC, DC, TCA).

\subsubsection{1 - Experimento com água deionizada:}

Os ápices das raízes dos dentes dos grupos VA, DYA, AA, DA, TCA foram seccionados na politriz (DP-9a Panambra Industrial e Técnica 
S/A, BR) e os orifícios dos condutos radiculares preparados com ponta diamantada n¹013 (KG Sorensen). Em seguida, esses orifícios foram vedados com Vitremer ${ }^{\mathrm{TM}}(3 \mathrm{M})$, com a utilização da seringa tipo Centrix. Os dentes de todos os grupos, raiz e coroa, foram recobertos com duas camadas de esmalte cosmético para unha (Colorama Maybeline-secagem rápida, $\mathrm{BR}$ ) obedecendo à distância de $1 \mathrm{~mm}$ das margens de cada restauração para promover um adequado selamento da sua superfície externa.

Os grupos VA, DYA, AA, DA, TCA, foram armazenados em água deionizada na estufa a $37^{\circ} \mathrm{C}$ e umidade relativa de $100 \%$ por 14 dias, até a avaliação da infiltração. Esses grupos foram utilizados como controle, para a infiltração, por não terem sido submetidos ao desafio de ciclagem.

\subsubsection{2 - Experimento com Ciclagem de $\mathrm{pH}$}

Nos grupos VC, DYC, AC, DC, TCC, os ápices foram vedados com a utilização de amálgama (Permite C-SDI) e cola Super Bonder (Henkel Loctite Adesivos Ltda., BR). Os dentes de todos os grupos, raiz e coroa, foram isolados com duas camadas de esmalte cosmético anteriormente citado, obedecendo à mesma distancia de $1 \mathrm{~mm}$ das margens da restauração. Foi utilizado o modelo dinâmico de desmineralização e remineralização proposto por Featherstone et al. ${ }^{22}$ de maneira semelhante ao aplicado para o experimento de liberação de flúor. Todos os dentes de cada grupo foram imersos em $100 \mathrm{~mL}$ de solução desmineralizante a $37^{\circ} \mathrm{C}$, por 6 horas. Após esse período os dentes foram lavados em água deionizada e secos com papel absorvente e colocados em $100 \mathrm{~mL}$ de solução remineralizante por 18 horas a $37^{\circ} \mathrm{C}$, a fim de completarem o ciclo de 24 horas. Esse processo foi repetido durante 14 dias. Ao término da ciclagem os dentes ficaram armazenados em água deionizada a $37^{\circ} \mathrm{C}$, por 24 horas. 


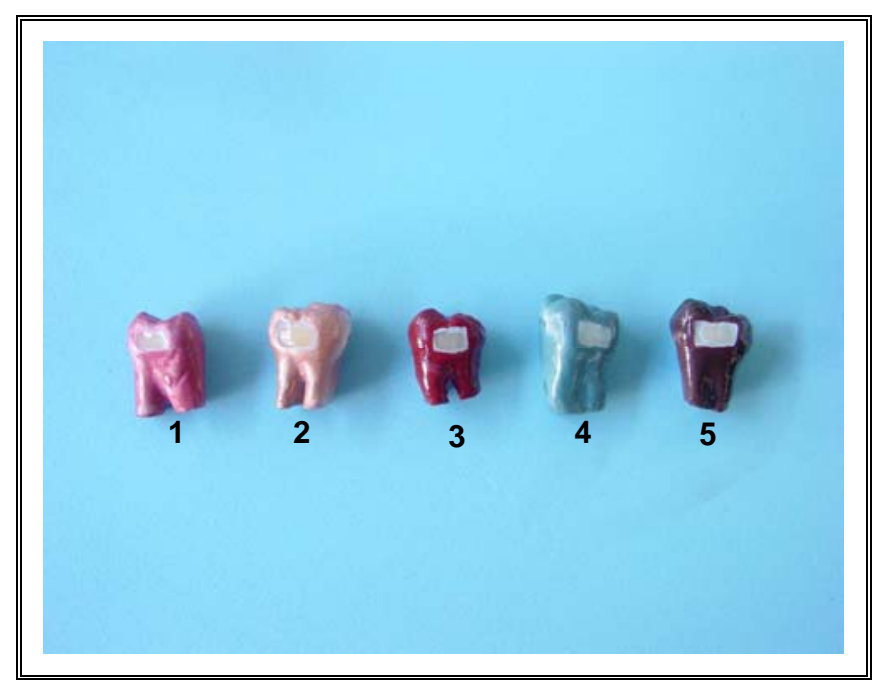

FIGURA 4.6 - Amostra dos dentes dos grupos restaurados

(1) Definite ${ }^{\circledR}$; (2) Dyract AP; (3) Vitremer ${ }^{\mathrm{TM}}$;

(4) Ariston ${ }^{\circledR} \mathrm{AT}$; (5) Tetric ${ }^{\circledR}$ Ceram.

\subsubsection{3 - Avaliação da microinfiltração}

Para a avaliação da microinfiltração os dentes de todos os grupos foram imersos em solução de fucsina básica a $0,5 \%$, à temperatura ambiente por 24 horas e em seguida, lavados em água corrente pelo, mesmo período de tempo.

Todos os dentes, depois de secos, foram incluídos em moldes de resina cristal (Redelease-SP, BR) e posteriormente seccionados no sentido longitudinal com disco diamantado especial para cortes finos (12210 Extec Corporation-USA) montados em uma máquina para corte (Isomet) para obtenção de 3 cortes de aproximadamente $0,6 \mathrm{~mm}$ de espessura.

Os cortes dos espécimes receberam identificação de acordo com o grupo experimental correspondente e, com auxílio de uma lupa esteroscópica (mod. Citoval2 Carl Zeiss, Jena-Germany), com aumento de $60 \mathrm{X}$, foram visualizados e selecionado o corte mais infiltrado de cada grupo de dentes. 
Os cortes selecionados foram levados ao scanner (Genius) estando sobre a sua superfície, posicionada lateralmente, uma régua milimetrada que foi utilizada como referência de unidade de medida, em uma equivalência de $5 \mathrm{~mm}$ igual a 114 pixels ${ }^{*}$.

Desta forma, as imagens coloridas juntamente com a régua milimetrada foram registradas, gravadas e observadas em um micro computador.

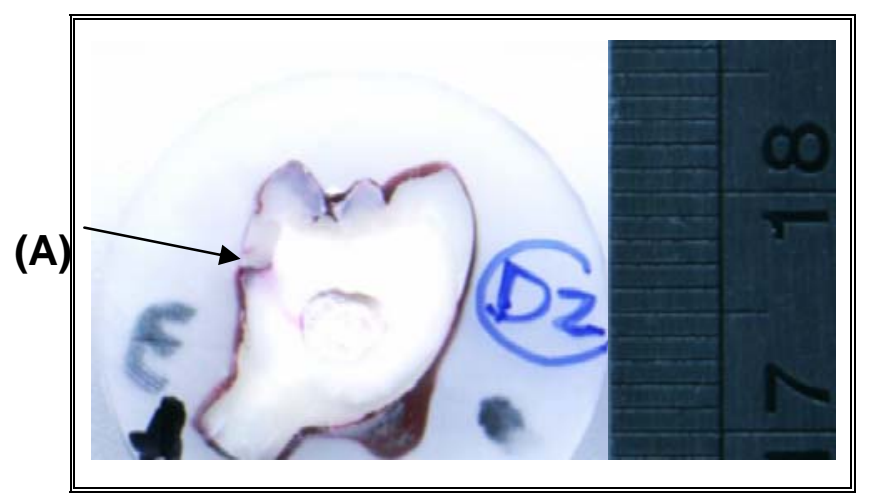

FIGURA 4.7 - Visualização da área de infiltração $(A)$ escaneada pelo Software Image Tools.

O grau de infiltração foi avaliado por meio de um softweare Image Tool (UTHSCSA, San Antonio-TX, USA) possibilitando medir por análise quantitativa a infiltração, em milímetros na interface dente/restauração (Figura-4.7). As medidas de cada corte foram realizadas em quatro repetições. As três primeiras leituras foram realizadas com o objetivo de calibrar um único avaliador. Os valores obtidos na $4^{\mathrm{a}}$ leitura foram tabelados e submetidos ao tratamento estatístico. 


\section{3 - Análise estatística}

Os valores obtidos foram tabelados, as médias e os desviospadrão calculados e submetidos à análise de variância (ANOVA) a dois critérios. Em seguida, foi aplicado o teste de Tukey para avaliar os resultados das concentrações de flúor liberadas em cada uma das soluções de ciclagem, no total das 24 horas em ambos os grupos experimentais sem e com recarga, como também os valores obtidos na análise de microinfiltração, em água deionizada e em $\mathrm{CpH}$, com teste de significância para $p<0,05$. 
Resultados 


\section{$5 \quad$ RESULTADOS}

Os resultados obtidos pelos experimentos serão apresentados em dois tópicos:

- análise da liberação de flúor sem e com recarga.

- análise da microinfiltração.

\subsection{Análise da liberação de flúor}

Os valores das médias e desvios-padrão das taxas de liberação de flúor dos materiais restauradores sem e com recarga, submetidos a $\mathrm{CpH}$, (solução desmineralizante e solução remineralizante), durante 24 horas, no período de 1 a 15 dias, estão representados nas tabelas 5.1 e 5.2.

Os maiores valores de liberação de íons flúor foram registrados pelo material Vitremer, tanto em $\mathrm{CpH}$ sem recarga $\left(418,05 \mu \mathrm{gF}^{-} / \mathrm{cm}^{2}\right)$ como em $\mathrm{CpH}$ com recarga $\left(811,40 \mu \mathrm{gF}^{-} / \mathrm{cm}^{2}\right)$. 
TABELA 5.1 - Médias das quantidades de liberação de $\mathrm{F}^{-} \mathrm{em} \mu \mathrm{g} / \mathrm{cm}^{2}$ e desviospadrão dos materiais restauradores em $\mathrm{CpH}$ sem recarga, durante 15 dias, e os totais acumulados nas $1^{\mathrm{a}}$ e $2^{\mathrm{a}}$ semanas.

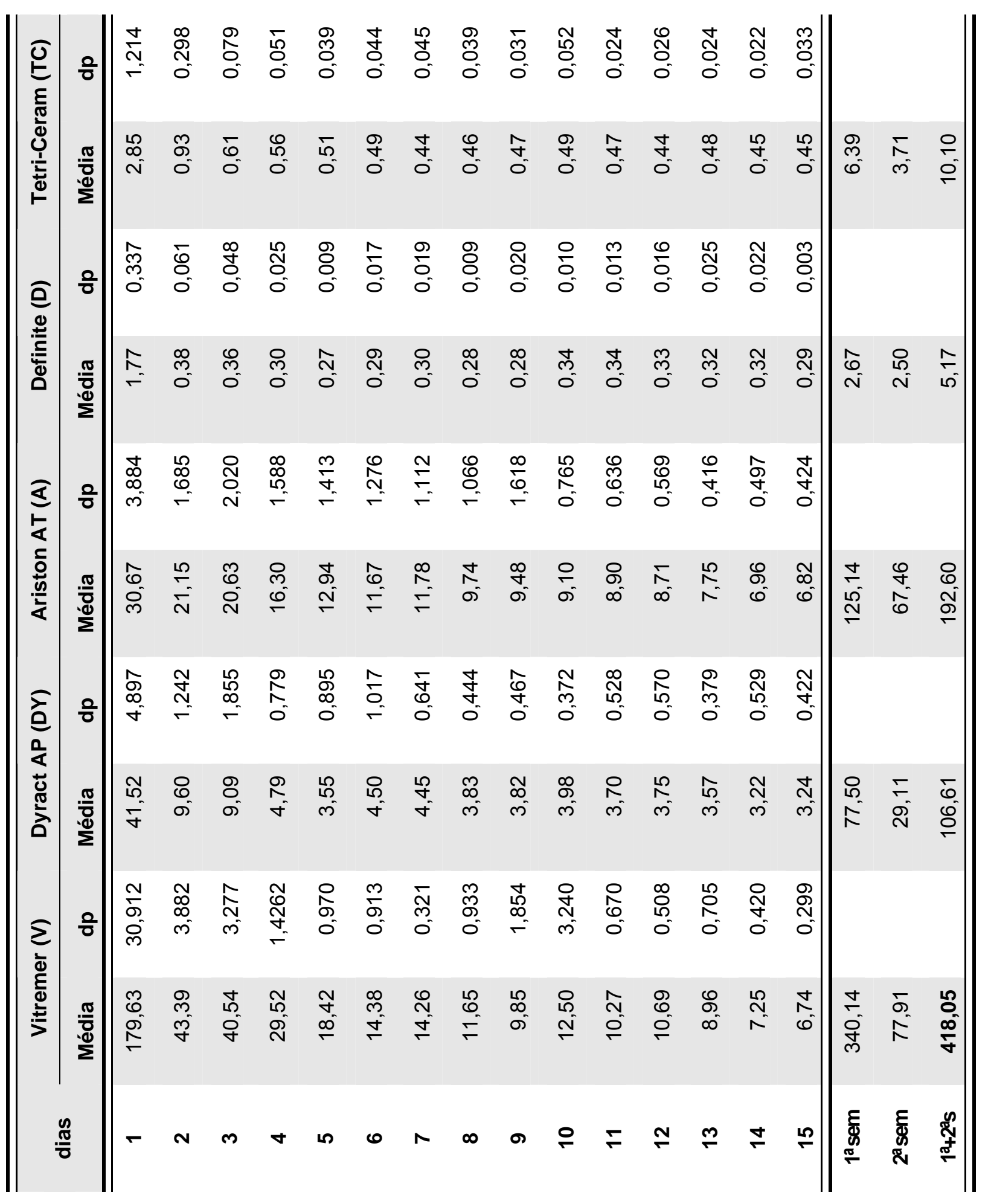


As médias de liberação de flúor dos materiais, em cada meio, sem recarga foram analisadas pelo teste de Tukey para comparações múltiplas.

As figuras 5.1, 5.2 e 5.3 representam, respectivamente, o padrão de liberação de $\mathrm{F}^{-}$sem recarga, em $\mathrm{CpH}$, em solução $\mathrm{DES}^{-}$, em solução RE e o total de liberação em 24 horas.

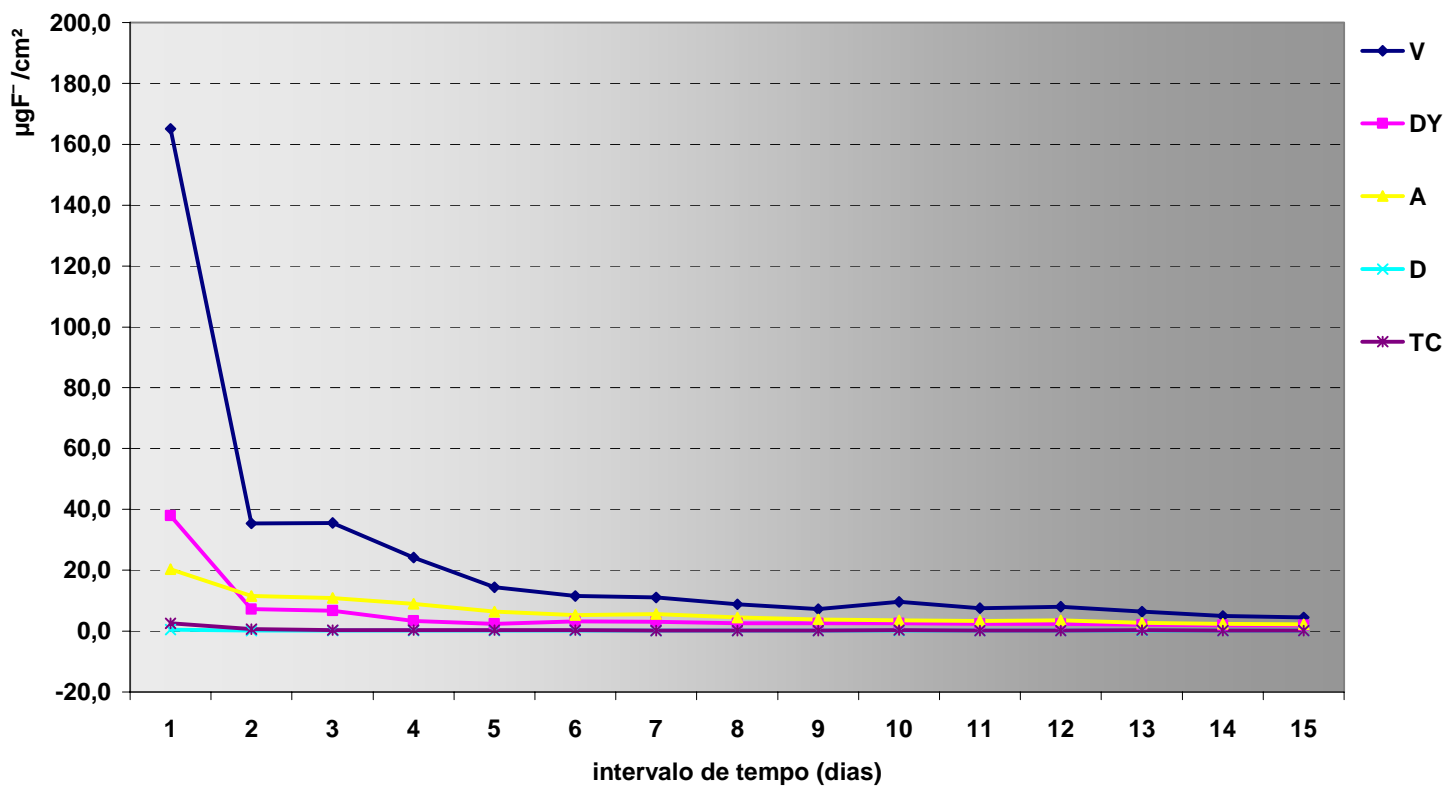

Figura 5.1 - Gráfico da liberação diária de $\mathrm{F}^{-}$, em $\mathrm{CpH}$ - solução DES $^{-}$(6h), sem recarga, durante 15 dias 


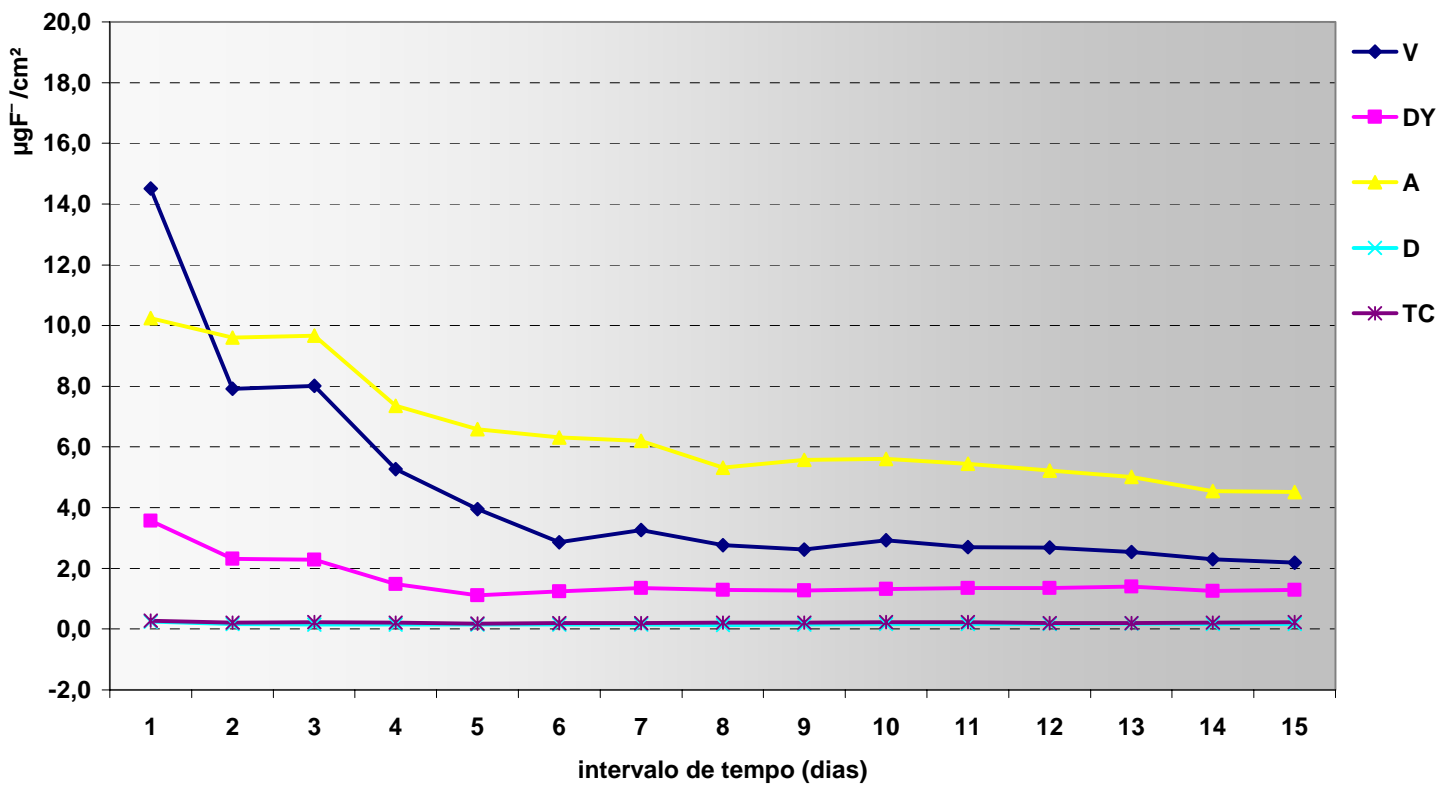

Figura 5.2 - Gráfico da liberação diária de $\mathrm{F}^{-}$em $\mathrm{CpH}$ - solução RE (17h), sem recarga, durante 15 dias

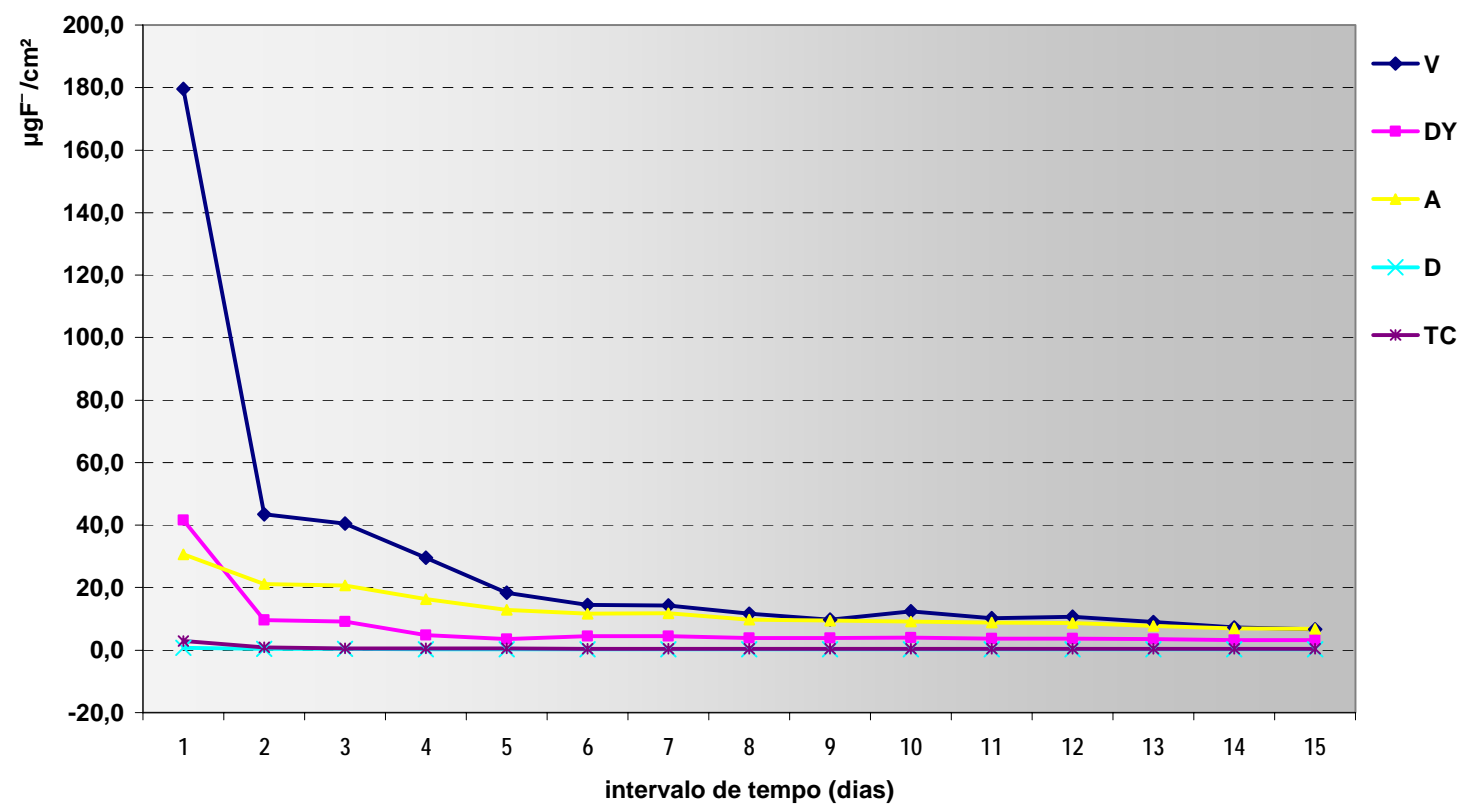

Figura 5.3 - Gráfico da liberação diária de $\mathrm{F}^{-}$em $\mathrm{CpH}$ - solução $\mathrm{DES}^{-} / \mathrm{RE}(24 \mathrm{~h})$, sem recarga, durante 15 dias 
TABELA 5.2 - Médias das quantidades de liberação de $F^{-}$em $\mu \mathrm{g} / \mathrm{cm}^{2}$ e desvios-padrão dos materiais restauradores em $\mathrm{CpH}$ com recarga, durante 15 dias, e os totais acumulados nas $1^{\mathrm{a}}$ e $2^{\mathrm{a}}$ semanas.

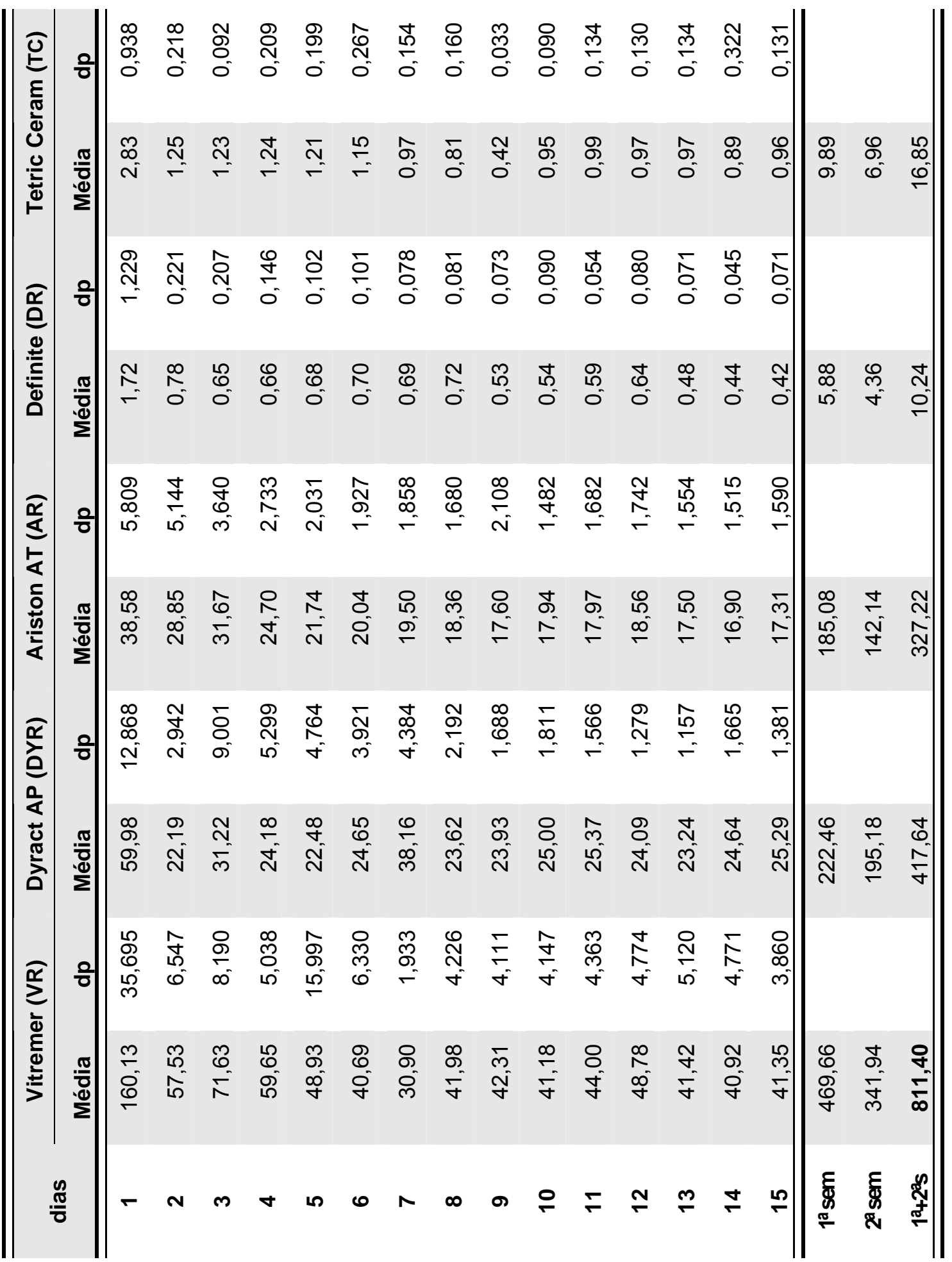


As figuras 5.4, 5.5.e 5.6 registram o padrão de liberação de flúor dos materiais restauradores expostos ao processo de recarga. Observa-se que houve uma maior liberação de flúor na solução de DES ${ }^{-}$.

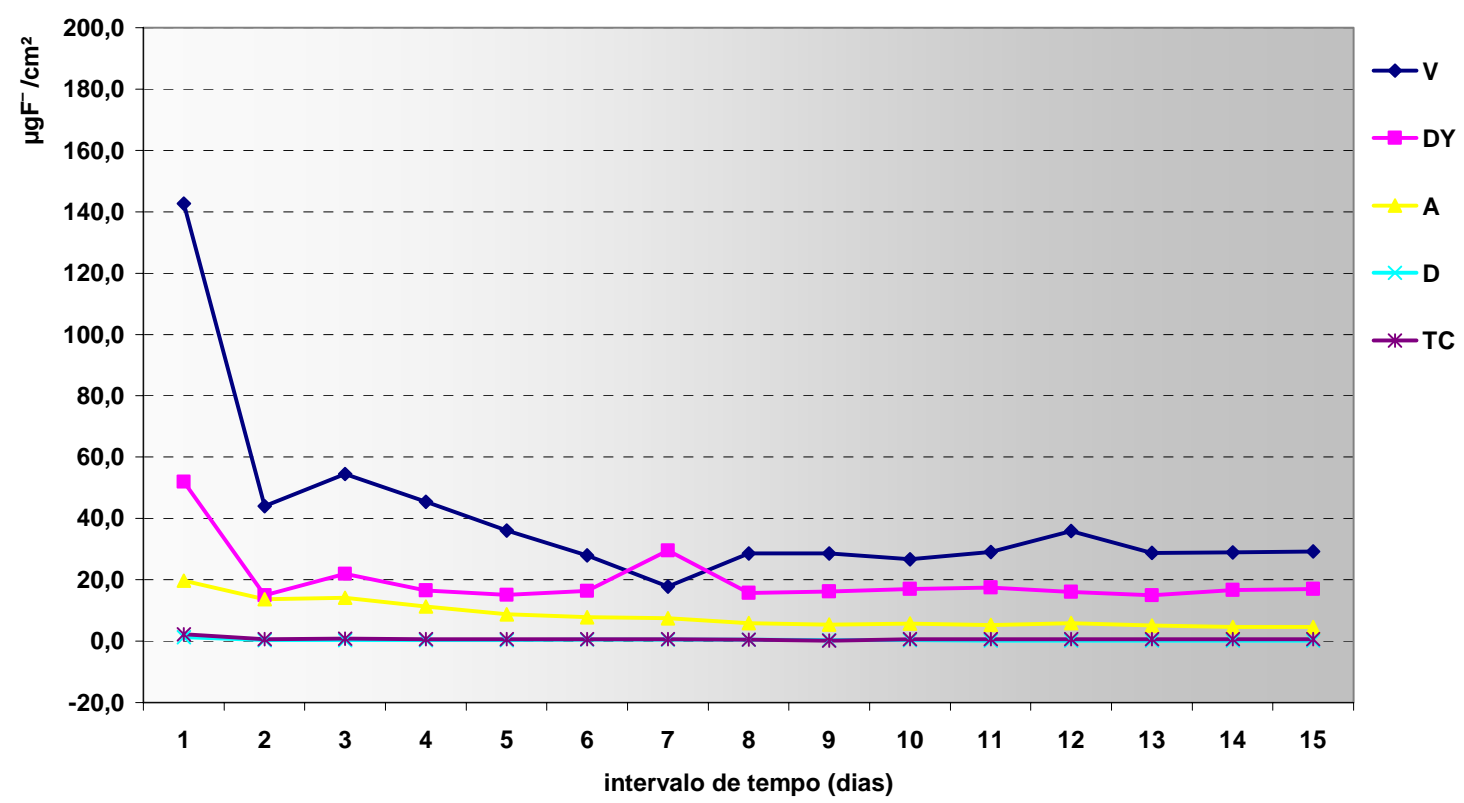

Figura 5.4 - Gráfico da liberação de $\mathrm{F}^{-}$diária em $\mathrm{CpH}$ - solução $\mathrm{DES}^{-}$(6h), com recarga, durante 15 dias

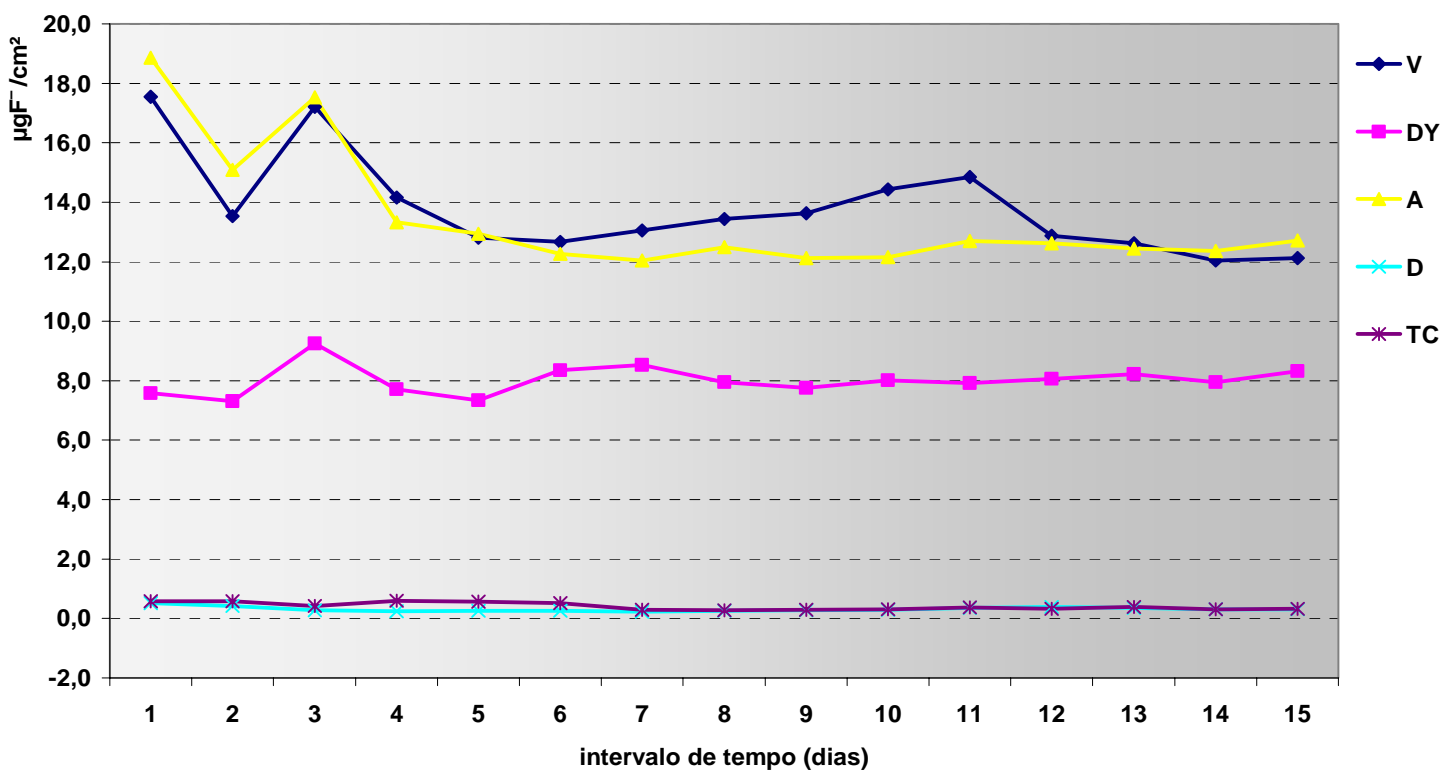

Figura 5.5 - Gráfico da liberação diária de $\mathrm{F}^{-}$em $\mathrm{CpH}$ - solução RE (17h), com recarga, durante 15 dias 


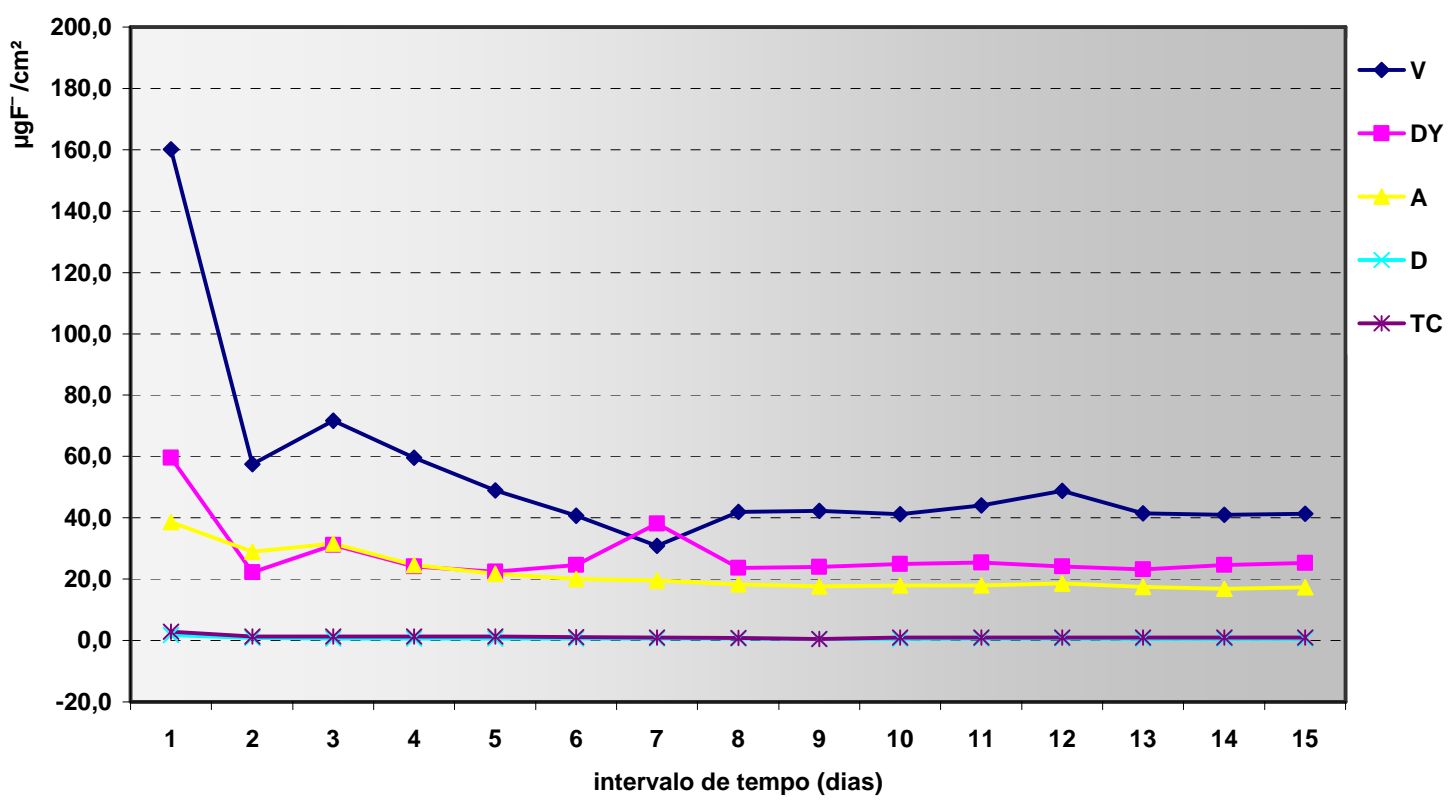

Figura 5.6 - Gráfico da liberação diária de $\mathrm{F}^{-}$em $\mathrm{CpH}$ - solução $\mathrm{DES}{ }^{-} / \mathrm{RE}$ (24h), com recarga, durante 15 dias

O padrão de liberação de flúor observado nos gráficos apresentados foi o mesmo para os materiais $V$, DY e $A$. O maior pico de liberação está representado no $1^{\circ} \mathrm{dia}$, declinando em torno do $7^{\circ}$ e $8^{\circ}$ dias, com tendência a liberação lenta de íons e estabilização até o final do experimento. Os materiais D e TC apresentaram os mais baixos valores de liberação em todos os períodos do experimento, mas seguindo o mesmo padrão dos demais.

As tabelas 5.3, 5.4 e 5.5 referem-se ao teste de análise de variância (ANOVA) a dois critérios, material e meio. De acordo com o resultado dessa análise, conclui-se que houve significância dos fatores e interação entre os critérios, portanto são estatisticamente significantes, quando $p<0,05\left(^{*}\right)$. 
Tabela 5.3 - Análise de variância à 2 critérios, meio e material, durante 24 horas, no período de 15 dias.

\begin{tabular}{l|r|r|r|r|r|c}
\hline \hline Efeito & $\begin{array}{r}\text { gl } \\
\text { efeito }\end{array}$ & $\begin{array}{c}\text { QM } \\
\text { efeito }\end{array}$ & $\begin{array}{r}\text { gl } \\
\text { erro }\end{array}$ & $\begin{array}{r}\text { QM } \\
\text { erro }\end{array}$ & F & p \\
\hline \hline Meio & $1^{*}$ & $1,595744^{*}$ & $50^{*}$ &, $002081^{*}$ & $776.758^{*}$ & $0,000000^{*}$ \\
\hline Material & $4^{*}$ & $8,641054^{*}$ & $50^{*}$ &, $002081^{*}$ & $4152,042^{*}$ & $0,000000^{*}$ \\
\hline Meio/Material & $4^{*}$ &, $069899^{*}$ & $50^{*}$ &, $002081^{*}$ & $33,587^{*}$ &, $000000^{*}$ \\
\hline \hline
\end{tabular}

* estatisticamente significante $(p<0,05)$

Tabela 5.4 - Análise de variância à 2 critérios, meio e material, no total de 6 horas em solução DES ${ }^{-}$, durante 15 dias.

\begin{tabular}{l|r|r|r|r|r|r}
\hline \hline Efeito & $\begin{array}{r}\text { gl } \\
\text { efeito }\end{array}$ & $\begin{array}{c}\text { QM } \\
\text { efeito }\end{array}$ & $\begin{array}{r}\text { gl } \\
\text { erro }\end{array}$ & $\begin{array}{r}\text { QM } \\
\text { erro }\end{array}$ & F & p \\
\hline Meio & $1^{*}$ & $1,183672^{*}$ & $50^{*}$ &, $003095^{*}$ & $382,486^{*}$ &, $000000^{*}$ \\
\hline Material & $4^{*}$ & $9,421281^{*}$ & $50^{*}$ &, $003095^{*}$ & $3044,344^{*}$ & $0,000000^{*}$ \\
\hline Meio/Material & $4^{*}$ &, $082151^{*}$ & $50^{*}$ &, $003095^{*}$ & $26,546^{*}$ &, $000000^{*}$ \\
\hline \hline
\end{tabular}

* estatisticamente significante $(p<0,05)$

Tabela 5.5 - Análise de variância à 2 critérios, meio e material, no total de 17 horas em solução RE, durante 15 dias.

\begin{tabular}{l|c|c|c|c|c|c}
\hline Efeito & $\begin{array}{c}\text { gl } \\
\text { efeito }\end{array}$ & $\begin{array}{c}\text { QM } \\
\text { efeito }\end{array}$ & $\begin{array}{c}\text { gl } \\
\text { erro }\end{array}$ & $\begin{array}{c}\text { QM } \\
\text { erro }\end{array}$ & F & P \\
\hline Meio & $1^{*}$ & $2,595340^{*}$ & $50^{*}$ &, $001640^{*}$ & $1582,353^{*}$ & $0,000000^{*}$ \\
\hline Material & $4^{*}$ & $7,251280^{*}$ & $50^{*}$ &, $001640^{*}$ & $4421,031^{*}$ & $0,000000^{*}$ \\
\hline Meio/Material & $4^{*}$ &, $099580^{*}$ & $50^{*}$ &, $001640^{*}$ & $60,713^{*}$ &, $000000^{*}$ \\
\hline \hline
\end{tabular}

* estatisticamente significante $(p<0,05)$ 
$\mathrm{Na}$ comparação dos valores médios de liberação de flúor sem e com recarga (Tabela 5.6) observa-se que todos os materiais apresentaram maiores valores de liberação quando submetidos à recarga.

O teste de Tukey mostrou que no $7^{\circ}$ dia, período que ainda observa-se declínio da liberação de flúor, para os materiais $A(11,78$ $\left.\mu \mathrm{gF}^{-} / \mathrm{cm}^{2}\right)$ e $\mathrm{V}\left(14,24 \mu \mathrm{gF}-/ \mathrm{cm}^{2}\right)$ não houve diferenças estatisticamente significantes $(p<0,05)$, do experimento sem recarga, o que não ocorreu com demais materiais, DY, D, TC. 
Tabela 5.6 - Médias das quantidades de liberação de $\mathrm{F}^{-}\left(\mu \mathrm{g} / \mathrm{cm}^{2}\right)$ dos materiais restauradores em $\mathrm{CpH}$ sem e com recarga, durante 15 dias, em $24 \mathrm{~h}$.

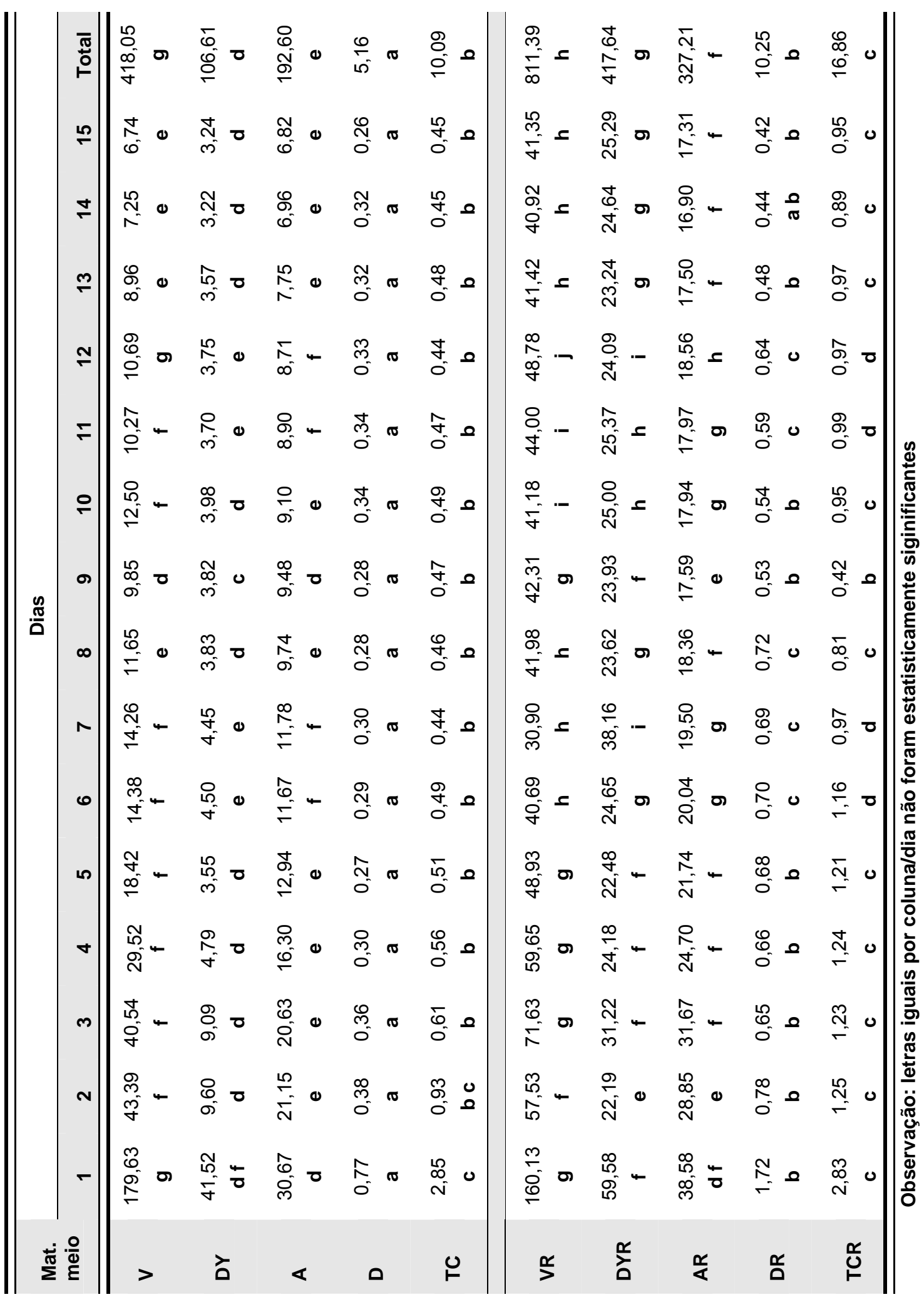


As figuras 5.7, 5.8 representam a liberação de flúor total por material, sem recarga $(\mathrm{CpH})$ e com recarga $(\mathrm{CPH}+\mathrm{F})$, no período de 15 dias, respectivamente em solução de $\operatorname{DES}^{-}$(6h) e em solução de RE (17h).

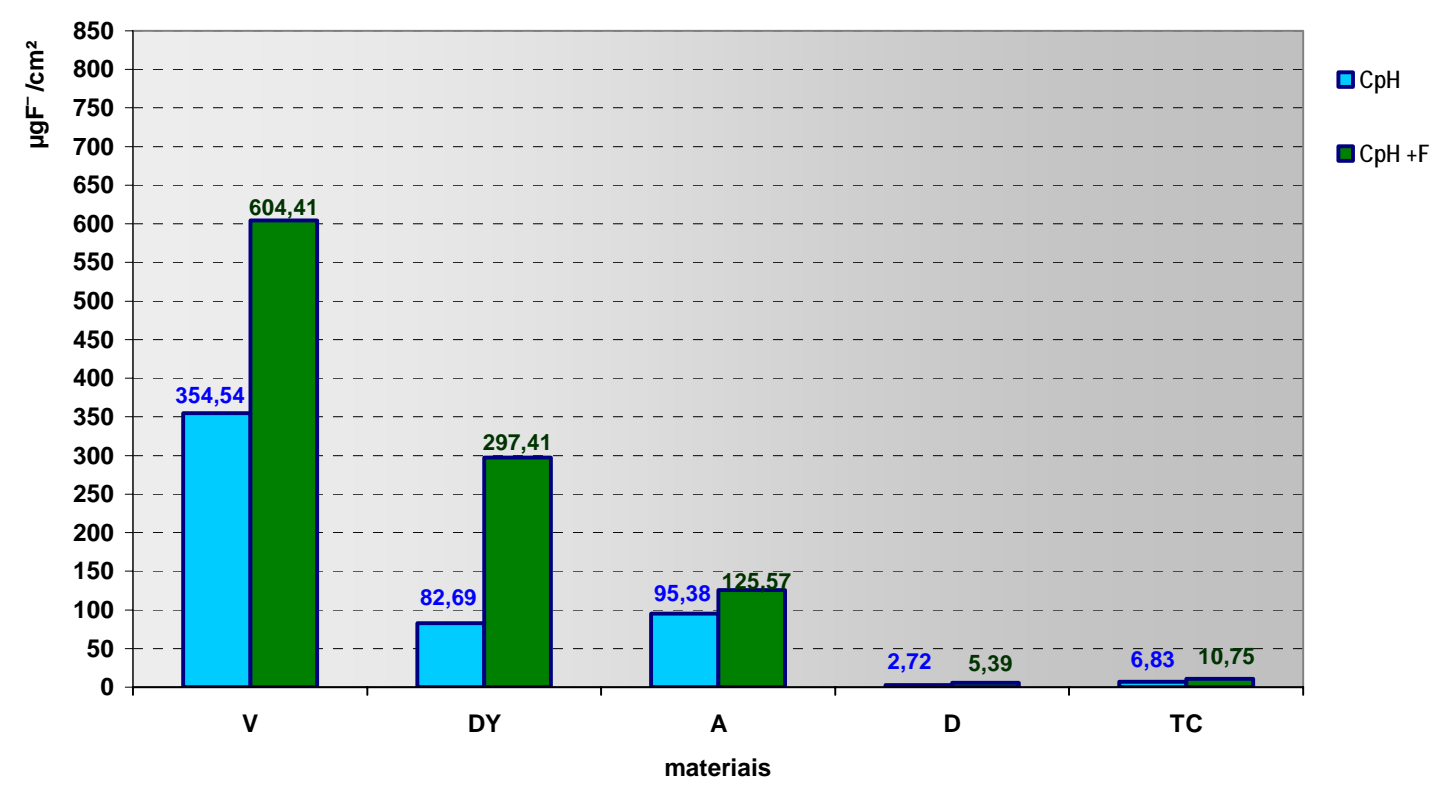

Figura 5.7 - Gráfico da liberação total de $\mathrm{F}^{-}$, solução DES ${ }^{-}$(6h), sem e com recarga.

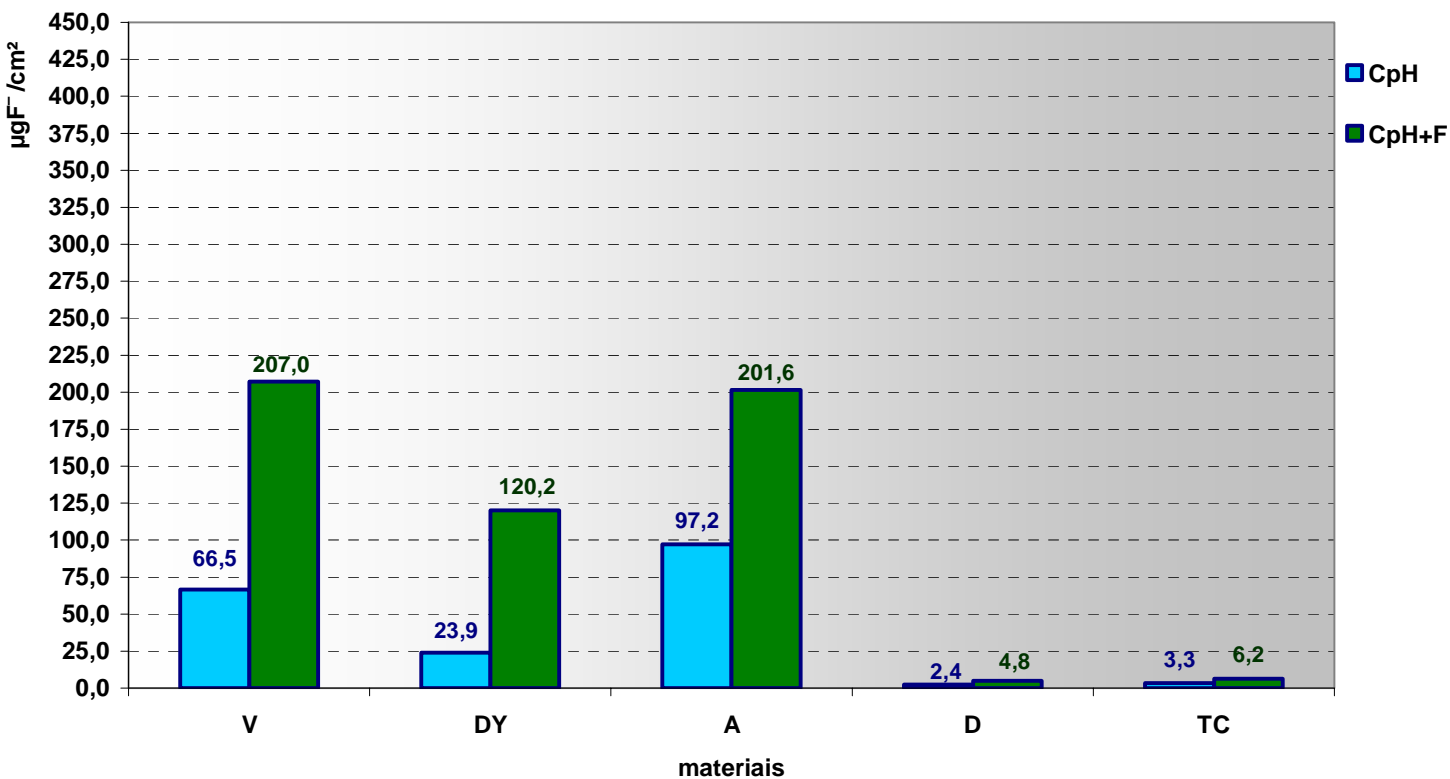

Figura 5.8 - Gráfico da liberação total de $\mathrm{F}^{-}$, solução $\mathrm{RE}(17 \mathrm{~h})$, sem e com recarga. 
A figura 5.9 representa a liberação total de flúor de todos os materiais avaliados no processo sem recarga e no processo de recarga.

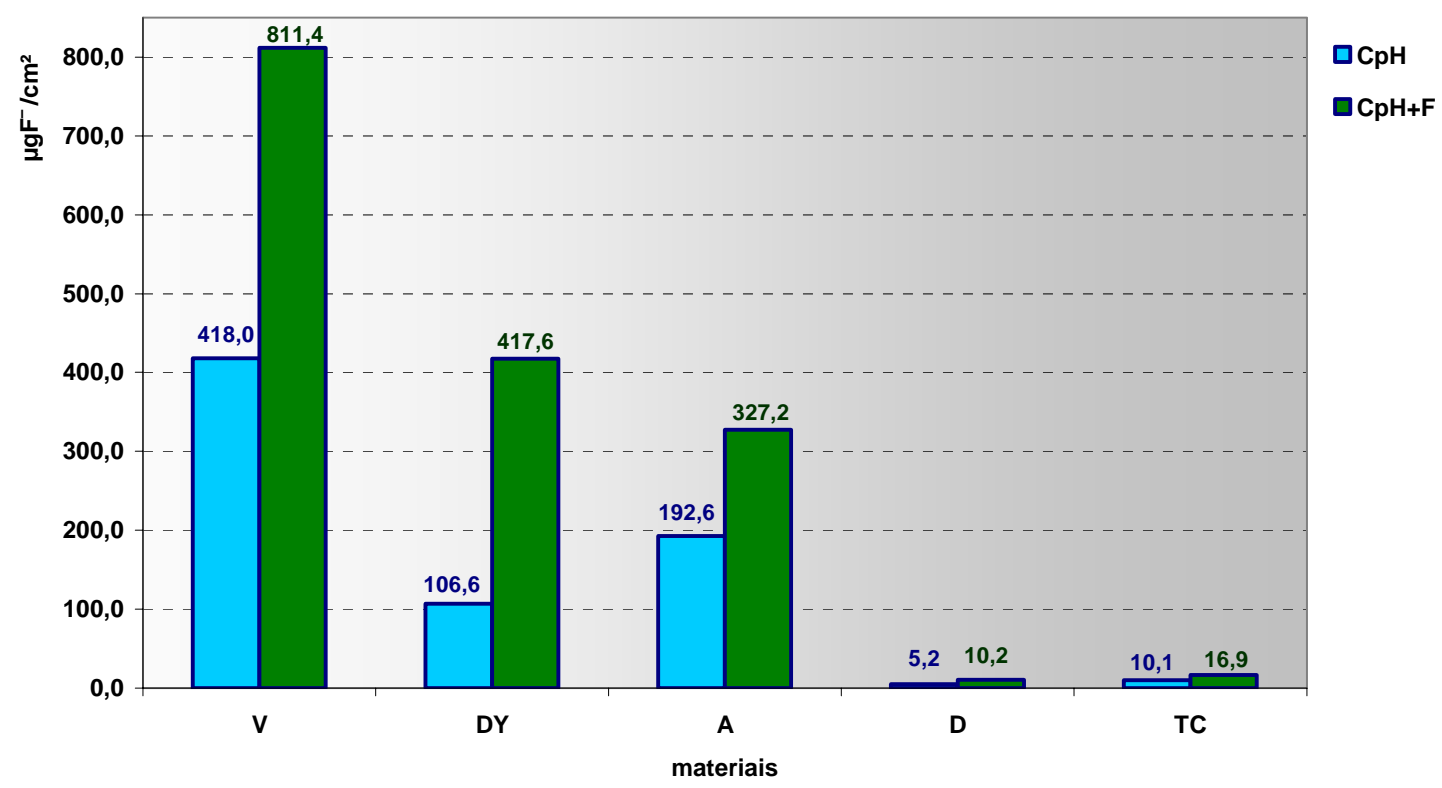

Figura 5.9 - Gráfico da liberação total de $\mathrm{F}^{-}$, solução $D E S^{-}-R E(24 h)$, sem e com recarga.

Entre os materiais, o Vitremer apresentou a maior liberação de íns flúor, tanto sem tratamento de recarga, $418,05 \mu \mathrm{gF}^{-} / \mathrm{cm}^{2}(\mathrm{~V})$ como com tratamento de recarga, $811,40 \mu \mathrm{gF}^{-} / \mathrm{cm}^{2}$ (VR). Os materiais que apresentaram os menores valores de liberação de íons flúor foram o Definite, $5,16 \mu \mathrm{gF}^{-} / \mathrm{cm}^{2}$ (D), seguido do DR $\left(10,25 \mu \mathrm{gF}^{-} / \mathrm{cm}^{2}\right)$, TC $\left(10,09 \mu \mathrm{gF}^{-} / \mathrm{cm}^{2}\right)$ e TCR $\left(16,86 \mu \mathrm{gF}^{-} / \mathrm{cm}^{2}\right)$, mas sem diferenças estatisticamente significantes entre DR e TC.

Os materiais D, TCR, DY, A, AR, VR apresentaram diferenças estatisticamente significantes entre si. Entretanto, entre os materiais TC $\left(10,10 \mu \mathrm{gF}^{-} / \mathrm{cm}^{2}\right)$ e DR $\left(10,24 \mu \mathrm{gF}^{-} / \mathrm{cm}^{2}\right)$, e entre DYR $\left(417,64 \mu \mathrm{gF}^{-} / \mathrm{cm}^{2}\right)$ e V $\left(418,04 \mathrm{\mu gF}^{-} / \mathrm{cm}^{2}\right)$ as diferenças não foram estatisticamente significantes. 


\subsection{Análise da microinfiltração}

Os valores de microinfiltração foram obtidos pelo softweare Image Tool a partir de uma medida linear, medida em pixels, no qual 115 pixels correspondiam a $0,5 \mathrm{~cm}$. As médias e desvios-padrão da análise da microinfiltração em água $(\mathrm{A})$ e em $\mathrm{CpH}(\mathrm{C})$ estão representados na tabela 5.7.

Tabela 5.7 - Médias e desvios-padrão dos valores de microinfiltração dos materiais restauradores nos meios de imersão, $\mathrm{A}$ e $\mathrm{CpH}$, durante 15 dias.

\begin{tabular}{c|c|c|c|c}
\hline \multirow{2}{*}{ Material } & \multicolumn{2}{|c|}{ Água (A) } & \multicolumn{2}{c}{ CpH (C) } \\
\cline { 2 - 5 } & Média & dp & Média & dp \\
\hline V & 0,017 & 0,027 & 0,071 & 0,091 \\
\hline DY & 0,023 & 0,032 & 0,036 & 0,039 \\
\hline A & 0,019 & 0,014 & 0,025 & 0,028 \\
\hline D & 0,050 & 0,084 & 0,147 & 0,117 \\
\hline TC & 0,062 & 0,078 & 0,045 & 0,026 \\
\hline
\end{tabular}

A figura 5.10 representa os valores de microinfiltração dos materiais nos dois meios de imersão, água e ciclagem de $\mathrm{pH}$. Observa-se que os valores de microinfltração foram maiores em solução de $\mathrm{CpH}$. 


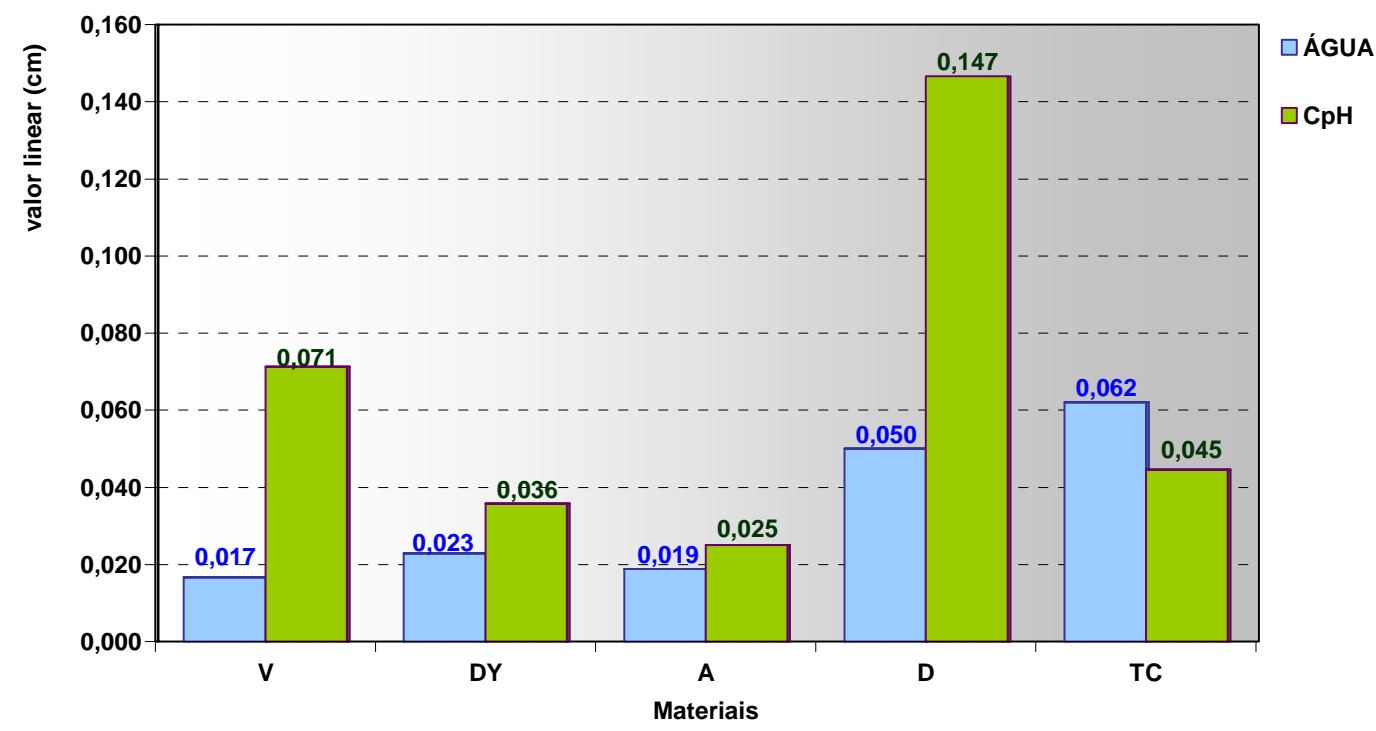

Figura 5.10 - Distribuição das médias de microinfiltração em cm dos materiais avaliados, em $\mathrm{A}$ e $\mathrm{CpH}$.

A tabela 5.8 refere-se ao teste de análise de variância (ANOVA) a dois critérios, meio e material. De acordo com o resultado dessa análise conclui-se que houve diferença estatística entre os fatores, meio e material, e não houve interação entre os mesmos $(p<0,05)$.

Tabela 5.8 - Análise de variância a 2 critérios, meio e material.

\begin{tabular}{l|r|l|l|l|l|l}
\hline \hline Efeito & $\begin{array}{r}\text { gl } \\
\text { efeito }\end{array}$ & $\begin{array}{r}\text { QM } \\
\text { efeito }\end{array}$ & $\begin{array}{r}\text { gl } \\
\text { erro }\end{array}$ & $\begin{array}{r}\text { QM } \\
\text { erro }\end{array}$ & $\mathbf{F}$ & $\mathbf{p}$ \\
\hline \hline Meio & $1^{*}$ &, $018686^{*}$ & $70^{*}$ &, $004038^{*}$ & $4,627305^{*}$ &, $034920^{*}$ \\
\hline Material & $4^{*}$ &, $014384^{*}$ & $70^{*}$ &, $004038^{*}$ & $3,561787^{*}$ &, $010569^{*}$ \\
\hline Meio/Material & 4 &, 008163 & 70 &, 004038 & 2,021471 &, 100795 \\
\hline \hline
\end{tabular}

* estatisticamente significante $(p<0,05)$ 
As médias de microinfiltração foram analisadas pelo teste de Tukey para comparações entre os meios, concluindo que houve diferença estatística significante entre os meios de imersão avaliados (tabela 5.9). Os materiais restauradores apresentaram um maior grau de infiltração em $\mathrm{CpH}$ do que em água.

Tabela 5.9 - Distribuição das médias de microinfiltração de acordo com o meio de imersão (teste de Tukey, $p<0,05$ ).

\begin{tabular}{c|c}
\hline MEIO & Média \\
\hline Água & $0,034100 \quad$ a \\
\hline CpH & $0,064667 \quad$ b \\
\hline
\end{tabular}

A figura 5.11 representa a distribuição de valores de microinfiltração dos materiais avaliados, nos dois meios de imersão, água e $\mathrm{CpH}$.

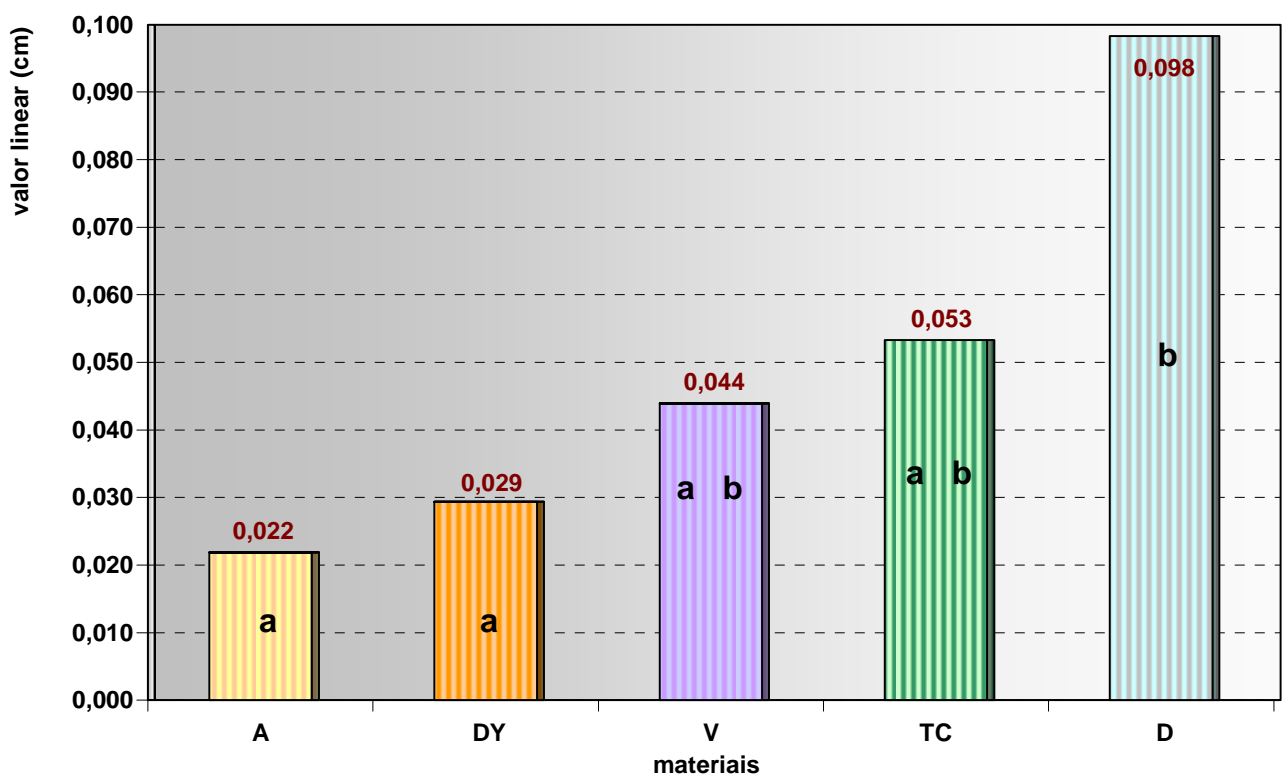

Figura 5.11 - Gráfico das médias dos valores de microinfiltração dos materiais restauradores em $\mathrm{A}$ e $\mathrm{CpH}$. 
O teste de Tukey (tabela 5.10) mostrou que o material D apresentou diferença estatística significante em relação ao A e DY. Os materiais com letras iguais não apresentaram diferenças estatisticamente significantes entre si.

Tabela 5.10 - Médias do grau de microinfiltração dos materiais em relação ao meio de imersão, água e $\mathrm{CpH}$ (Teste de Tukey, $\mathrm{p}<0,05$ ).

\begin{tabular}{|c|c|c|c|}
\hline \multicolumn{2}{|r|}{ MATERIAL } & \multicolumn{2}{|c|}{$\begin{array}{l}\text { Média - Valor de } \\
\text { microinfiltração }\end{array}$} \\
\hline A & - Ariston & 0,022 & $\mathbf{a}$ \\
\hline DY & - Dyract & 0,029 & $\mathbf{a}$ \\
\hline V & - Vitremer & 0,044 & a $\quad b$ \\
\hline TC & - Tetric-ceram & 0,053 & a $\quad b$ \\
\hline D & - Definite & 0,098 & b \\
\hline
\end{tabular}

Embora nas condições em que foram realizados os experimentos de liberação de flúor e microinfiltração marginal, observa-se que os materiais DY apresentaram os menores valores no grau de microinfiltração (tabela 5.7), entretanto não é possível afirmar que a liberação tenha influenciado o grau de microinfiltração dos materiais.

Contraditoriamente em valores absolutos, o material TC apresentou baixa liberação de flúor, sem e com recarga, seu grau de infiltração foi semelhante aos materiais que liberaram maiores quantidades de flúor, V, DY e A, embora estatisticamente não significantes entre si na análise da microinfiltração (tabela 5.10). 


\section{Discussão}




\section{DISCUSSÃO}

\subsection{Liberação e Recarga de flúor}

A ação do flúor no meio bucal tornou-se bastante evidente quando estudos populacionais longitudinais realizados durante décadas revelaram sua associação ao declínio da prevalência da cárie dentária, principalmente pelo uso difundido das pastas dentais fluoretadas ${ }^{35}$. Os conceitos atuais quanto à atividade cariostática do flúor estão em função da sua concentração e freqüência no meio bucal. Os estudos clínicos mostram que o mais efetivo regime na prevenção da cárie dentária está associado à disponibilidade desse íon no meio bucal em baixa concentração e com maior freqüência ${ }^{44,54,55,59}$. Essa exposição ao flúor, inicialmente no fluido da placa e na saliva, resulta em um elevado e estável nível de íons em contato com a estrutura dentária ${ }^{19}$. Embora seja pouco conhecida a concentração de flúor no meio bucal necessária para promover um efeito cariostático em seu local de ação ${ }^{41}$, é razoável admitir que pode existir uma relação entre a concentração de flúor nesses fluidos e o potencial cariostático ${ }^{19,50}$ do íon flúor presente na água de abastecimento e nos produtos para aplicação tópica, como as soluções, géis, vernizes e dentifrícios, que são métodos eficazes na prevenção e controle da cárie dentária ${ }^{1,41}$.

Diferentes níveis de flúor contribuem para potencializar o processo de remineralização do esmalte e da dentina expostos ao desafio ácido $^{34,51}$ reduzindo o processo de desmineralização, além de agir na ecologia da microbiota bucal ${ }^{25}$. Não se pode, porém, deixar de admitir que a ação terapêutica do flúor engloba a prevenção e o controle da doença cárie tornando-se mais eficaz quando o tratamento está associado ao efetivo controle de placa, à adequação de higiene bucal e de hábitos alimentares, 
medidas capazes de equilibrar o meio bucal, ou melhor, atuar na promoção da saúde bucal.

O mecanismo de ação do flúor liberado ocorre por adsorção ou integração com os componentes minerais da estrutura dentária, carbonatos e fosfatos presentes na hidroxiapatita (HA), formando a fluorapatita e que se apresenta mais resistente ao ataque ácido. Por dissolução da fluorapatita pelos ácidos do meio bucal, íons de flúor e de cálcio formam fluoreto de cálcio que se deposita sobre os cristais não dissolvidos, diminuindo por parte desses cristais, a liberação de íons cálcio e fósforo, interferindo no processo de difusão do ácido nos cristais não dissolvidos da estrutura dentária.

A liberação de flúor pelos materiais restauradores é uma condição desejável ${ }^{55}$, em algumas situações clínicas, por terem boa capacidade de inibir a formação de cáries secundárias no esmalte adjacente às restaurações $27,50,51,55,59$. Houve uma constante evolução nessas características dos materiais restauradores a partir das propriedades anticariogênicas do cimento de silicato $^{23,24,66}$. O primeiro nessa linha de evolução foi o cimento de ionômero de vidro, desenvolvido por Wilson e Kent na década de 70 , que já apresentava boa capacidade de liberar flúor ${ }^{51,54}$ e também propriedades adesivas, sem interferência nas propriedades físicas e mecânicas do material. Entretanto, apresentava algumas desvantagens, como manipulação crítica, baixa resistência à fratura sendo, portanto de indicação limitada em áreas de estresses. Com o propósito de melhorar as propriedades mecânicas e estéticas desses materiais surgiram os cimentos de ionômero de vidro modificados por resinas e os compômeros que são resinas modificadas por poliácidos.

O flúor encontrado nos materiais restauradores pode fazer parte da sua composição química ou ser adicionado ao material durante a fabricação. As maiores quantidades de flúor aparecem nos materiais que contem fluoretos na sua estrutura química sem efeito negativo sobre as propriedades físico-mecânicas e a liberação desses íons depende da cinética do material ${ }^{23}$. 
Os materiais restauradores resinosos com capacidade de liberação de flúor possuem cargas de vidro a base de fluorsilicato de alumínio, de bário, de estrôncio que são as mais encontradas nos ionômeros de vidro modificados por resina e nas resinas modificadas por poliácidos ${ }^{20}$. A reação de presa desses materiais difere daquela dos cimentos de ionômero de vidro convencionais que pela mistura do pó e líquido resulta na liberação de fluoretos como subproduto da reação e, por conter água, esta atua como meio de transporte na movimentação dos íons causando o endurecimento do material. Entretanto, nos cimentos de ionômero de vidro híbridos o endurecimento do material ocorre pela reação ácido-base ${ }^{51,59}$, iniciada durante a manipulação, e a reação de polimerização da resina. O pó apresenta composição semelhante ao CIV convencional e o líquido contém monômeros, poliácidos e água ${ }^{43}$. A presença de uma base fotopolimerizável porosa permite a difusão do flúor ${ }^{20}$

Apesar das resinas modificadas por poliácidos, os compômeros, terem comportamento clinico mais próximo ao das resinas $\operatorname{compostas}^{59}$, a liberação de flúor ocorre por processo de transferência por absorção de água ${ }^{55}$, após a sua colocação e em contato com a saliva, sendo esta absorção importante para que forme ligações químicas no material, por meio de reações ácido-base, tal qual ocorre no cimento de ionômero de vidro ${ }^{43}$. A absorção da água dentro do material é necessária para a formação de íons $\mathrm{H}^{-}$livres que atacam as partículas de vidro contendo flúor ocorrendo assim, a sua liberação ${ }^{5,43,51,55}$.

No presente estudo, a resina modificada por poliácido, Dyract AP, como no estudo de ATTIN et al. ${ }^{7}$ apresentou valores mais baixos de liberação de flúor, $106,6 \mu \mathrm{gF}^{-} / \mathrm{cm}^{2}$ quando comparada com o Vitremer ${ }^{\mathrm{TM}}$, $418,0 \mu \mathrm{gF}^{-} / \mathrm{cm}^{2}$. Essa maior liberação de flúor pelo Vitremer pode ocorrer devido à influência positiva de HEMA aumentando a capacidade hidrofílica da matriz polimérica e facilitando o transporte de água e íons, neste caso, tanto para o íon $\mathrm{H}^{-}$como para o íon $\mathrm{F}^{-5,50}$. Essa diferença pode também estar associada ao tipo e ao tamanho da partícula. As partículas de carga de vidro de estrôncio-flúor-silicato, presentes no Dyract AP liberam menor 
quantidade de flúor ${ }^{54}$ do que as de alumínio-flúor-silicato, encontradas no Vitremer $^{\mathrm{TM}}$, de acordo com o estudo de PENG et al. ${ }^{51}$, e a presença de uma base fotopolimerizadora porosa que permite a difusão do fluoreto ${ }^{20}$.

As resinas compostas apresentam outro mecanismo de liberação de flúor, ou seja, por troca iônica. As partículas de carga contem fluoretos dispersos na matriz resinosa que migram da resina composta para o meio bucal e retornam com íons de $\mathrm{OH}^{-}$da saliva, por um processo de difusão. A resina composta Tetric $^{\circledR}$ Ceram contém, além do trifluoreto de itérbio, partículas de carga de vidro de fluorsiliciato de bário e de alumínio ${ }^{20}$.

Entre as resinas avaliadas nesse estudo, Tetric ${ }^{\circledR}$ Ceram e Definite ${ }^{\circledR}$ apresentaram os menores valores de liberação de íons flúor, respectivamente $10,10 \mu \mathrm{gF}^{-} / \mathrm{cm}^{2}$ e $5,20 \mu \mathrm{gF}^{-} / \mathrm{cm}^{2}$ comparados ao Vitremer ${ }^{\text {TM }}$ a ao Dyract AP. Esse padrão de liberação das resinas compostas está de acordo com estudos anteriores ${ }^{12,70}$.

Definite ${ }^{\circledR}$ definida como uma resina composta híbrida contém partículas de vidro de bário, iniciadores e pigmentos, sulfato-fosfato-apatita (apatita modificada) e a matriz "ormocer" (organically modified ceramics) fotopolimerizável, constituída de blocos de polisiloxane ligados aos grupos metacrilatos por ligações covalentes de átomos de silício. A apatita modificada tem a função de tampão ácido e liberação/recarga de flúor, capaz de ativar o processo de remineralização quando adicionada de flúor tornando mais intensa a liberação de íons pela queda do $\mathrm{pH}$ bucal ${ }^{18}$. Entretanto, no presente trabalho, os valores de liberação de flúor apresentados pelo material Definite ${ }^{\circledR}$ foram os mais baixos $5,2 \mu \mathrm{gF}^{-} / \mathrm{cm}^{2}$, não confirmando as observações do fabricante ${ }^{18}$.

A resina composta Ariston ${ }^{\circledR} A T$ apresentou padrão de liberação de flúor diferente das demais resinas compostas. Entre as resinas compostas estudadas, esse material registrou o mais alto valor de liberação, $192,60 \mu \mathrm{gF}^{-} / \mathrm{cm}^{2}$. Essa maior liberação decorre da sua formulação que apresenta uma matriz de monômero obtida de uma mistura de dimetracilatos e cargas inorgânicas de vidro alcalino (fluorsilicato de bário, fluorsilicato de 
alumínio, trifluoreto de itérbio e dióxido de silício) que liberam três tipos diferentes de íons, flúor, cálcio e hidroxila $3,40,51,66$.

Entre as propriedades dos materiais restauradores quanto à ação do flúor contribuindo para o equilíbrio do $\mathrm{pH}$ crítico bucal ${ }^{67}$, existe ainda a possibilidade desses materiais serem reservatórios desse íon por um processo de liberação, seja por sorção ou troca iônica, absorvido por fontes externas de flúor, pelo processo de recarga ${ }^{41,51}$. As principais fontes de flúor, de ampla utilização pela população, estão na água de abastecimento e nas pastas dentais fluoretadas, as quais apresentam diferentes concentrações. A água de abastecimento tem sua ação por via sistêmica e tópica e, as pastas dentais atuam de forma primária pelo efeito de ação tópica do flúor ${ }^{35}$ em contato direto com a superfície da restauração e da estrutura dentária, intensificando o processo de remineralização e inibindo a fase de desmineralização ${ }^{27,35}$.

Portanto, a presença do flúor em baixas concentrações e em maior freqüência pode agir na dinâmica natural do desafio ácido, especialmente em pacientes de alto desafio cariogênico ${ }^{54,67}$. Essa liberação no meio bucal, mais particularmente na interface dente/restauração é de grande importância para prevenir a desmineralização inicial e secundária da estrutura dentária nas margens da restauração ${ }^{50}$.

Os modelos de estudos laboratoriais de medir a liberação de flúor vêm sendo realizados por diferentes métodos não havendo, portanto, uma padronização. Existe uma variação de métodos quanto ao meio de conservação dos corpos-de-prova que utilizam a água deionizada, soluções ácidas e saliva artificial como meios de imersão $6,7,9,24,40,50,51,54$, como também quanto ao tempo, normalmente, de algumas semanas. Nessa situação, os valores obtidos são acumulativos e não representativos do comportamento clínico dos materiais no meio bucal, quanto à liberação de flúor ${ }^{23}$.

A metodologia empregada no presente trabalho tem como fundamento os estudos de Featherstone et al. $^{22}$, pelo qual tornou possível simular in vitro a dinâmica natural do desafio ácido do esmalte dentário 
utilizando um sistema de ciclagem de pH. Esse sistema consiste em ciclos de desmineralização e de remineralização por um período de 15 dias, também aplicado por CARVALHO e CURY ${ }^{12}$; GARCEZ ${ }^{26}$; VIEIRA, SOUZA, MODESTO ${ }^{67}$.

O presente estudo no qual foram observadas a liberação e recarga de flúor dos materiais estudados foi realizado em sistema de ciclagem de $\mathrm{pH}^{12,22,26,67}$ que compreende dois ciclos durante 24 horas. $\mathrm{O}$ primeiro por um período de 6 horas em solução de $\operatorname{DES}^{-}\left(\mathrm{pH}^{4}\right.$ 4.3) simulando os vários períodos diários de ingestão de alimentos, resultando em queda de pH intrabucal de 5.5 para 4.5, produzindo ciclos de desmineralização e, por conseguinte, favorecendo a instalação e progressão de lesões de cárie pela exposição do esmalte aos desafios ácidos. O segundo ciclo, em solução remineralizante $(\mathrm{pH} 7.0)$ durante de 18 horas, corresponde ao período de recuperação in vivo da queda de $\mathrm{pH}$ que ocorre no meio bucal, na presença de saliva.

Nessa pesquisa, o meio de imersão em água deionizada não foi incluído considerando que, esse modelo não reproduz as quedas cíclicas de $\mathrm{pH}$ do meio bucal. Os ensaios realizados nesse meio quantificam a liberação total de íons flúor que se apresentam livres de força iônica dos diversos elementos existentes no fluido salivar, como observado em estudos anteriores $^{12,26,67}$.

A literatura estudada relata ensaios com recarga de flúor por diversos meios como aplicação de soluções de bochecho, flúor tópico gel, vernizes e pastas dentifrícias fluoretadas, com diferentes concentrações e meios de imersão ${ }^{50,51,54,55,67}$. O não conhecimento da concentração ideal de flúor para neutralizar as quedas cíclicas de $\mathrm{pH}$ no meio bucal ${ }^{55}$, da quantidade necessária de liberação e recarga de flúor do material restaurador sem interferir nas suas propriedades físico-químicas, capazes de promover padrão de remineralização na estrutura dentária, limita estudos comparativos qualitativos e quantitativos. 
As mais comuns fontes de flúor das pastas dentais são $\mathrm{NaF}$ e MFP que são liberados para a cavidade oral por diversos mecanismos. O $\mathrm{NaF}$, presente na maioria das pastas dentais e soluções de bochecho ${ }^{55}$, encontra-se disponível livremente nos fluidos orais, enquanto o MFP necessita de um sistema enzimático ${ }^{35}$, para que ocorra o processo de hidrólise e a liberação de íons flúor, ausente em soluções inorgânicas como a solução de remineralização. A indicação de uma pasta dental com $\mathrm{NaF}$, para o presente estudo, está de acordo com os meios de imersão do sistema de $\mathrm{CpH}$ utilizados que compreendem soluções desmineralizante e remineralizante. Segundo citam EKSTRAND e OLIVEBY ${ }^{19}$, esta pode ser a maior razão a ser observada em estudos com dentifrícios, nos quais as maiores concentrações de flúor no fluido salivar e no fluido da placa foram registrados com pastas de $\mathrm{NaF}$ do que com pastas dentais de MFP.

O processo de recarga de flúor foi realizado no presente trabalho pela imersão dos corpos-de-prova em uma solução de $3 \mathrm{~mL}$ de água deionizada e $1 \mathrm{~g}$ da pasta dental fluoreteda "Crest" (Procter\&Gable, $\mathrm{OH}$, USA), na concentração de 1,100ppm de $\mathrm{NaF}$, por 5 minutos, entre as trocas das soluções do sistema de ciclagem, assim como proposto por VIEIRA, SOUZA, MODESTO ${ }^{67}$.

O padrão de liberação de flúor apresentado pelo Vitremer $^{\mathrm{TM}}$, Dyract AP, Ariston ${ }^{\circledR}$ AT, Definite ${ }^{\circledR}$ e Tetric ${ }^{\circledR}$ Ceram nos meios de imersão, sem e com tratamento de recarga, foi o mesmo para todos esses materiais. Neste estudo, o material Vitremer ${ }^{\mathrm{TM}}$ apresentou os maiores valores de liberação total no período do experimento, $418,05 \mu \mathrm{gF}^{-} / \mathrm{cm}^{2}$ sem recarga e $818,40^{-} \mu \mathrm{gF} / \mathrm{cm}^{2}$ com recarga, semelhante ao observado por PRESTON et al. ${ }^{55} \mathrm{e}$ WEIDLICH et al. ${ }^{70}$. Esse padrão de liberação dos materiais está de acordo com o encontrado na literatura ${ }^{12,13,67,70}$, independente do meio de imersão, volume e tipo de solução, tempo de estocagem, veiculo de recarga e intervalo de tempo dos experimentos quando comparados com outros materiais resinosos. 
O maior pico de liberação conhecido como "efeito de explosão do flúor" ocorreu no primeiro dia para todos os materiais avaliados, tanto no experimento sem recarga (Figura 5.3), como no experimento com recarga (Figura 5.6) de acordo com o padrão encontrado na literatura, ${ }^{6,7,50,59,67}$. Ao $2^{\circ}$ dia registra-se um rápido declínio, mas em torno do $5^{\circ}$ ao $7^{\circ}$ os valores se tornam quase constantes ${ }^{51} \mathrm{e}$, em seguida apresentam contínuo decréscimo gradual e lento até o final do experimento ${ }^{59,67}$ (Tabela 5.6).

A recarga do material foi iniciada ao $2^{\circ}$ dia, após as primeiras 24 horas, período em que ocorre o pico de liberação de flúor dos materiais, para que a recarga fosse realizada rapidamente tal qual ocorre no meio bucal. Esse procedimento difere de outros estudos cuja recarga inicia-se após o período de estabilização de liberação de $\mathrm{F}^{-}$, em torno do $7^{\circ}$ a $8^{\circ}$ dia ${ }^{32,59,67}$ ou após a exaustão da liberação de flúor ${ }^{6,32,50,51,55}$. Ao $3^{\circ}$ dia, nos grupos com recarga (Tabela 5.6), observa-se que todos os materiais apresentaram maiores valores de liberação de flúor ${ }^{59,67}$, declinando lentamente e mantendo valores estáveis de flúor liberado. Ao final do experimento, ao $15^{\circ}$ dia, os valores encontrados aproximam-se aos do ensaio sem recarga, obtidos no $2^{\circ}$ dia do experimento (Tabela 5.6).

As resinas compostas Definite ${ }^{\circledR}$ e Tetric $^{\circledR}$ Ceram apresentaram os mais baixos valores de liberação de íons flúor, em ambos experimentos, sem recarga e com recarga, $\quad \mathrm{D}=5,17 \mu \mathrm{gF}^{-} / \mathrm{cm}^{2} ; \quad \mathrm{DR}=10,24 \mu \mathrm{gF}^{-} / \mathrm{cm}^{2}$ e $\mathrm{TC}=10,10 \mu \mathrm{gF}^{-} / \mathrm{cm}^{2}, \quad \mathrm{TCR}=16,85 \mu \mathrm{gF}^{-} / \mathrm{cm}^{2}, \quad$ mas sem diferenças estatisticamente significantes entre DR e TC. Entretanto a resina composta Ariston ${ }^{\circledR} \mathrm{AT}$, diferente das demais resinas, obteve a maior liberação após recarga $\left(327,2 \mu \mathrm{gF}^{-} / \mathrm{cm}^{2}\right)$ compatível com o padrão de liberação também apresentado no processo sem recarga $\left(192,60 \mu \mathrm{gF}^{-} / \mathrm{cm}^{2}\right)$, provavelmente associada à composição do material que permite uma maior troca iônica com o meio de imersão.

Os maiores valores de liberação de flúor foram registrados na solução desmineralizante $(\mathrm{pH} 4.3)$, para todos os materiais estudados (Figura 5.7), independente do processo de tratamento do experimento, sem 
e com recarga, semelhantes aos observados nos estudos de ATTIN et al. ${ }^{7}$; CARVALHO e CURY ${ }^{12}$; POSADA, EMILSON, BIRKED ${ }^{54}$; VIEIRA, SOUZA, MODESTO ${ }^{67}$. Essa maior liberação de íons sugere a ação do flúor iônico livre ou em forma de fluoretos, presente no material restaurador, quando ocorre desequilíbrio do $\mathrm{pH}$ crítico do meio bucal ${ }^{54,66,67}$.

Os materiais Definite ${ }^{\circledR}$ e Tetric ${ }^{\circledR}$ Ceram mantém o padrão de baixa liberação ao registrar os menores valores totais de liberação de flúor sem recarga, respectivamente $\mathrm{D}=2,72 \mu \mathrm{gF}^{-} / \mathrm{cm}^{2}$ e $\mathrm{TC}=6,83 \mu \mathrm{gF}-\mathrm{cm}^{2}$ e com recarga, respectivamente $\mathrm{DR}=5,39 \mu \mathrm{gF}-\mathrm{cm}^{2}$ e $10,75 \mu \mathrm{gF}^{-} / \mathrm{cm}^{2}$. Os valores referentes ao Definite ${ }^{\circledR}$ não correspondem as indicações do material pelo fabricante de promover maior liberação de flúor em situações de queda de pH e a capacidade de maior incorporação de flúor ao material a partir de fontes externas pela presença da apatita modificada na composição ${ }^{18}$.

$\mathrm{Na}$ solução remineralizante $(\mathrm{pH}$ 7.0) todos os materiais apresentaram menor liberação quando comparados com a solução DES ${ }^{-}$, tal qual foi observado na literatura ${ }^{7,70}$. Definite ${ }^{\circledR}$ e Tetric ${ }^{\circledR}$ Ceram mantiveram o padrão de liberação ao registrar os menores valores totais de liberação de flúor sem recarga respectivamente $2,40 \mu \mathrm{gF}^{-} / \mathrm{cm}^{2}$ e $3,30 \mu \mathrm{gF}-1 \mathrm{~cm}^{2}$ e com recarga respectivamente $4,80 \mu \mathrm{gF}^{-} / \mathrm{cm}^{2}$ e $6,20 \mu \mathrm{gF}-1 \mathrm{~cm}^{2}$.

Desta forma, com base nos resultados apresentados torna-se evidente a capacidade de recarga de flúor pelo padrão de liberação de flúor dos materiais estudados que apresentaram liberação lenta e constante e valores de liberação superiores aos iniciais, a partir de uma fonte externa de flúor, como os observados por CREANOR et al. ${ }^{17}$; POSADA et al. ${ }^{54} \mathrm{e}$ VIEIRA, SOUZA e MODESTO ${ }^{67}$. Entretanto, como já elucidado, a forma de liberação de íons ocorre por dissolução superficial, difusão de micro canais e poros e, difusão de massa, sendo este o mecanismo de liberação nas resinas compostas, como também o mais lento ${ }^{7,50,67}$.

As diferentes variáveis nas metodologias utilizadas nos estudos de liberação e recarga de flúor que incluem tipo do material restaurador, tamanho do corpo-de-prova, meio de imersão, volume do meio de imersão, 
medidas e diferentes métodos para mensurar a quantidade de flúor liberado dificultam a comparação dos resultados dos diferentes estudos. Portanto, as comparações dos resultados devem ser realizadas mais com base no comportamento do material do que nos valores absolutos encontrados decorrentes da liberação e recarga do flúor $^{70}$, que ficam limitados para a análise dos dados do respectivo estudo.

\subsection{Microinfiltração}

Apesar dos materiais restauradores com proposta de liberação de flúor contribuírem para o aumento da resistência do esmalte adjacente às restaurações, a infiltração marginal independentemente desse processo ocorre na interface dente/restauração. O processo de microinfiltração é definido como a passagem de bactérias, fluidos e substâncias químicas, na forma de moléculas e íons, entre as paredes cavitárias e o material restaurador $^{15,30,37,48,53}$.

Esse processo, ao longo do tempo, pode levar a descoloração marginal $^{8,63}$, cáries secundárias ${ }^{8,30,53}$, sensibilidade dentinária, inflamação pulpar e, em condição extrema à necrose $\mathrm{e}^{2,14,39,63}$. Trata-se, portanto, de um problema clínico, não desejável, considerando que a maioria das interfaces dente/ restauração registra vários graus de microinfiltração ${ }^{14,48}$.

A infiltração marginal pode estar relacionada a alguns fatores como ao fator-C (fator de configuração cavitária) ${ }^{10}$, à contração de polimerização do material ${ }^{14,21,52}$, como também, à resistência do material à biodegradação ${ }^{64}$ na interface dente/restauração ${ }^{53}$.

O fator-C é interpretado como a relação entre as superfícies aderidas e não aderidas do material restaurador na cavidade ${ }^{63}$ e, pode em alguns casos ser controlado pelo clínico. Nesse estudo, o desenho realizado 
foi de cavidades Classe $\mathrm{V}$ em esmalte de terceiros molares extraídos medindo $3,0 \mathrm{~mm}$ de largura por $2,0 \mathrm{~mm}$ de altura e $1,5 \mathrm{~mm}$ de profundidade reproduzindo elevado fator-C, o qual foi minimizado utilizando-se o método de inserção de 2 a 3 incrementos. Entretanto, a contração de polimerização está relacionada com a composição do material durante o processo de endurecimento. A utilização da técnica incremental pode minimizar os efeitos causados tanto pelo alto fator-C como pela contração de polimerização ${ }^{14}$.

O processo de endurecimento do polímero ocorre pela ligação de moléculas que passam a ocupar distâncias menores entre si, do que aquelas quando estavam na condição de monômero, o que identifica a contração de polimerização. Esse processo ocorre em três fases, conhecidas como prégel, gel e pós-gel. Na primeira, a resina composta ainda encontra-se viscosa podendo haver escoamento e mudança de forma, assim como uma certa compensação da contração; na segunda fase, gel, o material em contínuo processo de polimerização, transforma a massa em material sólido pela formação de moléculas maiores e cadeias de polímeros. Em seqüência, a movimentação e a difusão das moléculas ficam limitadas, dada a rigidez da massa e a diminuição de volume que gera tensões nas superfícies aderidas. O processo de polimerização é natural e inerente aos materiais poliméricos e essas tensões internas, devido a contração do material, refletem-se na linha de união da estrutura aderida provocando fendas na interface dente/restauração ${ }^{14}$.

As diferenças dos coeficientes de expansão térmica e do módulo de elasticidade entre o tecido dentário e os materiais restauradores, além da contração de polimerização interferem no processo de microinfiltração ${ }^{52}$. Os novos materiais restauradores associados ao condicionamento ácido prévio do esmalte e da dentina e, às técnicas consideradas adesivas, ainda não proporcionam um perfeito selamento e vedamento marginal, mesmo os com capacidade de aderir quimicamente aos tecidos dentários, como os CIV convencionais que não apresentam contração de polimerização ${ }^{11}$. Portanto, materiais restauradores que possam resistir às mudanças de temperatura 
sem proporcionar alterações volumétricas e assim mesmo promover um perfeito selamento marginal, ainda são desejáveis.

O processo de infiltração marginal vem sendo observado por meio de estudos in vitro do grau desse fenômeno na interface dente/restauração, seja pela análise qualitativa ${ }^{11}$ ou quantitativa. Os testes laboratoriais consistem em submeter unidades dentárias restauradas a ciclos de carga e/ou temperatura, simulando condições intrabucais de estresse ou fadiga, decorrentes dos esforços mastigatórios e das diferenças térmicas dos alimentos, para avaliar a formação de fendas na linha de adesão na interface dente/restauração, resultando em possível infiltração ${ }^{14,47}$, visualizada então pela penetração de substâncias corantes ${ }^{2}$, como a fucsina básica, por ser um método compararativo, simples e de baixo custo.

Esses testes, em sua maioria, utilizam como meios de imersão a água deionizada, além de soluções ácidas mas que não expõem a estrutura dentária a uma situação de desafio cariogênico pelo desequilíbrio do $\mathrm{pH}$ crítico bucal, como nos testes de ciclagem de $\mathrm{pH}^{22}$. De acordo com LARSON $^{39}$, o meio ambiente bucal é a chave para o entendimento do efeito deste sobre os materiais e restaurações. Entretanto, as condições in vivo diferem dos estudos in vitro nos quais não existe película protetora salivar e os efeitos tampão da saliva, como nos ensaios realizados com ácido lático por GÖHRING et al. ${ }^{29}$.

Desta forma, a avaliação da interface dente/restauração de alguns materiais restauradores submetidos ao sistema de $\mathrm{CpH}$, solução desmineralizante e solução remineralizante, como aplicado nesse estudo, pode complementar a simulação de situações clínicas como as quedas cíclicas de $\mathrm{pH}$ às quais a estrutura dentária encontra-se permanentemente exposta na saliva na boca.

No presente estudo foram empregados os mesmos materiais restauradores resinosos estudados no experimento anterior, Vitremer ${ }^{\mathrm{TM}}$, Dyract AP, Ariston ${ }^{\circledR} A T$, Definite ${ }^{\circledR}$, Tetric ${ }^{\circledR}$ Ceram, para avaliar o padrão de microinfiltração nos meios de imersão, água deionizada e $\mathrm{CpH}$. O meio de 
imersão não interferiu no comportamento do material, ou seja, o fenômeno da microinfiltração ocorreu tanto em água deionizada como em $\mathrm{CpH}$. Entretanto o maior grau de microinfiltração foi observado em $\mathrm{CpH}$ (Tabela 5.9), com diferença estatística significante em relação a água deionizada. Essa maior infiltração em $\mathrm{CpH}$, pode está associada a solução desmineralizante $(\mathrm{pH} 4.3)$, tal qual encontrado na literatura, quando o meio de imersão apresentava $\mathrm{pH}$ baixo ${ }^{29}$.

Nesse estudo, os preparos classe $V$ foram realizados com margem em esmalte e profundidade em dentina. Para as restaurações com resina composta foi empregada a técnica de condicionamento ácido total aplicando-se ácido fosfórico $37 \%$ e os sistemas adesivos de frasco único (ATLiner/Ariston ${ }^{\circledR}$ AT; Prime\&Bond 2.1/Definite ${ }^{\circledR}$; Single Bond/Tetric ${ }^{\circledR}$ Ceram). Para os materiais restauradores, CIV modificado por resina e o compômero, a superfície de dentina recebeu tratamento com primer/Vitremer ${ }^{\mathrm{TM}}$ e Prime\&Bond 2.1/Dyract AP. Todos os materiais foram utilizados de acordo com as orientações dos fabricantes nos protocolos de cada material, considerando que não foi objeto desse estudo avaliar a resistência adesiva.

A maioria dos estudos avalia o grau de microinfiltração por medidas em escores ${ }^{2}$, portanto análise qualitativa o que difere da realizada nesse estudo. A superfície infiltrada foi avaliada quantitativamente por um softweare Image Tool, indicado para essas avaliações pelo registro de uma medida linear da interface corada. Os resultados obtidos mostraram que todos os materiais apresentaram microinfiltração na interface dente/restauração sendo observada a maior infiltração na resina composta Definite $^{\circledR}$, seguida em valores absolutos, pela Tetric $^{\circledR}$ Ceram, Vitremer ${ }^{\mathrm{TM}}$, Dyract AP e Ariston ${ }^{\circledR}$ AT. Entretanto, não houve diferença estatisticamente significante entre os materiais Tetric ${ }^{\circledR}$ Ceram, Vitremer ${ }^{\mathrm{TM}}$, Dyract AP e. Ariston ${ }^{\circledR} \mathrm{AT}$.

O maior grau de infiltração observado na resina composta Definite $^{\circledR}$ pode estar relacionado com o seu comportamento ao meio de imersão $\mathrm{CpH}$ que pode provocar um aumento de rugosidade devido a 
degradação química da superfície e da sub-superfície com envolvimento da matriz resinosa, a carga ou a interface carga/matriz ${ }^{45}$, diferente do comportamento do Tetric ${ }^{\circledR}$ Ceram e Ariston ${ }^{\circledR} A T$. Segundo ÖRTENGREN e ANDERSON $^{45}$, a infiltração e a degradação hidrolítica ${ }^{62}$ são processos tempo dependentes e as variações de $\mathrm{pH}$ no meio bucal e na superfície do dente afetam negativamente à resistência ao desgaste dos materiais à base de resinas compostas ${ }^{6,40}$.

Os testes in vitro de microinfiltração são realizados normalmente com exposição dos materiais à ciclagem de carga e temperatura que naturalmente levam a diferentes resultados dos encontrados em $\mathrm{CpH}$, como no estudo de BRACKETT et al. ${ }^{11}$ em que o compômero (Dyract AP) apresentou maior grau de microinfiltração comparado ao CIV modificado por resina (Vitremer ${ }^{\mathrm{TM}}$ ), resultado contrário ao obtido no teste realizado com $\mathrm{CpH}$. Entretanto, em ambos os estudos, os resultados não apresentaram diferenças estatísticas significante entre os materiais.

Esse comportamento do material pode ser devido a capacidade de absorção de água que pode compensar a contração inicial que ocorre durante a polimerização pelos compômeros de acordo com os resultados de GROBLER, ROSSOUW, VAN WYK KOTZE ${ }^{30}$, no qual o Dyract apresentou a menor infiltração.

No presente estudo, o material Ariston ${ }^{\circledR}$ AT apresentou o menor grau de microinfiltração, seguido do Dyract AP comparado ao Definite ${ }^{\circledR}$ que registrou a maior microinfiltração com diferença estatística significante para o A e DY. O padrão de infiltração apresentado pelo Ariston ${ }^{\circledR}$ AT pode estar associado à estrutura química do material e a natureza das soluções de imersão. O material apresenta uma mistura de metacrilatos na matriz orgânica em menor proporção de peso e partículas inorgânicas em maior proporção que favorece a troca iônica com liberação de íons $\mathrm{Ca}^{+}, \mathrm{F}^{-} \mathrm{e} \mathrm{OH}^{-}$ para o meio, quando ocorre queda de $\mathrm{pH}$. A capacidade hidrofílica da matriz de polímero pode causar uma expansão higroscópica pelo mecanismo de difusão controlada, logo nas fases iniciais, resultando no aumento de volume 
do material que pode fechar algumas falhas, liberar estresses na interface e aliviar as tensões internas geradas pela contração de polimerização como observado por MARTIN, JEDYNAKIEWICZ, FISCHER ${ }^{40}$ em seu estudo com o Ariston pHc. O material adapta-se mais intimamente às paredes da cavidade aumentando a longevidade da união adesiva para a estrutura dentária.

O maior grau de infiltração registrado pelo Definite ${ }^{\circledR}$ provavelmente tem relação com a estrutura do material que é referenciada como uma matriz organicamente modificada de cerâmica e uma cadeia inorgânica de siloxano que tem seletivamente sido modificada pela incorporação de grupos orgânicos. No estudo de MARTIN, JEDYNAKIEWICZ, FISCHER ${ }^{40}$, a resina composta Definite ${ }^{\circledR}$ apresentou um aumento muito pequeno em volume pela baixa expansão higroscópica $(0,5 \%)$ que foi bem menor do que a registrada pela contração de polimerização $(1,8 \%$ vol.). Isto sugere que no presente trabalho o material Definite $^{\circledR}$ deve ter tido esse comportamento, ou seja, houve baixa expansão higroscópica e uma maior contração do material, condição natural em resinas compostas.

A exposição dos materiais à $\mathrm{CpH}$ (solução $\mathrm{DES}^{-} / \mathrm{RE}$ ) parece interferir físico-quimicamente na estrutura e no comportamento do material e, nas alterações físico-mecânicas como as observadas nos estudos de microinfiltração com ciclagem térmica e ciclagem de carga. Nestas situações ocorrem alterações na interface dente/restauração ${ }^{2}$ dos espécimes sejam elas decorrentes da contração, expansão, fadiga e estresse do material e, em sua maioria traduzida pela alteração da camada adesiva. Entretanto o estudo de PAZINATTO et al. ${ }^{49}$ concluiu que não haver uma relação direta entre teste de termociclagem e aumento de microinfiltração ao variar número de ciclos.

Diante das limitações desse estudo e frente aos resultados encontrados, observa-se o efeito deletério do meio de imersão $\mathrm{CpH}$ aos 
materiais restauradores resinosos quando em situação de desafio cariogênico.

O processo de liberação e recarga de flúor, do ponto de vista clínico, pode promover maior dureza superficial ao esmalte adjacente à interface dente/restauração a partir de materiais com essa capacidade. A infiltração marginal em $\mathrm{CpH}$ foi observada na interface de todos os materiais restauradores avaliados pelo qual, parece claro, a importância do controle do meio bucal dentro do contexto preventivo da Odontologia contemporânea. Entretanto, os materiais testados como o Vitremer ${ }^{\mathrm{TM}}$, Dyract AP, Ariston ${ }^{\circledR}$ AT mesmo tendo apresentando valores significativos de liberação de flúor e capacidade de recarga, o processo de microinfiltração em $\mathrm{CpH}$ foi observado o que sugere que essa propriedade de liberação e recarga não foi capaz de impedir ou minimizar o processo de microinfiltração.

Portanto, a escolha do melhor material restaurador para cada situação clínica deve estar baseada na observação de suas propriedades fisico-quimico-mecânicas, assim como em seu comportamento para cada situação individual de desafio cariogênico, sempre visando promover as condições ideais para a longevidade do material restaurador e o equilíbrio do meio bucal. 
Conclusão 


\section{CONCLUSÕES}

Com base nos resultados obtidos na realização do presente trabalho, duas hipóteses nulas levantadas foram rejeitadas, ou seja:

- a recarga de flúor foi capaz de alterar a taxa de liberação desse íon de materiais restauradores resinosos em ciclagem de $\mathrm{pH}$;

- a ciclagem de pH interferiu no padrão de infiltração marginal de materiais restauradores resinosos. 



\section{Referências Bibliográficas}




\section{REFERÊECIAS BIBLIOGRÁFICAS:}

1. American Dental Association. Restorative materiais containing fluoride: Council on Dental Materiais, Instruments, and Equipament. J Amer Dent Ass, v.116, n.6, p.762-3, May 1998.

2. Arias, V. G.; Campos, I. T.; Pimenta, L. A. F. Microleakage study of three adhesive systems. Bras Dent J, v. 15, n. 3, p. 194-98. 2004.

3. Ariston pHc - Documentación científica Aristón pHc, Vivadent, 1998.

4. Argenta, R. M. O; Tabchoury, C.P. M.; Cury, J. A. A modified ph-cycling model to evaluate fluoride effect on enamel demineralization. Pesq Odont Bras, v. 17, n. 3, p. 241-6, 2003.

5. Asmussen, E.; Peutzfeldt, A. Long-term fluoride release from a glassionomer cement, a compomer, and from experimental resin composites. Acta Odontol Scand, v.60, n. 2, p. 93-97, Mar. 2002

6. Attar, N.; Önen, A. Fluoride release and uptake characteristics of aesthetic restorative materials. J Oral Rehabil, v. 29, p. 791-98, 2002.

7. Attin, T. et al. Fluoride release/uptake of poliacid-modified resin composite compomers in neutral and acid buffer solutions. J Oral Rehab, v. 26, n. 5 , p. 88-93, May 1999.

8. Besnault, C.; Attal, J. P. Influence of a simulated oral environment on micoleakage of two adhesive systems in Class II composite restorations. J Dent, v.30, p. 1-6, Dec. 2002. 
9. Bilgin, Z.; Ozalp, N. Fluoride release from three different types of glass ionomer cements after exposure to $\mathrm{NaF}$ solution and APF gel. J Clin Pediat Dent, v. 22, n. 3, p. 237-41, Spring. 1998.

10. Brackett, W. W. et al. Microleakage of class $V$ resin composite restorations placed with self-etching adhesives. J Prosthet Dent, v. 91, n. 1, p. 42-5, Jan. 2004.

11. Brackett, W. W. et al. Microleakage of class $\mathrm{V}$ compomer and light-cured glass ionomer restorations. J Prosthet Dent, v. 79, n. 3, p. 261-63, Mar. 1998.

12. Carvalho, A. S.; Cury, J. A. Fluoride release from some dental materials in different solutions. Oper Dent, v. 24, n. 1, p. 14-9, Jan.-Feb. 1999.

13. Carvalho, A. S.; Cury, J. A. Liberação de flúor de materiais restauradores. Rev Odont USP, v. 12, n. 4, p.367-373, out./dez. 1998.

14. Chimello, D. T. et al. In vitro evaluation of microleakage of a flowable composite in class $\mathrm{V}$ restorations. Pesq Odont Bras, v. 13, n. 3, p. 18487, 2002.

15. Cortes, O. et al. Marginal microleakage around enamel and cementum surfaces of two compomers. Journ Clin Pediat Dent, v. 44, n. 4, p. 307310, 1998.

16. Costa, B. et al. Estudo comparativo da liberação de flúor de materiais dentários restauradores.Rev Odont USP, v.9, n.4, p.279-84, out./dez. 1995. 
17. Creanor, S. L. et al. Fluoride uptake and release characteristics of glassionomer cements. Caries Res, v. 28, n. 5, p. 322-8, Sept.-Oct. 1994.

18. Definite ${ }^{\circledR}$ - Technical manual (VI), Degussa, June 1998.

19. Ekstrand, J.; Oliveby, A. Fluoride in oral environment. Acta Odontol Scand, v.57, n.6, Dec., 1999.

20. Farah, J.W.; Powers, J.M. Fluoride-releasing restorative materials. Dent Adv, v. 15, n. 10, p. 2-5, Dec. 1998.

21. Farias, D. G.; Avelar, R. D.; Bezerra, A. C. B. Estudo comparativo da infiltração marginal em restaurações de classe V. Pesq Odont Bras, v. 16, n.1, p. 83-88, jan-mar, 2002.

22. Featherstone, J.D.B. et al. Enhancement of remineralization in vitro and in vivo. In: $\mathrm{LEACH}$, S.A. Factors relating to demineralization and remineralization of the teeth Oxford: IRL Press p. 23-34, 1986.

23. Forsten, L. Fluoride release and uptake by glass-ionomers and related material and its clinical effect. Biomaterials, v. 19, n. 6, p 503-8, 1998.

24. Forsten, L. Resin-modified glass ionomer cements: fluoride release and uptake. Acta Odont Scand, v. 53, n. 4, p. 222-225, Aug. 1995.

25. Friedl, K.H. et al. Resin-modifed glass ionomer cements: fluoride release and influence on Streptococus mutans growth. Eur J Oral Science, v. 105, n. 1, p.81-5, Feb. 1997. 
26. Garcez, R. M. V. B. Avaliação de flúor de resinas compostas em água e em ciclagem de pH. Bauru, 2001. 124p. Dissertação (Mestrado) Faculdade de Odontologia de Bauru, Universidade de São Paulo-USP.

27. Glasspoole, E. A.; Erickson, R. L.; Davidson, C. L. Demineralization of enamel in relation to the fluoride release of materials. Am J Dent, v. 14, n. 1, p. 8-12, Feb. 2001.

28. Glasspoole, E. A.; Erickson, R. L.; Davidson, C. L. A fluoride-releasing composite for dental applications. Dent Mat, v. 17, n. 2, p. 127-33, Mar. 2001.

29. Göhring, T.N. et al. In vitro microleakage of adhesive-sealed dentin with lactic acid and saliva exposure: a radio-isotope analysis. J Dent, v.32, p. 235-40, 2004.

30. Grobler, S. R.; Rossouw, R. J.; Van Wyk Kotze, T. J. In vitro, relative microleakage of five restorative systems. Int Dent J, v. 49, n. 1, p. 47-52, Feb. 1999.

31. Gwinnett, J. A.; Tay, F. R.; Pang, K. M.; Wei, S. H. Y. Comparasion of three methods of critical evaluation of microleakage along restorative interfaces. J Prosthetic Dent, v. 74, n. 6, p. 575-85, Dec. 1995.

32. Hsu, $\mathrm{H}$ et al. A continuous flow systen for assessinf fluoride release/ uptake of fluoride-containing restorative materials. Dental Materials, v.20, p. 740-49, 2004.

33. lazzetti, G.; Burgess, J. O.; Gardiner, D. Selected mechanical properties of fluoride-releasing restorative materials. Oper Dent, v. 26, n. 1, p. 2126, Jan-Feb. 2001. 
34. Ismail, A.I. What is the effective concentration of fluoride? Community Dent Oral Epidem, v. 23, p. 246-251, 1995

35. Itthagarun, A.; Wei, S. H. Y.; Wefel, J.S. The effect of different commercial dentifrices on enamel lesion progression: an vitro $\mathrm{pH}$-cycling study. Int Dent J, v.50, n.1, p. 27-8, Feb. 2000.

36. Kawai, K. et al. In vitro enamel and cementum fluoride uptake from three fluoride-containing composites. Caries Res, v. 32, n. 6, p. 463-9, Nov.Dec.1998.

37. Kidd, E. A. M. Microleakage: A review. J Dent, v.4, n.5, p.199-206, 1976

38. Koliniotou-Koumpia, E.; Dionysopoulos P.; Koumpia, E. In vivo evaluation of microleakage from composites with new dentine adhesives. J Oral Rehabilit, v. 31, p. 1014-23, 2004.

39. Larson T. D. The clinical significance and management of microleakage. Northwest Dent, v. 84, n.1, p. 23-31, Jan-Feb. 2005.

40. Martin. N.; Jedynakiewicz, N. M.; Fisher, A. C. Hygroscopic expansion and solubity of composite restoratives. Dent Mater, v.19, p. 77-86, 2003.

41. McCabe, J. F.; Carrick, T. E.; Shidu, S. K. Determining low levels of fluoride released from resin based dental materials. Eur J Oral Sci, v. 110, p. 380-84, 2002.

42. Mitsui F. H. O et al. Influence of load cycling on marginal microleakage with two self-etching and two one bottle dentin adhesive systems in dentin. J Adhes Dent, v. 5, n. 3, p. 209-16, 2003. 
43. Musanje, L.; Shu, M.; Darwell, B.W. Water sorption and mechanical behaviour of cosmetic direct restorative materials in artificial saliva. Dent Mat, v.17, p. 394-401, 2001.

44. Narvai, P.C. Cárie dentária e flúor: uma relação do século XX. Ciência e Saúde Coletiva, v. 5, n. 2, p. 381-392, 2000.

45. Örtengren, $U$. et al. Influence of $\mathrm{pH}$ and storage time on the sorption and solubility behaviour of three composite resin materials. J Dent, v.29; p. 35-41, 2001.

46. Osório, R. et al. Microleakage and interfacial morphology of self-etching adhesives in class $\mathrm{V}$ resin composite restorations. J Biomed Mat Res B Appl Biomat, v. 66B, n. 1, p. 399-409, July, 2003.

47. Ozturk, A. N. et al. Influence od different light sources on microleakage of class $\mathrm{V}$ composite resin restorations. J Oral Rehabilit, v. 31, p. 500-504, 2004.

48. Pashley, D. H. Clinical considerations of microleakage. J Endod, v. 16, n. 2, p. 70-7, Feb. 1990.

49. Pazinatto, F. B et al. Effect of the number of thermocycles on microleakage of resin composite. Pesq Odont Bras, v. 17, n. 4, p. 33741, Oct-Dec. 2003.

50. Pedrini, D. et al., Fluoride release by restorative materials before and after a topical application of fluoride gel. Pesq Odont Bras, v. 17, n. 2, p. 137-41, 2003 
51. Peng, D. et al. In vitro fluoride release from aesthetic restorative materials following recharging with APF gel. Aust Dent Journal, v. 45, n. 3, p. 198203, Sep. 2000.

52. Piemjai, M. et al. Effect of remaining demineralised dentine on dental microleakage accessed by adye penetration: how to inhibit microleakage? J Dent, v.32, n. 6, p. 495-501, Aug. 2004.

53. Piva, E. et al. Dyes for caries detection: influence on composite and compomer microleakage. Clin Oral Invest, v. 6, p. 244-248, 2002.

54. Posada, A.; Emilson, C.; Birked, D. Fluoride release in vitro from a resinmodified glass ionomer after exposure to $\mathrm{NaF}$ solutions and toothpaste. Swed Dent, v.24, n.3, p. 117-25, 2000.

55. Preston et al. The recharge of esthetic dental retorative materials with fluoride in vitro-two years' results. Dent Materials, v.19, n.1, p.32-37, Jan. 2003.

56. Raskin, A. et al. Influence of the number of sections on reliability of in vitro microleakage evaluations. Amer J Dent, v. 16, n. 3, p. 207-10, June, 2003.

57. Rothwell, M.; Anstice, H. M.; Pearson, G. J. The uptake and release of fluoride by ion-leaching cements after exposure to toothpaste. J Dent, v. 26, n. 7, p. 591-7, Sep. 1998.

58. Scherer, W. et al. Efects of pH on the dentin surface. J Esthet Dent, v.5, n. 5, Sep.-Oct. 1992. 
59.Suljak, J.P.; Hatibovic-Kofman, S. A fluoride release-adsorption-release system applied to fluoride-releasing restorative materials. Quintessence Int. v.27, n. 9, p. 635-638, 1996.

60.Sung, E. C. et al. Effects of various irrigation solutions on microleakage of class V composite restorations. J Prosthet Dent, v. 91, n. 3, p. 265-7, Mar. 2004.

61. Tavss, E. A. et al. Relationship between dentrifice fluoride concentration and clinical caries reduction. Amer J Dent, v. 16, n. 6, p. 369-374, Dec. 2003.

62. Toledano, M. et al. F. Sorption and solubility of resin-based restorative dental materials. J Dent, v.31, p. 43-50, 2003.

63.Tung, F. F.; Estafan, D.; Scherer, W. Use of a compomer in class V restoration: a microleakage study. Quintessence Int, v. 31, n.9 , p. 66872, Oct. 2000.

64.Turssi, C. P. et al. Effect of storage media upon the surface micromorphology of resin-based restorative materials. J Oral Rehabilit, v. 29 , p. $864-871,2002$.

65. Vandewalle, K. S. et al. Effect of energy density on properties and marginal integrity of posterior resin composite restorations. Dent Mater, v. 20, p. 96-106, 2004.

66. van Dijken, J. W. V. Three-year perfomance of a calcium-, fluoride-, and hydroxyl-ions-releasing resin composite. Acta Odont Scand, v. 60, p. 155-59, 2002. 
67. Vieira, A. R.; Souza, I. P. R.; Modesto, A. Fluoride uptake and release by composites and glass ionomers in a high caries challenge situation. Amer J Dent, v. 12, n. 1, p. 14-18, Feb. 1999.

68. Vitremer TM - Ionômero de vidro de ativação tripla; perfil técnico do produto. s.I., 3M, 1994.

69. Wahab, F. K.; Shaini, F. J.; Morgano, S. M. The effect of thermocycling on microleakage of several commercially avaiable composite class $\mathrm{V}$ restorations in vitro. J Prosthet Dent, v. 90, n. 2, p. 168-74, Aug. 2003.

70. Weidlich, P. et al. Fluoride release and uptake from glass ionomer cements and composite resins. Braz Dent J, v. 11, n. 2, p. 89-86, 2000

71. Williams, P. T.; Schramke, D.; Stockton, L. Comparison of two methods of mesuaring dye penetration in restoration microleakage studies. Operat Dent, v. 27, n. 6, p. 628-35, Nov.-Dec. 2002.

72. Yazici, A. R.; Çelik, Ç.; Ozgünaltay, G. Microleakage of different resin composite types. Quintessence Int, v. 35, n.10, p. 790-94, Nov.-Dec. 2004. 
Abstract 


\section{ABSTRACT}

$\mathrm{pH}$ cyclic alterations in the oral environment seems to be one of the largest challenges in which the restoratives materials are subjected. Therefore, fluoride $\left(\mathrm{F}^{-}\right)$release/uptake capacity evaluation of the tooth/restorative interfaces by microleakage test under $\mathrm{pH}$-cycling $(\mathrm{CpH})$ regimen, for 15 days might simulate in vitro the clinical situations of caries challenging. Twelve cylindrical samples with diameter of $11 \mathrm{~mm}$ and thickness of $1.5 \mathrm{~mm}$ of the materials Vitremer ${ }^{\mathrm{TM}}(\mathrm{V} / \mathrm{VR})$, Dyract $\mathrm{AP}$ (DY/DYR), Ariston ${ }^{\circledR} \mathrm{AT}(\mathrm{A} / \mathrm{AR})$, Definite ${ }^{\circledR}(\mathrm{D} / \mathrm{DR})$, Tetric ${ }^{\circledR}$ Ceram $(\mathrm{TC} / \mathrm{TCR})$ were fabricated and distributed in two groups of $\mathrm{F}^{-}$release and uptake. Samples were individually immersed in $4 \mathrm{~mL}$ of $\mathrm{CpH}$ solution, i.e., 6 hours in demineralizing solution $(\mathrm{pH} \mathrm{4.3)}$ followed by 17 hours in remineralizing solution $(\mathrm{pH}$ 7.0). The fluoride uptake was started at $2 \mathrm{nd}$ day by means of dentifrice slurry containing $1.100 \mathrm{ppm}$ of $\mathrm{F}^{-}$ (Crest), applied daily, before $\mathrm{DES}^{-} / \mathrm{RE}$ solutions changing. The analysis of $\mathrm{F}^{-}$release/uptake concentration was measured by a specific $\mathrm{F}^{-}$ionelectrode with $0.5 \mathrm{~mL}$ of test solution added to $0.5 \mathrm{~mL}$ of TISAB II. The results were submitted to ANOVA and Tukey's Test $(p<0.05)$. The highest $\mathrm{F}^{-}$values were registered in $\mathrm{DES}^{-}$solution. All materials, in both experiments, presented the same pattern of fluoride release and the highest rates were obtained by $\mathrm{V}\left(418.04 \mu \mathrm{gF}^{-} / \mathrm{cm}^{2}\right)$ and $\mathrm{VR}\left(818.39 \mu \mathrm{gF}^{-} / \mathrm{cm}^{2}\right)$ groups. At 3rd day, all materials presented the highest amount of $\mathrm{F}^{-}$releasing after the uptake, with slowly decrease, reaching stable values at the 15th day, when fluoride release presented similar levels of that at 2 nd day. Composite resins $D$ and TC released the lowest fluoride amounts, $D\left(5.16 \mu \mathrm{gF}^{-} / \mathrm{cm}^{2}\right)$; $\mathrm{DR}\left(10.25 \mu \mathrm{gF}^{-} / \mathrm{cm}^{2}\right) ; \mathrm{TC}\left(10.09 \mu \mathrm{gF}^{-} / \mathrm{cm}^{2}\right) ; \mathrm{TCR}\left(16.86 \mu \mathrm{gF}^{-} / \mathrm{cm}^{2}\right)$, in both experiments, although no statistically difference was observed between DR and TC. AR released the highest amount of $\mathrm{F}^{-}\left(327.21 \mu \mathrm{gF}^{-} / \mathrm{cm}^{2}\right)$ among composites. Eighty human 3rd molars were used to evaluate microleakage under $\mathrm{pH}$-cycling regimen. Class $\mathrm{V}$ cavities $(4.0 \mathrm{~mm}, 2.0 \mathrm{~mm}, 1.5 \mathrm{~mm})$ with margins in enamel were prepared and restored with the same materials. They were distributed in two immersion media, groups: deionized water $(A)$ 
and $\mathrm{pH}$-cycling (DES ${ }^{-} / \mathrm{RE}$ ), for 15 days. After this period, specimens were then immersed in $0.5 \%$ basic fucsine dye for 24 hours. They were washed in tap water and sectioned for evaluation. The samples were analyzed by means of an optical stereomicroscope (60X) and slices with the greatest dye penetration were choosen and submitted to Image Tool area analysis softweare. Data was submitted to stattiscal analysis using two-way ANOVA and Tukey's test $(\alpha=0.05)$, revealing that there was statistically difference between immersion media factor. The greatest level of dye penetration was obtained in $\mathrm{CpH}$. All materials tested registered some microleakage but the greatest level was registered by Definite ${ }^{\circledR}$ followed by TC, V, DY and A. However, there were no statistically significant differences amongst TC, V, DY and A. Definite ${ }^{\circledR}$ was significantly different to A and DY. Within the limits of this study and in the basis of the obtained results, the fluoride release/uptake was not able in reducing preventing the microleakage of the evaluated materials. Therefore, the restorative material to each clinical situation should be analyzed on his physical, chemical and mechanical aspects as well as his behavior under caries challenge. 
Apêndice 


\section{APÊNDICE A - Parecer do Comitê de Ética da FOB-USPS}

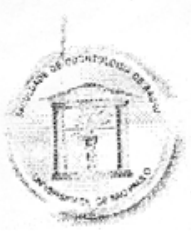

\section{Universidade de São Paulo \\ Faculdade de Odontologia de Bauru}

Al. Dr. Octávio Pinheiro Brisolla, 9-75 - Bauru-SP - CEP 17012-901 - C.P. 73

PABX (0XX14)235-8000 - FAX (0XX14)223-4679

Comitê de Éfica em Pesquisa

Processo n ${ }^{\circ}$ 96/2003

Bauru, 02 de setembro de 2003

Senhor Professor,

O projeto de pesquisa encaminhado a este Comitê de Ética em Pesquisa em Seres Humanos, denominado "Avaliação in vitro da infiltração marginal e liberação de flúor com e sem recarga de materiais restauradores resinosos, em

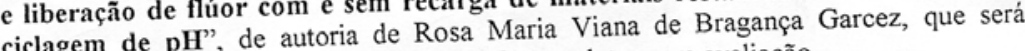

ciclagem de $\mathbf{p H}$, desenvolvido sob sua orientação, foi enviado ao relator para avaliação.
Na reunião de $\mathbf{2 7}$ de agosto de 2003 o parecer do relator, aprovando o projeto, foi aceito pelo Comitê, considerando que não existem infrações éticas pendentes.

Informamos que após o envio do trabalho concluído, este Comitê enviará o parecer final, que será utilizado para publicação do trabalho.

Atenciosamente,

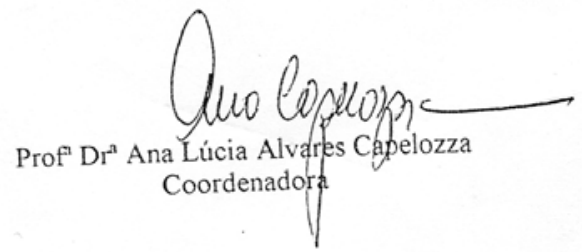

$I m^{\circ} \mathrm{Sr}$. Prof. Dr. Paulo Amarante de Araújo

Ilm Sr. Prof. Dr. Paulamento de Dentística, Endodontia e Materiais Dentários 